\title{
Some Aspects of Cost/Benefit Analysis for In-Service Inspection of PWR Steam Generators
}

Prepared by G. E. Zima, G. H. Lyon, P. G. Doctor,

G. R. Hoenes, S. E. Petty, S. A. Weakley

Pacific Northwest Laboratory

Operated by

Battelle Memorial Institute

Prepared for

U.S. Nuclear Regulatory

Commission 


\title{
NOTICE
}

This report was prepared as an account of work sponsored by an agency of the United States Government. Neither the United States Government nor any agency thereof, or any of their employees, makes any warranty, expressed or implied, or assumes any legal liability or responsibility for any third party's use, or the results of such use, of any information, apparatus product or process disclosed in this report, or represents that its use by such third party would not infringe privately owned rights.

\author{
Available from \\ GPO Sales Program
}

Division of Technical Information and Document Control

U. S. Nuclear Regulatory Commission Washington, D. C. 20555

Printed copy price: $\$ 4.75$

and 


\section{Some Aspects of Cost/Benefit Analysis for In-Service Inspection of PWR Steam Generators}

Manuscript Completed: December 1980

Date Published: May 1981

\section{Prepared by}

G. E. Zima, G. H. Lyon, P. G. Doctor,

G. R. Hoenes, S. E. Petty, S. A. Weakley

Pacific Northwest Laboratory

Richland, WA 99352

\section{Prepared for}

Division of Reactor Safety Research

Office of Nuclear Regulatory Research

U.S. Nuclear Regulatory Commission

Washington, D.C. 20555

NRC FIN B2315 



\section{ACKNOWLEDGMENTS}

This report was prepared as part of the work under USNRC "Unresolved Safety Issue" A-3, 4, 5, "Westinghouse, Combustion Engineerina, and Babcock $\&$ Wilcox Steam Generator Tube Integrity." Its primary purpose is to provide a cost/benefit evaluation of various steam generator tube in-service inspection programs.

The authors are indebted to the various personnel of the Conam Inspection Division of Nuclear Energy Systems, Zetec Inc., the Inspection Division of the Babcock \& Wilcox $\mathrm{Co}$., and the Westinghouse Corporation for their cooperation and help during the preparation of this report. The assistance of C. H. Bloomster, G. J. Posakony, C. J. Morris, B.W. Mercer and F. M. Cummings of the Pacific Northwest Laboratory is also appreciated. 



\section{ABSTRACT}

This report discusses a number of aspects of cost/benefit (C/B) analysis for in-service inspection (ISI) of pressurized water reactor (PWR) steam generators (SGs) and identifies several problem areas that must be addressed prior to a full C/B analysis capability.

Following a brief review of the impact of SG problems on the productivity of PWR units and of the scope and variability of SG problems among U.S. PWRs, various occupational implications of SG ISI are considered, namely manpower, time, and rad exposure. The opportunities provided by refueling outages in respect to ISI frequency and work time windows are reviewed. Indices for characterizing the nondestructive testing (NOT) information, rad exposure, $\$$ impact, and manpower and time attributes of single ISIs and a series of ISIs over an arbitrary evaluation period are presented and calculated for a number of ISI cases using SG parameters for three typical PWR units.

A comparison of the $\$$ impact of unscheduled outages attributable to $S G$ problems with the $\$$ cost of ambitious ISI strategies indicates that the $\$$ cost is virtually negligible for well-planned ISIs. Considering the ALARA constraint on occupational rad exposure, the skilled manpower pool for NDT work appears to be the principal factor limiting ISI scope and frequency. Analys is of the manpower and time requirements for inspection of a 40-unit PWR population indicates, however, that an ISI strategy embodying two campaigns per year and a total population inspection within a 2-year interval is not far beyond current capabilities. 



\section{CONTENTS}

\section{ACKNOWLEOGMENTS}

ij i

ABSTRACT

INTRODUCTION

SUMMARY

IMPACT OF STEAM GENERATOR PROBLEMS ON PRODUCTIVITY OF PWR UNITS

SCOPE AND VARIABILITY OF STEAM GENERATOR TUBING PROBLEMS

FACTORS AFFECTING SCDPE AND FREQUENCY OF IN-SERVICE INSPECTION $\quad$ • • 19

Time, Manpower, and $\$$ Factors . $\quad . \quad$. $\quad . \quad$. 19

The Radiation Exposure Factor in Steam Generator

In-Service Inspection . . . . . . . . 22

Fuel outage In-Service Inspection Opportunities . $\quad$. 27

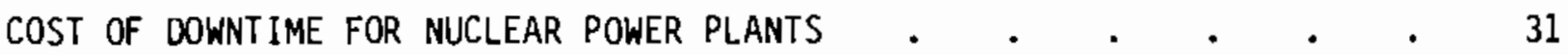

CHARACTERISTIC INDICES FOR IN-SERVICE INSPECTIONS AND THEIR APPLICATION 37

The NDT Information Index (Iisi) . . . . . . 37

Rad Exposure Index (MAN-REM) . . . . . . . . . 38

$\$$ Impact Index $(\$ i s i) \quad . \quad . \quad . \quad . \quad . \quad . \quad . \quad 39$

Composite Indices . . . . . . . . . . 40

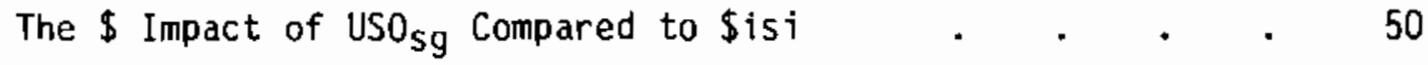

IN-SERVICE INSPECTION MANPOWER AND TIME ESTIMATES FOR 40-UNIT

PWR POPULATION .

Manpower Estimate--Rad Exposure Basis . . . . . 53

Manpower Estimate--Crew Assumption Basis . . . . $\quad$. 54

Time Estimate for In-Service Inspection . . . . . 59

COMMENTS ON PROBABILISTIC ANALYSIS OF STEAM GENERATOR TUBING PROBLEMS . 65 
ESTIMATED COSTS FOR DISPOSAL OF SOLID WASTES ASSOCIATED WITH PRIMARY TO SECONDARY LEAKAGE IN PWR STEAM GENERATORS . •

FURTHER COST/BENEFIT ANALYSIS OBJECTIVES. . . . . . . . . . . 79

Analysis of Outage Costs for PWR Units . . . . . . 79

Analysis of Steam Generator Tubing Performance . . . $\quad$. 79

Analys is of Foreign Steam Generator In-Service Inspection Strategies and Related PWR SG Performance . . . . 80

REFERENCES

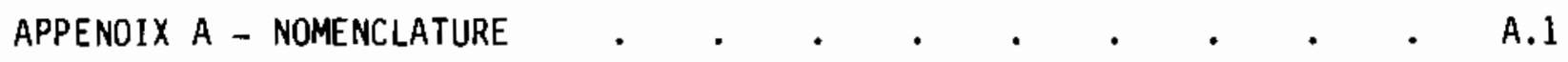

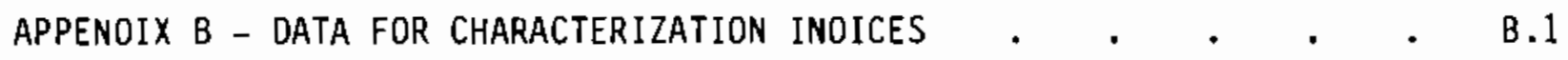

APPENOIX C - A RELIABILITY ANALYSIS TECHNIQUE * . . . . . . . C.1

APPENDIX D - OATA FOR COSTING SOLID WASTE DISPOSAL. . . . . . . 0.1 


\section{FIGURES}

1 Histogram of Outages Involving Generators . $\quad$ - . $\quad$. 8

2 Histograms of Various Unit Steam Generator Parameters - * . 13

3 Histogram of CTFI for U.S. Units Surveyed $\quad$ * . . . . . 14

4 Man-Hour Expenditure for Various ISI Items . . . . . 20

5 Cost/Tube for Testing Versus Sample Size . . . . . . . 21

6 Dose Distribution for Various Units; Inspection

Personnel Only . . . . . . . . . . . . . . 23

7 Dose Distribution for Various Units (B\&W); Inspection and Support Personnel . . . . . . . . . . . . 23

8 Dose Distribution for Various Units; Inspection and

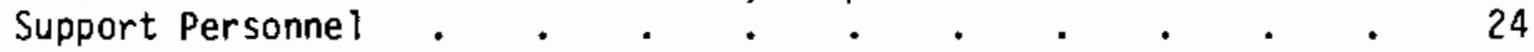

9 Refueling Outage Duration as a Function of the

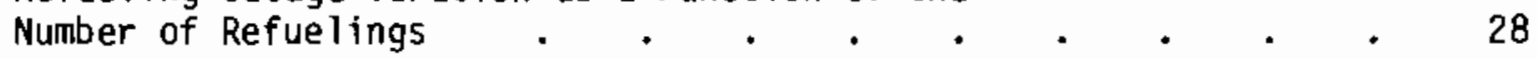

10 Refueling Durations: Comparison Between U.S. and

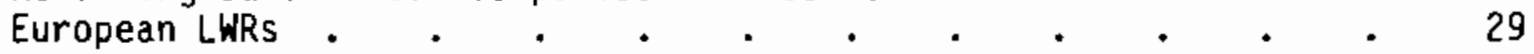

11 The Interval Between Refueling Outages . . . . . . . 29

12 Comparison of ISI Frequencies Based on Fuel Outages

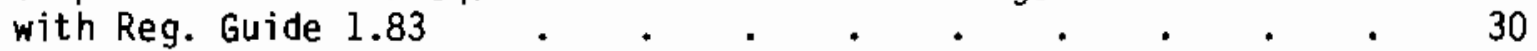

13 Man-Rem Index Yersus Iisi Index; High Field Case . . . . . 46

14 Man-Rem Index Versus I isi Index; Zero T Component Case . . . 47

15 Sisi Index Versus Iisi Index; F=0 Case . . . . . . . 47

16 Sisi Index Versus Iisi Index; Proportional f Case . . . . . 48

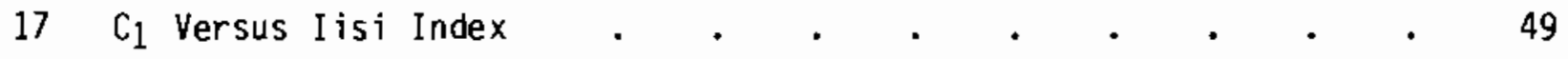

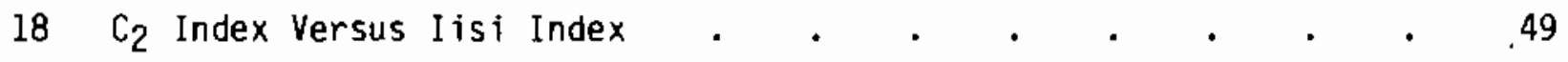

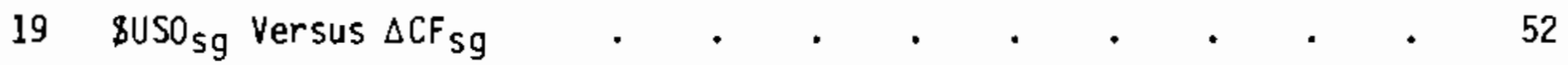

20 Minimum Personnel for Yearly Inspection of 40 PWR Units $\quad$ • . 57 
21 ISI Time Versus Scope for "Average" Unit . . . . . . . 62

22 Histogram for Beginning Date of Fue1 Outages . . . . . . . 63

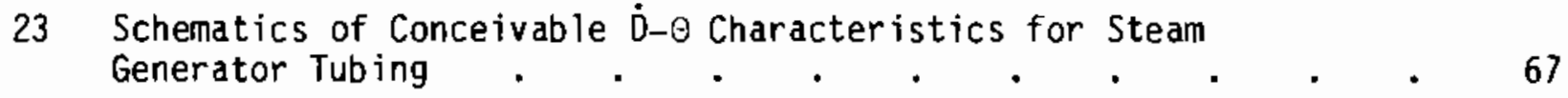




\section{TABLES}

1 Distribution of Tubes Plugged Among Unit Steam Generators • $\quad 17$

2 Test of Failure Uniformity Among Steam Generators . • . . 17

3 Average Data for Various Time/Manpower ISI Items . . . . 21

4 Miscellaneous Tube Plugging Information . . . . . . . 22

5 Occupational Doses for Inspection Team Only . . . . . $\quad 25$

6 B\&W Occupational Doses for Inspection Plus Support Personnel. . 25

7 Occupational Doses for Inspection Team Plus Support

Personnel . . . . . . . . . . . . 26

8 Man-Rem Estimates for Setup and Removal Phases of Inspection • . • • • • • • • . • 26

9 Information for Tube Plugging Operation . . . . . . . 26

10 Ground Rules for Calculation of ISI Indices . . . . . 42

11 Definition of ISI Cases . . . . . . . . . . . 43

12 Parameter Values Used for Calculation of Indices . . . . 44

13 Cases Used for Calculation of Indices . . . . . . 45

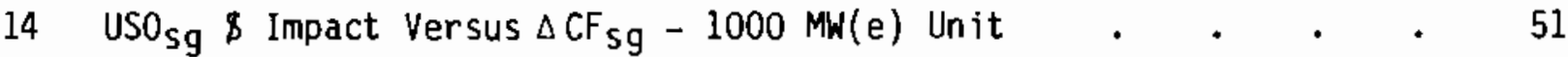

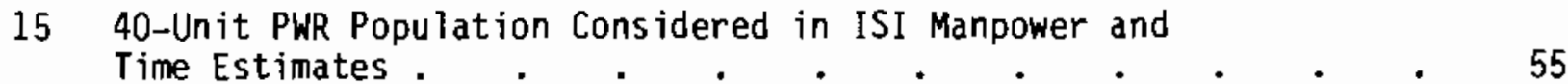

16 Manpower Estimate for 40-Unit Inspection; Rad Exposure . . . . . . 56

17 Estimated Crew Sizes for Various ISI Campaigns . . . . . 58

18 ISI Time Values for "Average" Unit. . . . . . . 60

19 ISI Time Values for Specific Units (Variable U) . . . . 61

20 Summary of Annual Operating Costs . . . . . . . . 74

21 Capital Cost . . . . . . . . . . . . 75

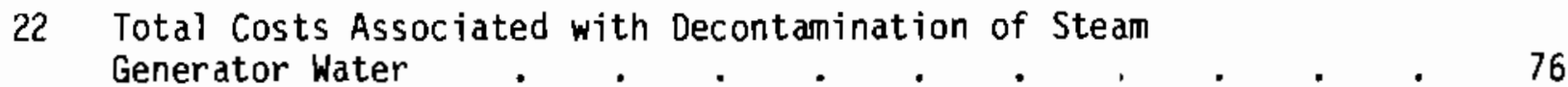





\section{INTRODUCTION}

There is ample incentive for improvement of the unit-wide performance of pressurized water reactor (PWR) steam generator (SG) tubing measured in terms of energy productivity loss and the occupational rad exposure attending SG inspection and requalification work.

Satisfactory resolution of the SG tubing degradation problem will require improvement both in tubing surveillance and in the material and environmental factors that affect tubing performance. The surveillance component of this improvement is the focus of this report. Nondestructive surveillance or inservice inspection (ISI) provides the principal measure of the tubing response to the working environment and, therefore, the principal guide to improvements in design, operation and maintenance practices that can optimize this response. Surveillance, in conjunction with degradation limits (e.g., plugging limits) on serviceability, also permits censoring of tubes that reach the "unacceptable" regime. Successive inspections provide a measure of the dynamics of the degradation processes and enable progressive refinement of censoring limits assuming reasonably steady-state working conditions.

The ability of an ISI program to satisfy the above functions is influenced by a number of factors: the overlap between the tubing sample of the inspection and the actual/potential problem zones within the SGs; the sensitivity of the nondestructive testing (NDT) technique to significant structural changes; the frequency of the inspections; the degradation limits used for censoring and the rate of the fastest degradation process; and the coordination of the ISI information with operation and maintenance details that could conceivably impact SG tubing performance, particularly those pertaining to management of the secondary water chemistry.

This report discusses a number of considerations that are preliminary to a full cost/benefit $(C / B)$ analysis of SG ISI strategies and identifies some of the problem areas for further study toward development of a practicable $\mathrm{C} / \mathrm{B}$ analys is technique. 

SUMMARY

The fundamental relationship in SG ISI C/B analysis is that between the intensity (frequency, duration) of the unscheduled outages attributable to SG problems ( $\left.\mathrm{USO}_{\mathrm{Sg}}\right]$ ) and the intensity (information content on tubing integrity) of the ISI program ([ISI]). A satisfactory quantification of this relationship does not appear possible at present because of the sparsity of unit-wide tube performance information and the complex coupling among ISI information, unit design/operation/maintenance (D/O/M) practice that affects tubing behavior, and the tubing response to $0 / 0 / M$ changes. It is reasonable, however, to expect [USO ${ }_{\mathrm{sg}}$ ] to decrease with more ISIs, assuming a conscientious effort to coordinate [ISI] with unit $0 / 0 / M$ practice affecting the tubing. Without the latter effort, persistent adverse working conditions for the SG tubing could force [USO $_{S g}$ ] to the point of periodic SG replacement and eventually to economic defeat of the unit irrespective of the level of [ISI].

In the absence of predictable levels of $\left[\mathrm{USO}_{\mathrm{sg}}\right]$ as a guide for ISIs, it is expected that consideration of occupational rad exposure, ISI manpower availability, inspection time, and $\$$ costs of the ISI will be invoked to limit inspections to the "maximum feasible" level. This is a somewhat subjective criterion, but its $\left[\mathrm{USO}_{\mathrm{sg}}\right.$ ] basis would be expected to improve under careful and comprehensive observation of tubing performance and correlation with relevant unit $0 / 0 / M$ practice.

To assist in the latter effort, several indices and relationships are suggested in this report that attempt to quantify a number of aspects of SG ISI, including: occupational rad exposure, $\$$ impact, manpower and time requirements as a function of the ISI information index (Iisi). The information index given here considers scope ( $\%$ of total tubes inspected), sample distribution (number of SGs involved in inspection), and frequency of inspections over an arbitrary evaluation period. This index does not take cognizance of the limitations of current NDT techniques in detecting significant changes in the tubing structure. While the information index would presumably be maximized by using state-of-the-art NOT techniques, the discrimination ability between nominal and unacceptable tubing structures represents an important and largely implicit 
limitation on the significance of any ISI information index. Several composite indices (comprised of two or more single indices) are also suggested for assessment of ISI strategies. All of these indices are evaluated for 14 ISI cases and for three typical PWR units (2, 3, and 4 SGs per unit). The 14 ISI cases considered in this report range from the minimum inspection cases under Regulatory Guide 1.83 and ASTM Code XI rules to various arbitrary cases extending to $100 \%$ scope for each inspection over the evaluation period of 9 years. The inspection frequency over this period for all ISI cases was determined by average data for refueling outages of PWR units in the United States. Preliminary analysis of SG ISI requirements indicates that very conservative tubing inspection programs can be accomplished when the basis frequency and work time windows are controlled by the refueling outages. The refueling outage schedule is therefore considered to be a natural basis for evaluation of the indices. The 9-year evaluation period was chosen to accomodate up to a 3-year interval between inspections. Each of the indices considered in this report has both an individual inspection and an evaluation period counterpart. For illustration purposes, only the evaluation period index was computed although data for computation of indices for individual inspections are given.

For all the units considered, the $c_{1}$ composite index (information index divided by rad exposure index) exhibits a near monotonically increasing behavior with increase in the information index over the full range of the latter index. The somewhat more comprehensive composite index $c_{2}$ (information index divided by the product of the rad exposure and \& impact indices) exhibits intermediate minima within the given information index range (see Figure 18 , p. 49). The latter index shows some promise as an indicator of practicable ISI strategies, given input appropriate to individual units.

The manpower and time requirements for inspection of a 40-unit PWR population are analyzed in this report using values obtained from our NDT contractor consultants. Time and manpower estimates are given for various inspection scopes and for various inspection campaigns involving different numbers of units. Analysis of Nuclear Regulatory Commission (NRC) data revealed the expected bimodal characteristic of the histogram of fuel outage calendar dates. Our data suggest that an ISI strategy comprised of two campaigns per year and 
a complete 40-unit population inspection within a 2-year period is not far removed from current or a reasonable extension of current SG NOT manpower capability under the ALARA (see Appendix A) constraint with respect to occupational rad exposure.

The $\$$ impact of USO ${ }_{\text {sg }}$ for a 1000-MW(e) unit is compared with the $\$$ impact index of the most ambitious ISI strategy considered in this report (100\% scope for each inspection over the 9-year evaluation period) over a range of the lost power cost factor (milis/kwh). Even under a fairly pessimistic assumption as to the critical path interference of the SG ISI work, the cost of the ISI work is much less than the unit-wide cost of USO ${ }_{\mathrm{sg}}$ based on 19761978 outage information for PWR units in the United States. The cost of wellplanned (low-interference) ISI activity appears quite negligible compared to current or near-term projected USO $_{\mathrm{Sg}}$ costs.

Some of the problems associated with a probabilistic analysis of SG tubing performance and calculation of the conditional failure probability that is related to specification of the interval between inspections are considered briefly. The prospects for a significant (probabilistic) tubing performance component in the SG ISI C/B analysis would be enhanced by increasing the NOT information content of inspections and better reporting of inspection findings.

An analysis of the costs and activities associated with the disposal of solid wastes derived from SG tubing leakage events indicates that this aspect of the $S G$ tubing problem is negligible in respect of occupational exposure and $\$$ impact when compared to the SG inspection/requalification work and the downtime costs assignabie to SG problems.

SG ISI C/B analysis will necessarily be a process of successive refinement due to current limitations on the knowledge of tubing behavior as a function of: (a) the as-installed state of the tubing; (b) the unit $0 / 0 / M$ practice pertinent to tubing performance. At the first level, a $C / B$ analys is code should assist the unit manager in identifying his maximum feasible ISI intensity, based on the financial situation, ISI manpower availability, and rad exposure factors specific to his unit. This report has attempted to quantify some of these factors and to obtain some measure of their importance to SG ISI. 
Successive levels of an SG ISI C/B code would represent progressive refinement of the maximum feasible concept based on $\left[\mathrm{USO}_{\mathrm{Sg}}\right.$ ] experience. For well managed units, this refinement would be expected to result in some relaxation of the ISI intensity.

Practicable $C / B$ analysis codes could be exercised by the individual unit managers at their discretion using local facilities or optionally a central agency serving a number of units for data banking and computation. It would appear feasible to incorporate many unit technical management functions within the purview of such a central agency in addition to the SG ISI service. 


\section{IMPACT OF STEAM GENERATOR PROBLEMS ON PRODUCTIVITY OF PWR UNITS}

A number of criteria have been used and proposed to measure the impact of various unit problems and operational functions on power production. The capacity factor (CF, energy produced per year/maximum possible) has both simplicity and minimum ambiguity to recommend it as a criterion and it will suffice for the purposes of this report.

Recent Electric Power Research Institute (EPRI)-sponsored reports on the outage picture for light water reactor (LWR) units $(1,2)$ summarize the distribution of outage time between fuel and nonfuel outages as follows:

$\begin{array}{lcc} & \begin{array}{c}\text { Total } \\ \text { Outage Time, \% }\end{array} & \begin{array}{c}\text { Capacity } \\ \text { Factor } \\ \text { Loss, \% }\end{array} \\ \text { Refueling } & 41 & 11 \\ \text { Nonfuel }(>100 \mathrm{hr}) & 40 & 11 \\ \text { Nonfuel }(<100 \mathrm{hr}) & 19 & 5\end{array}$

From these studies, it was indicated that outages (fuel and nonfuel) account for a CF loss of about $27 \%$ with nonfuel outages accounting for about 16\%. The outages attributable to $5 G$ problems generaliy fall within the $>100$-hour category as shown by the histogram of Figure 1 . The modal value (corresponding to the highest frequency) is near 150 hours while the mean value is in excess of 500 hours. A measure of the contribution of SG problems to the CF loss attributable to nonfuel outages is obtainable from another recent EPRIsponsored report that analyzed outages for both fossil and nuclear units. In this report, ${ }^{(3)}$ the CF loss attributable to SGs over the period from July 1976 to June 1978 is given below by the SG manufacturer:

$\begin{array}{ll}\text { Westinghouse }(\boldsymbol{W}) & 3.9 \% \\ \text { Babcock \& Wilcox (B\&) } & 4.8 \% \\ \text { Combustion Engineering (CE) } & 1.3 \% \\ \text { Composite } & 3.6 \%\end{array}$




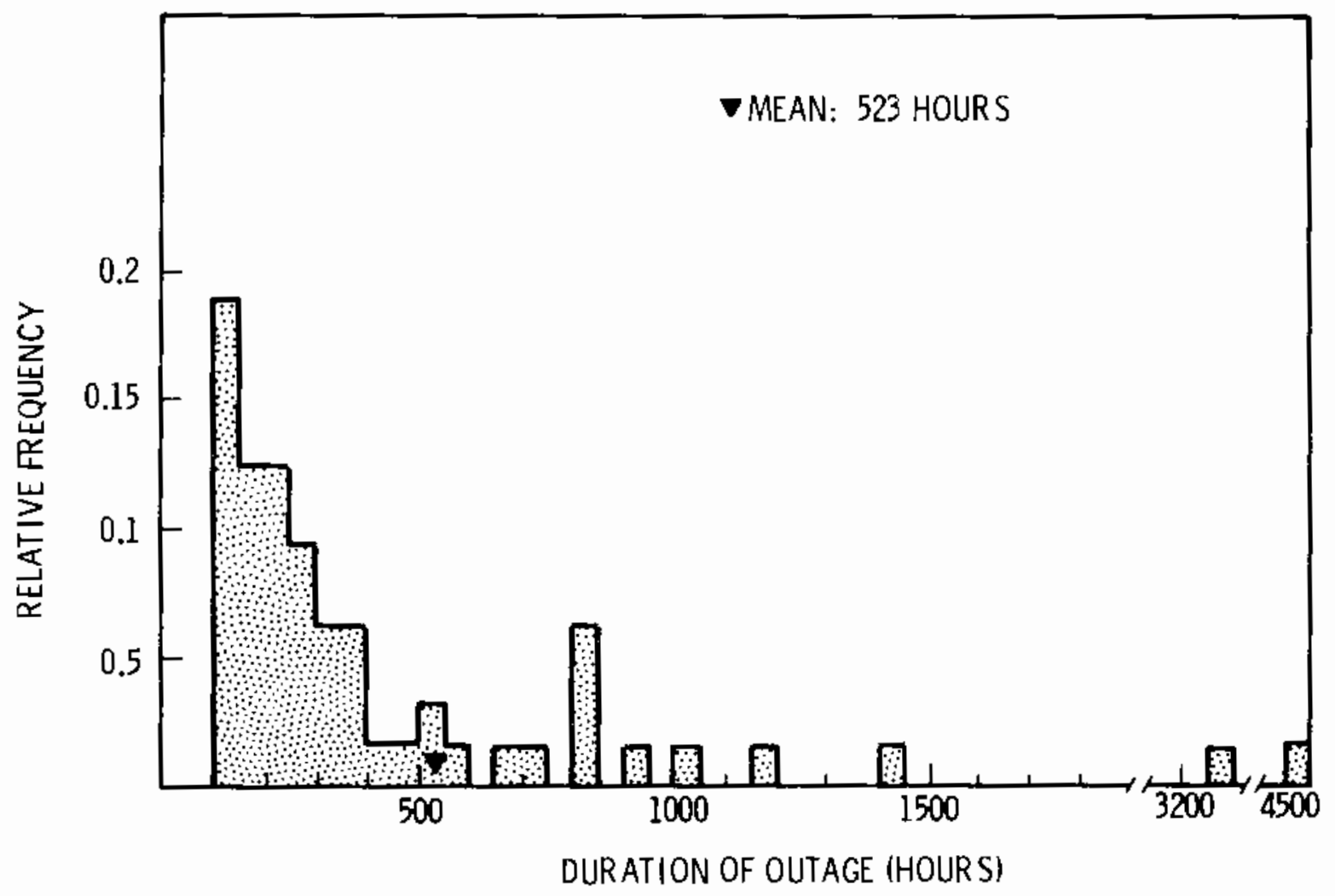

FIGURE 1. Histogram of Outages Involving Generators (>100 hr) (Reference 2)

Using the composite value of $3.6 \%$ for the SG impact on CF and the value of $16 \%$ CF loss due to nonfuel outages, it is seen that SG problems account for about $23 \%$ of the nonfuel outage time. From the relationship, ${ }^{(4)} 1000 \mathrm{MW}(\mathrm{e})$ $\mathrm{hr} \rightarrow 1500$ barrels (bbl) oil, the barrel of oil equivalent of a change in CF can be estimated as follows:

$$
\begin{aligned}
\text { bb } 1 / y r & =\frac{C F(q) \times[M W(e)] \times 1500 \times 365 \times 24}{100 \times 1000} \\
& =\Delta C F(q) \times[M W(e)] \times 1.31 \times 10^{2}
\end{aligned}
$$

where $[\mathrm{MW}(\mathrm{e})]$ is the unit rating and $\triangle C F$ is the incremental change in CF. For a 1000-MW(e) unit, a CF increment of $3.6 \%$ (given above as the composite value for the $S G$ impact) would be equivalent to: 
bbl $/ y r=3.6 \times 1000 \times 1.31 \times 10^{2}=472,000$

which is another rough measure of the impact of SG problems on nuclear units.

Detailed studies of the productivity of boiling water reactor (BWR) and PWR units have been made that help to quantify the impact of particular problem areas on unit productivity. Of the PWR units, reports have been issued on Turkey Point 3,(5) Oconee 1, (6) and Maine Yankee. (7) The Turkey Point report gives the productivity loss attributable to various critical path items over the two years, 1975 and 1976 . Using a base power level of $715 \mathrm{MH}(\mathrm{e})$, the SG tube problems accounted for a loss of $544,323 \mathrm{MWh}(\mathrm{e})$ over the observation period. In terms of CF loss this represents

$$
\Delta C F=\frac{544,323 \times 100 \%}{715 \times 2 \times 365 \times 24}=4.3 \%
$$

In contrast, the Maine Yankee unit has reported no outage time attributable to SG problems throughout its history (from December 1972 to the present) although other heat exchangers (principally the main condenser) have been troublesome. From a corrosion perspective, the Maine Yankee unit is of particular interest inasmuch as brackish (chloride-containing) water is used as the condenser coolant.

As indicated above and in the following section there is a wide variation among the nuclear units with respect to SG reliability and any generic indices of SG performance must be so qualified. A somewhat more comprehensive indication of the various costs associated with SG tubing problems is given in the following sections.

While, as noted above, the downtime associated with SG tubing problems is a significant component of the CF loss for U.S. PWR units, it should be pointed out that to date there has been no public hazard associated with SG problems. This is indicated by the following data on the incidence of actual tube ruptures among the population of tubes plugged over the period 1975-1980. $(8,9,15)$ 


$\frac{\text { Plugged Tubes }}{10^{\prime} \text { 's of thousands }} \quad \frac{\text { Known Leakers }}{100^{\prime} \mathrm{s}} \quad \frac{\text { Ruptures }}{5}$

Marsh(15) defines a rupture as a leak that is greater than the normal charging flow capacity of the unit. None of the ruptures resulted in a significant offsite radiation dose. 


\section{SCOPE ANO VARIABILITY OF STEAM GENERATOR TUBING PROBLEMS}

In the readily accessible literature data on tubing performance are exceedingly sparse. We refer to the service time corresponding to a particular spectrum of tubing defect conditions for all the tubes of the unit. More specifically, we refer to the number of operable tubes, the number of unfailed plugged tubes and some measure of their residual life expectancy at time of plugging, and the number of failed tubes and their approximate failure time. In most instances, the performance information appears to present quite a limited perspective on the tubing behavior of the overall unit. Consequently, we are at this time limited to rather crude indices of tubing performance.

The majority of work to date on the statistical analys is of the outage data entailed investigating what data are available in what form. We talked with people at the Nuclear Regulatory Commission (NRC), EPRI, Southwest Research Institute (SWRI), and a local nuclear power utility, Washington Public Power Supply System (WPPSS).

The NRC Gray Book computerized data base SISOR contains unscheduled outage data going back to 1974. One problem is that the cause of the outage is not always known at the time that the outage report is made so that there is a major source of error for a statistical analysis. There are also some inconsistencies in the definition of same of the unit performance indices. The advantage of this data base is that the raw data are made available for independent analyses.

The Nuclear Plant Reliability Data System (NPROS) data base being developed by SWRI contains more detailed engineering data than the SISOR data base. Since participation is voluntary, the completeness of the information and consistency of definition vary among the utilities. Combining data across plants for statistical analyses becomes problematical, and obtaining the raw data for our analyses appears to be a problem.

Another source of outage data is Nuclear Power Experience, Inc. This is perhaps the most complete and reliable source of outage data since incidence reports are generally followed up. The cause of an outage is more accurately 
known than the one given in the Gray Book data base. However, unlike the Gray Book and NPRDS systems, the data are not computerized. Data are presented in narrative form so the quantification of information for statistical analyses is a sizable but not insurmountable task.

References 1, 2, and 3 are recent EPRI-sponsored analyses of outage trends in LWRs. The data source for these documents is the Gray Books.

Reference 1 analyzes the length of outage time due to refueling as a function of plant life. Refueling is the major cause of outage time except in the first year of reactor operation.

Reference 2 analyzes the causes of major (>100 hours) forced outages. SG problems are ranked second behind problems with the steam system based on arithmetic averages of outage times taken over plants with vastly different operating experience. The hours of downtime associated with SG problems may be rather imprecise due to the uncertainty in the cause of the outage, but the ranking is probably reasonably accurate.

Reference 3 compares the various measures of the unit performance that are provided in the Gray Books; examples are the Availability Factor (AF), Equivalent Availability Factor (EAF), and Capacity Factor (CF). The major problem in understanding the information contained in these data is that none of the measures, individually, describe the complexity of reactor performance. There is a good discussion of this in Section 2 of the cited report. (3)

From these reports we have the relative contribution of $S G$ problems to outage time and a feel for the inaccuracies in the data. Based on the information decribed above, we obtained a data tape from NRC of all the unscheduled outage data contained in the SISOR data base for use in statistical analysis of SG-caused outages.

Because of time constraints, the statistical analyses have been quite 1 imited to date. Some of these are summarized in Figures 2 and 3 . The data for plants with at least two calendar years of data were obtained from several reports. $(8,9)$ The breakdown by manufacturer for the computerized analys is is Westinghouse, 28; Combustion Engineering, 8; Babcock \& Wilcox, 7; and 

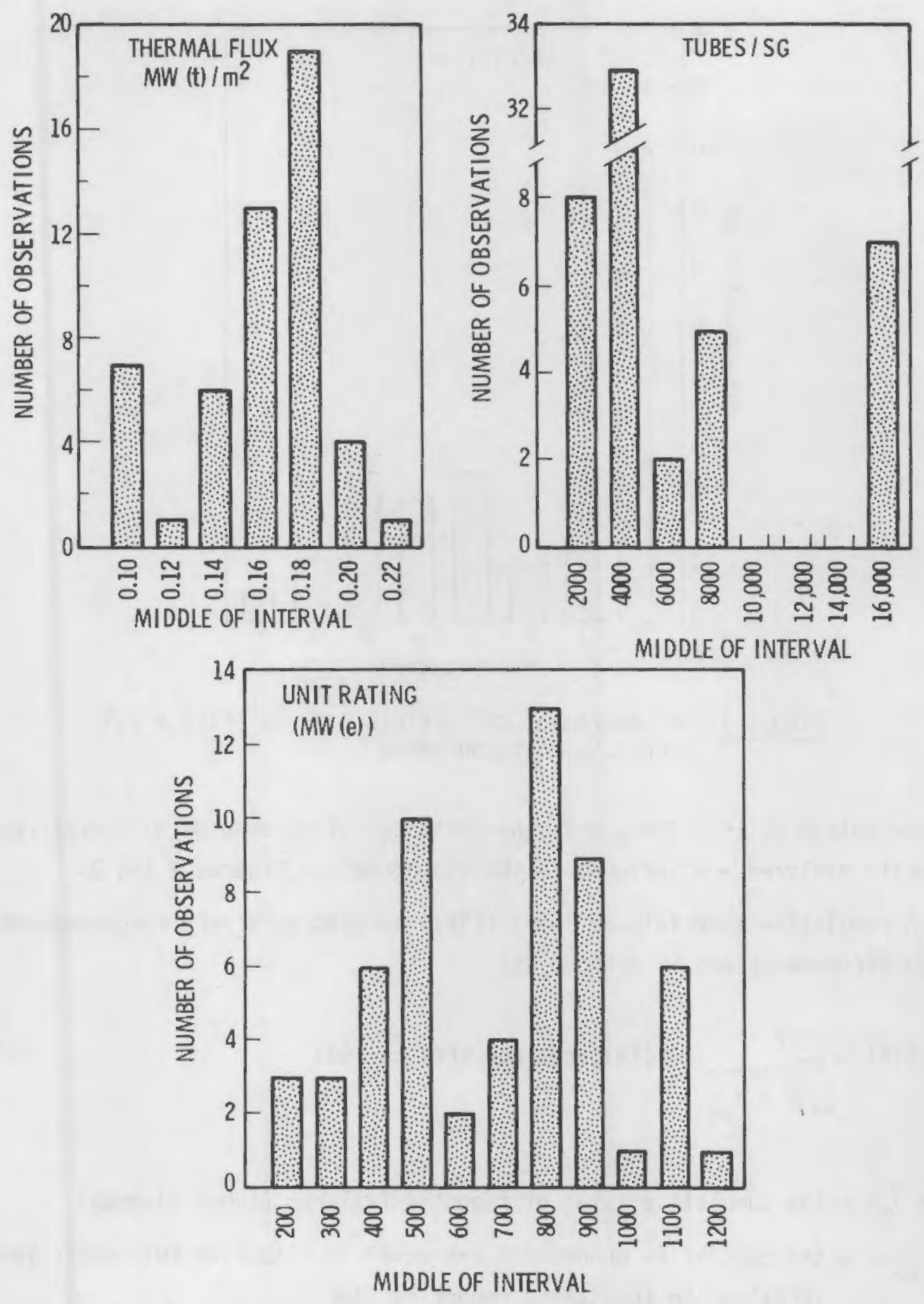

FIGURE 2. Histograms of Various Unit Steam Generator Parameters 


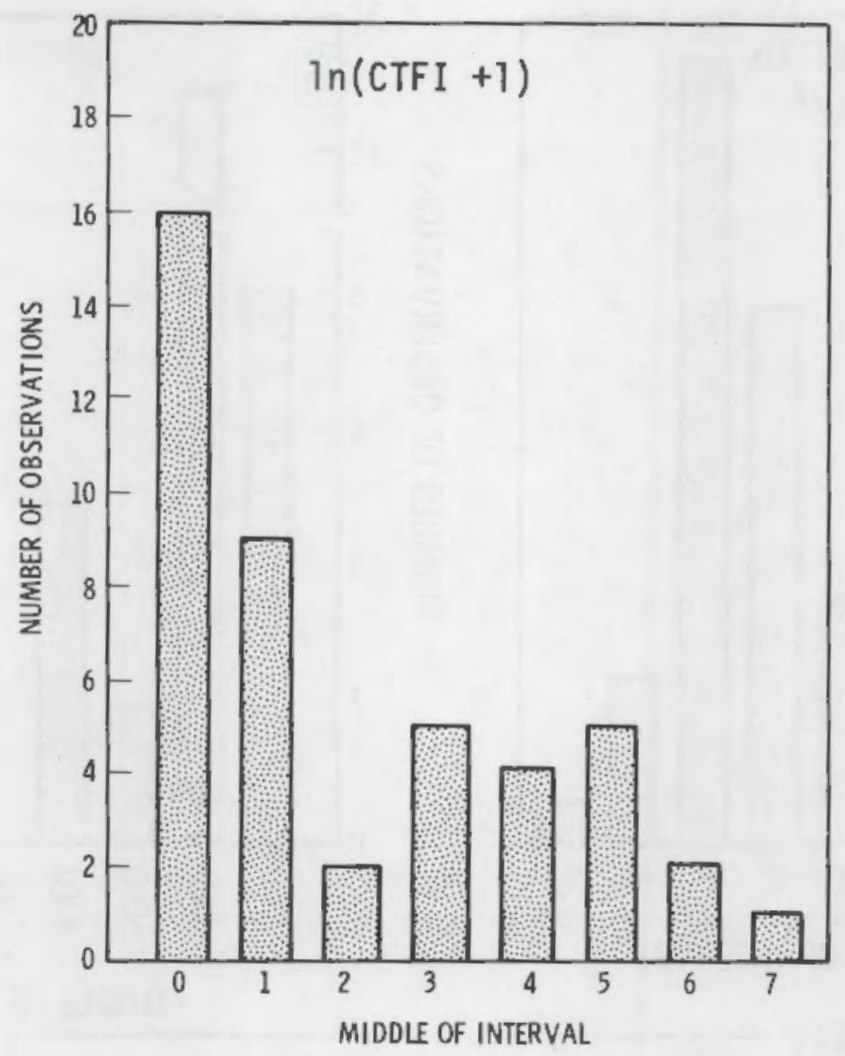

FIGURE 3. Histogram of CTFI [Plotted as $\ln ($ CTF I +1$)$ ] for U.S. Units Surveyed

foreign builders, 15. There are many instances of missing data; therefore, not all units analyzed are included in the histograms of Figures 2 and 3.

A cumslative tube failure index (CTFI) is used as a very rough measure of tubing performance and is defined as:

$$
\text { CTFI }=\frac{\sum f}{\sum \theta \times N_{S g}} \quad \text { (failures per EFPY per SG) }
$$

where $\sum f=$ the cumulative total of reported failures (tubes plugged)

$\sum \theta=$ the cumulative production expressed in effective full power years (EFPY) up to the latest reporting time

$N_{s g}=$ the number of SGs in the unit. 
Preliminary analyses were also done for several unit parameters that conceivably could influence tubing behavior, namely mean thermal power flux per $S G\left[M N(t) / m^{2}\right]$, plant rating $[M W(e)]$, and tubes per SG. Computer printer-plot histograms of the above variables for all plants are the basis for Figures 2 and 3 .

Histograms provide an easy way to see the structure of the data, its variability, and possible erroneous values. More importantly, they provide a method for evaluating the behavior of indices that are devised to describe plant performance. For example, the histogram of MW(e) is trimodal, which shows that reactors tend to cluster into three size groups. The histograms of number of tubes/generator and flux would show small variability if it were not for the Babcock \& Wilcox plants, where the number of tubes/ generator is very high $(15,000-16,000)$ and the thermal flux is low $(0.09-0.125)$. However, one Westinghouse plant, Yankee Rowe, had a flux of 0.106 .

The tube failure index ranged from 0 (no tube failures) to over 900 (Palisades). In order to get a meaningful histogram, the data were transformed to the following variable for Figure 3: In [(tube failure index) +1 ]. The behavior is highly skewed, even exponential, which suggests that the mean is not a good representative average value. The mean is approximately 7.39 on the untransformed scale, and the median (the $50 \%$ point of the histogram) is about 2.12. Of the units reviewed whose data allowed some computation of the CTFI (not all such units were used in the statistical analysis or histograms):

- the CTFI ranged from 0 to 230 for 26 Westinghouse units with 7 units at 0

- the index ranged from 0 to 950 for 5 Combustion Engineering units with 2 units at 0

- the index ranged from 0 to 6.5 for 6 Babcock \& Wilcox units with 1 unit at 0

- the index ranged from 0 to 46 for 9 foreign units with 2 units at 0 . 
It might be noted here that the yearly CTFI characteristics for these units also exhibit a wide variability and no correlation has been evident between the CTF I and the plant age. A cumulative plot of SG impact on CF versus plant age given in Reference 3 appears to support an "induction period" of roughly 4 years before tubing failures appear. Our preliminary findings do not support any induction period, certainly not on a generic basis. Furthermore, as noted above, the picture of the tubing defect state versus plant age or cumulative EFPY is far too diffuse to permit any identification of so subtle a feature as an induction period for tubing failure under a given plant's operating and maintenance history.

Of those units with some history of tubing failure, we have not acquired sufficient data to permit any failure rate analysis. The success of any prediction technique for tubing failure will depend on the degree to which cognizance can be taken of the internal (material) and external (environmental) factors affecting the tubing performance. Considering the complexity of such factors, the state of knowledge of the independent and synergistic action of these factors, and the unpredictable time displacement between cause and effect (which can range between weeks and years), we are not optimistic that tube failure prediction will enjoy much success in the near future. Such prediction will be aided by more comprehensive ISI and by more standardization of SG design, plant operation, and maintenance practice, particularly with respect to control of the secondary water system chemistry. Some additional comments on the problems of reliability analysis for SG tubes are given in a following section.

An ISI strategy receiving much current attention is a $100 \%$ inspection of one generator at a plant and then inferring the results to the other generators at the plant. This would be valid only if the failure rates do not differ significantly among the generators at the same plant. To test this hypothesis, separate tube plugging rates were obtained for the generators at six plants. The data and statistical results are given in Tables 1 and 2 . The plugging rates within the same plant were compared by a $x^{2}$ test for the equality of proportions. The value of the $\chi^{2}$ statistic and the significance level are given in Table 2. The significance levels of only two of the plants are 
TABLE 1. Oistribution of Tubes Plugged Among Unit SGs

\begin{tabular}{|c|c|c|c|c|c|c|}
\hline Unit & $S G(A)$ & $S G(B)$ & $S G(C)$ & $S G(0)$ & Period & $\underset{\text { Parameters }}{\mathrm{Plant}}(\mathrm{b})$ \\
\hline $\begin{array}{l}\text { Robinson } 2 \\
\text { (Westinghouse) }\end{array}$ & $\begin{array}{l}52(a) \\
44 \%\end{array}$ & $\begin{array}{l}32 \\
28 \%\end{array}$ & $\begin{array}{l}32 \\
28 \%\end{array}$ & -- & $172-177$ & $\begin{array}{l}700 \mathrm{MW}(\mathrm{e}) \\
3260 \text { tubes/SG } \\
\text { CCW: fresh }\end{array}$ \\
\hline $\begin{array}{l}\text { Palisades } \\
\text { (Combustion Engineering) }\end{array}$ & $\begin{array}{l}1540 \\
51 \%\end{array}$ & $\begin{array}{l}1462 \\
49 \%\end{array}$ & -- & -- & '73-' 77 & $\begin{array}{l}700 \mathrm{MW}(\mathrm{e}) \\
\text { B519 tubes/SG } \\
\text { CCW: fresh }\end{array}$ \\
\hline $\begin{array}{l}\text { San Onofre } \\
\text { (West inghouse) }\end{array}$ & $\begin{array}{l}71 \\
33 \%\end{array}$ & $\begin{array}{l}40 \\
19 \%\end{array}$ & $\begin{array}{l}102 \\
48 \%\end{array}$ & -- & to $6 / 79$ & $\begin{array}{l}430 \mathrm{MW}(\mathrm{e}) \\
3794 \text { tubes/SG } \\
\text { CCW: sea }\end{array}$ \\
\hline $\begin{array}{l}\text { Haddam Neck } \\
\text { (West inghouse) }\end{array}$ & $\begin{array}{l}1 \\
3 \%\end{array}$ & $\begin{array}{l}2 \\
5 \%\end{array}$ & $\begin{array}{l}14 \\
36 \%\end{array}$ & $\begin{array}{l}22 \\
56 \%\end{array}$ & to $2 / 79$ & $\begin{array}{l}575 \text { MW(e) } \\
3795 \text { tubes/SG } \\
\text { CCW: fresh }\end{array}$ \\
\hline $\begin{array}{l}\text { Oconee } 1 \\
\text { (Babcock \& Wilcox) }\end{array}$ & $\begin{array}{c}7 \\
12 \%\end{array}$ & $\begin{array}{l}54 \\
88 \%\end{array}$ & -- & -- & to $7 / 79$ & $\begin{array}{l}871 \mathrm{MW}(\mathrm{e}) \\
15,531 \text { tubes/SG } \\
\text { CCW: fresh }\end{array}$ \\
\hline $\begin{array}{l}\text { Point Beach } 1 \\
\text { (West inghouse) }\end{array}$ & $\begin{array}{l}294 \\
53 \%\end{array}$ & $\begin{array}{l}264 \\
47 \%\end{array}$ & -- & -- & to $10 / 79$ & $\begin{array}{l}497 \mathrm{MW}(\mathrm{e}) \\
3260 \text { tubes/SG } \\
\text { CCW: fresh }\end{array}$ \\
\hline
\end{tabular}

(a) Top number is number of tubes plugged; bottom number is percent that this represents of tubes plugged for entire unit.

(b) $\mathrm{CCW}=$ condenser cooling water.

TABLE 2. Test of Failure Uniformity Among SGs

\begin{tabular}{|c|c|c|c|c|c|c|}
\hline \multirow[b]{2}{*}{ Plant } & \multicolumn{4}{|c|}{ Generator } & \multirow[b]{2}{*}{$x^{2-}$} & \multirow[b]{2}{*}{ Sig Level } \\
\hline & $A$ & $B$ & $C$ & $\mathrm{D}$ & & \\
\hline Robinson 2 & 0.0160 (a) & 0.0098 & 0.0098 & & 6.98 & 0.03 \\
\hline Palisades & 0.1808 & 0.1716 & & & 2.46 & 0.12 \\
\hline San Onofre & 0.0187 & 0.0105 & 0.0269 & & 27.59 & 0 \\
\hline Haddam Neck & 0.0003 & 0.0006 & 0.0037 & 0.0058 & 31.34 & 0 \\
\hline Oconee 1 & 0.0004 & 0.0035 & & & 36.28 & \\
\hline Point Beach 1 & 0.0902 & 0.0810 & & & 1.76 & 0.18 \\
\hline
\end{tabular}

(a) Oata under various SGS are fraction of tubes plugged for given SG. 
greater than 0.10 , which suggests that the equality of failure rates may not hold for a sizable number of plants. Plant records should yield further data on the failure distribution among SGs. Obviously these data are needed to characterize the course of ISI conservatism as the scope of the ISI is reduced on a regular or periodic basis.

The plans are to continue the statistical analyses using the data obtained from the SISOR data base. In addition to the analyses needed for the C/B analysis, an outgrowth of the work will be an evaluation of the quality of the data being collected for the data base and possible suggestions on how to improve the information content in the unit performance indices and how to present the results to increase understanding. 


\section{FACTORS AFFECTING SCOPE AND FREQUENCY OF IN-SERVICE INSPECTION}

The factors affecting the time, manpower, and radiation exposure components of an SG ISI have been analyzed by consulting various sources, including personal contacts with the following organizations: Conam Inspection Division of Nuclear Energy Systems; Zetec, Inc.; and the Inspection Division of the Babcock \& Wilcox Co. A brief summary of the findings to date are presented in this section. A number of aspects of the various costs of SG ISI are developed in somewhat more detail in the following section.

\section{Time, Manpower, and \$ Factors}

Figures $4 A$ and $4 B$ present bar graphs of the various aspects of the SG ISI that account for the man-hour expenditure. The unit number refers to the coded identity of a particular unit. The figures give the man-hours attributable to four aspects of the ISI, namely preparation time, setup time, test time, and administrative delays.

- preparation time: transportation, instrument calibration, normal indoctrination of special crews (health, security)

- setup time: mockup training, actual instrumentation setup, and removal outside and within SG

- test time: NDT of the selected tube sample

- administrative delays: miscellaneous delays over and above nominally expected administrative items

The tube sample size is given with each bar graph in Figures $4 A$ and $4 B$. Sample size ranges from 451 to 15,637 tubes. For this report, various average values obtained from the survey are of interest and are summarized in Table 3 .

Figure 5 presents some preliminary information on the total cost of an ISI on a per-tube-inspected basis.

Table 4 presents some miscellaneous information on the tube plugging operation. 


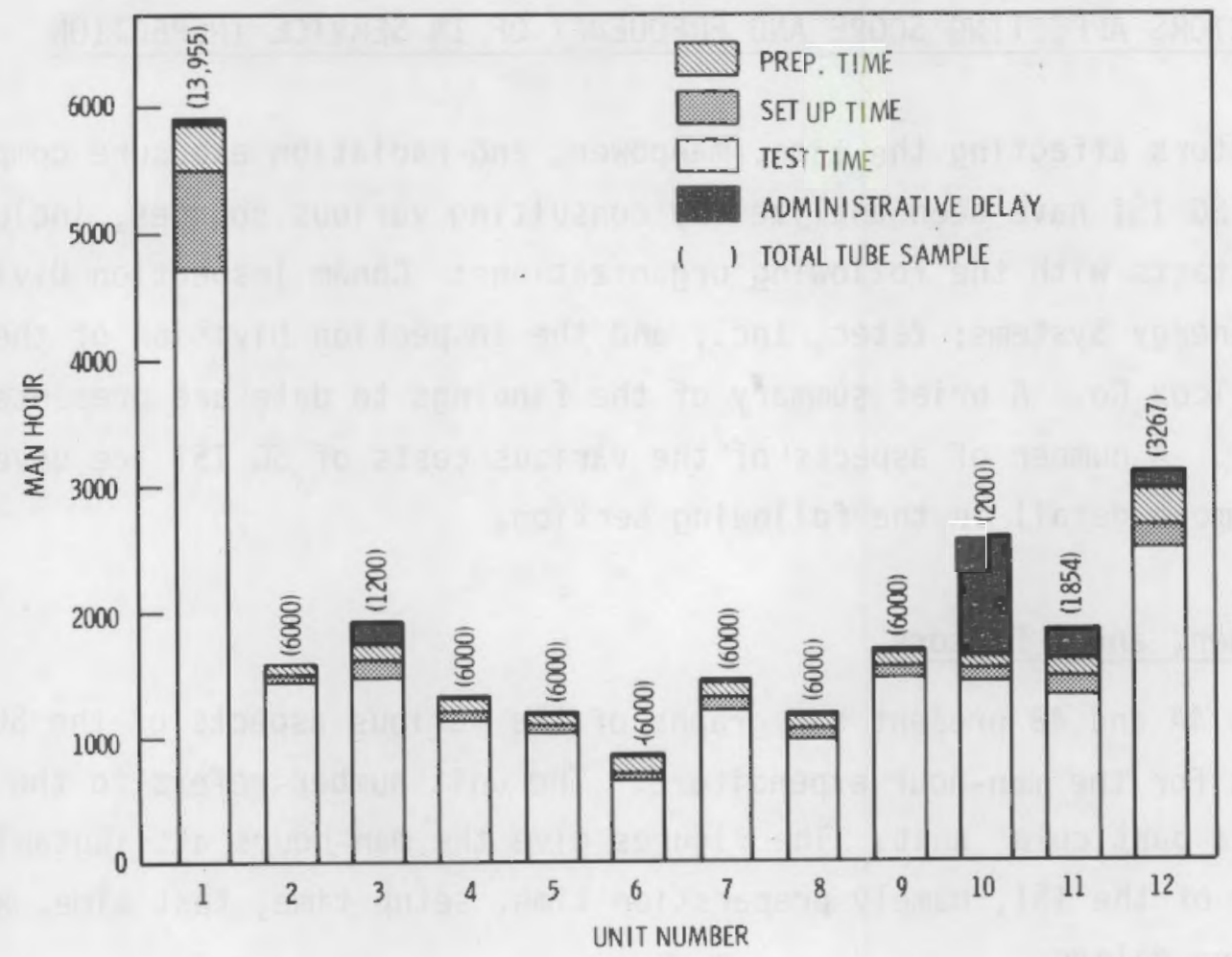

FIGURE 4A. Man-Hour Expenditure for Various ISI Items

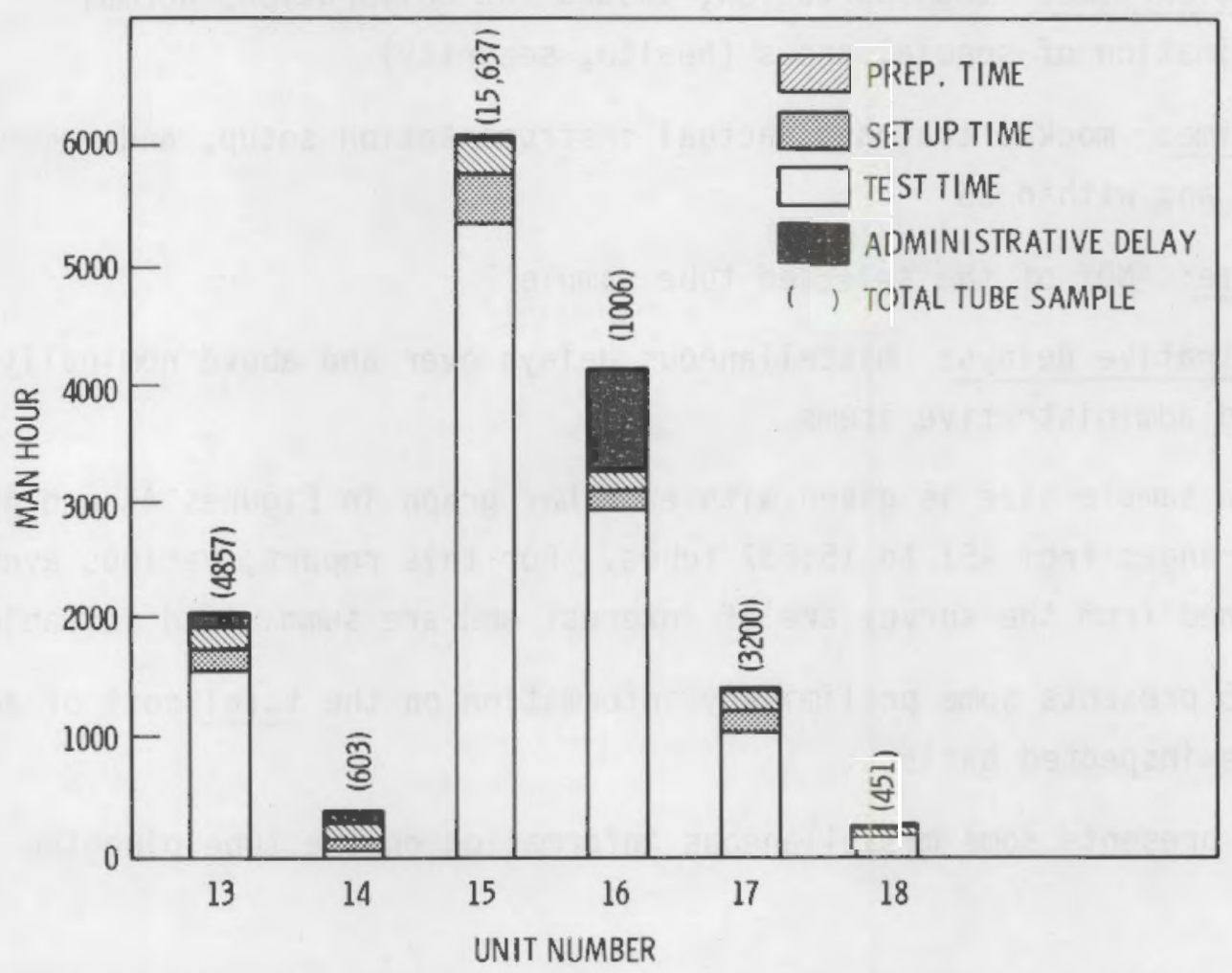

FIGURE 4B. Man-Hour Expenditure for Various ISI Items 
TABLE 3. Average Data for Various Time/Manpower ISI Items

\begin{tabular}{|c|c|}
\hline I tem & Average Value (a) \\
\hline tube samples & 5000 \\
\hline preparation time & 142 man-hours \\
\hline setup & 173 man-hours \\
\hline administrative delay & 162 man-hours \\
\hline test time & 1700 man-hours \\
\hline personnel involved & 10.4 men (contractor only) \\
\hline total time on job ${ }^{(b)}$ & $2160 \mathrm{hr}$ (contractor only) \\
\hline charge-out rate & $\$ 45 /$ man-hour \\
\hline total charge-out rate & $\$ 450 / \mathrm{hr}$ \\
\hline
\end{tabular}

(a) Average based on units surveyed and displayed in Figures $4 A$ and $4 B$.

(b) Door-to-door contractor's location.

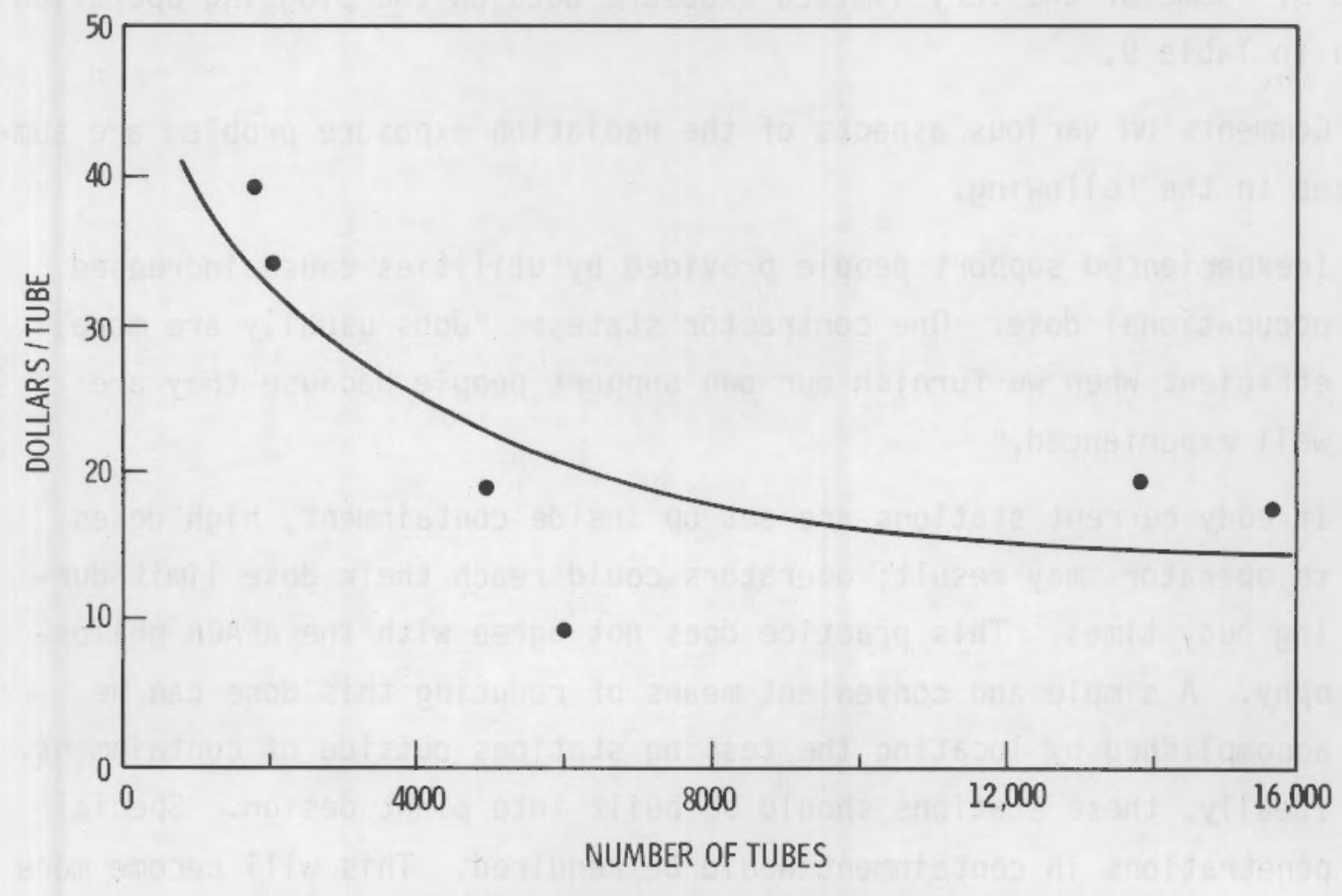

FIGURE 5. Cost/Tube for Testing Versus Sample Size 
TABLE 4. Miscellaneous Tube Plugging Information

- Explosive plugging requires $20 \mathrm{sec}-2 \mathrm{~min}$ per plug. Mechanical plugging requires 1-2 min per plug. Welding plugging requires $2 \mathrm{hr}-1$ week depending on rad field and equipment problems.

- Explosive plugging is used about $95 \%$ of the time compared to mechanical or manual plugging techniques.

- Mechanical plugging is seldom employed at present.

- Welded plugs are mainly used to supplement explosive plugs that are found to leak; the success record for explosive plugs has generally been excellent.

The Radiation Exposure Factor in SG ISI

Figures 6,7 , and 8 and Tables $5,6,7,8$, and 9 summarize our findings to date on the radiation exposure factor in SG ISI. Based on this review, the average exposure per ISI is about 2 rem per person. The range of exposures for the nontesting phases of the ISI operation for several types of SG is given in Table 8. Some of the very limited exposure data on the plugging operation are given in Table 9.

Corments on various aspects of the radiation exposure problem are summarized in the following.

1. Inexperienced support people provided by utilities cause increased occupational dose. One contractor states: "Jobs usually are more efficient when we furnish our own support people because they are well experienced."

2. If eddy current stations are set up inside containment, high doses to operators may result; operators could reach their dose 1 imit during busy times. This practice does not agree with the ALARA philosophy. A simple and convenient means of reducing this dose can be accomplished by locating the testing stations outside of containment. Ideally, these stations should be built into plant design. Special penetrations in containment would be required. This will become more of a problem if $100 \%$ inspection is required. 


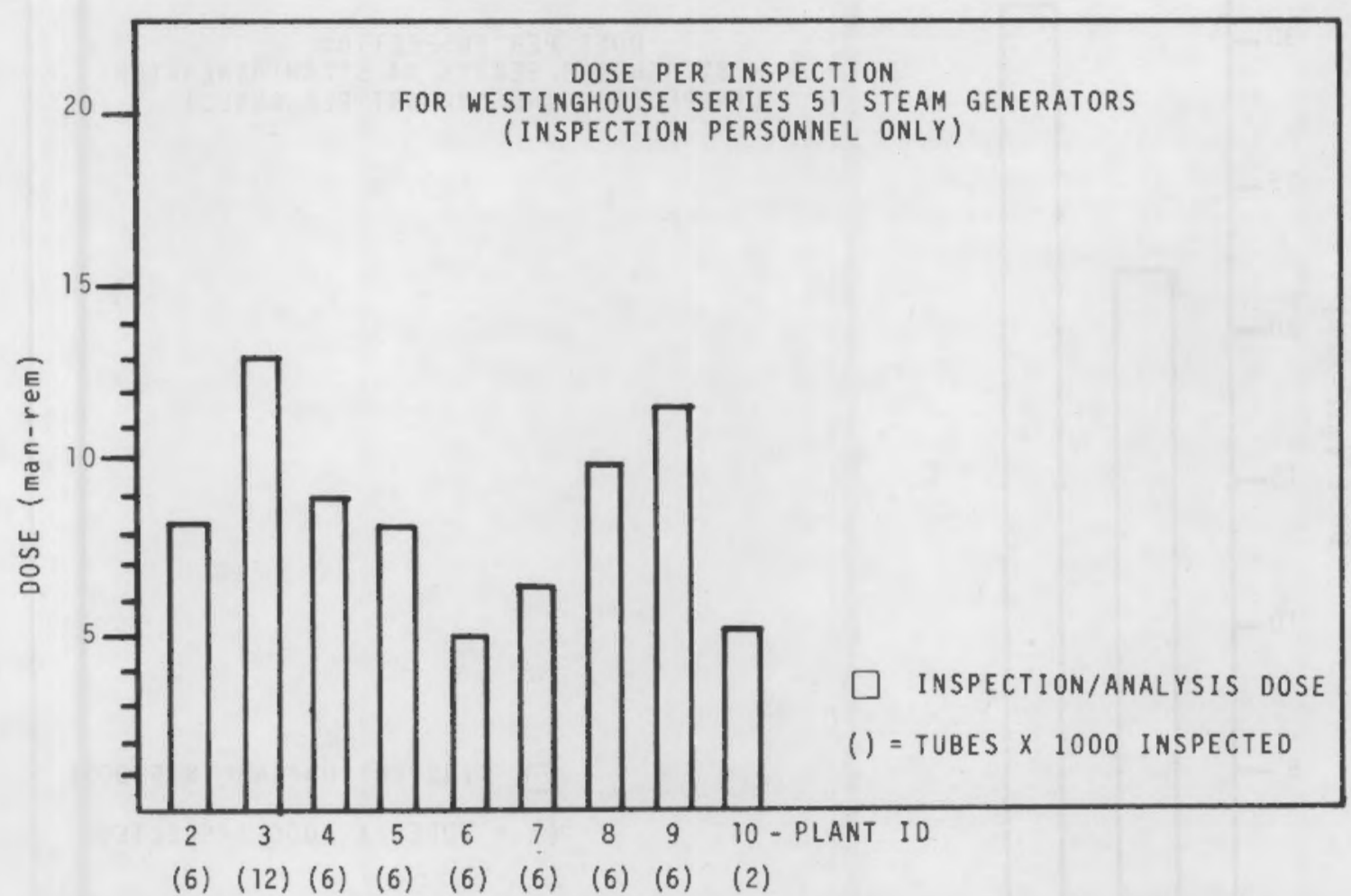

FIGURE 6. Dose Distribution for Various Units (W/Series 51); Inspection Personnel Dnly

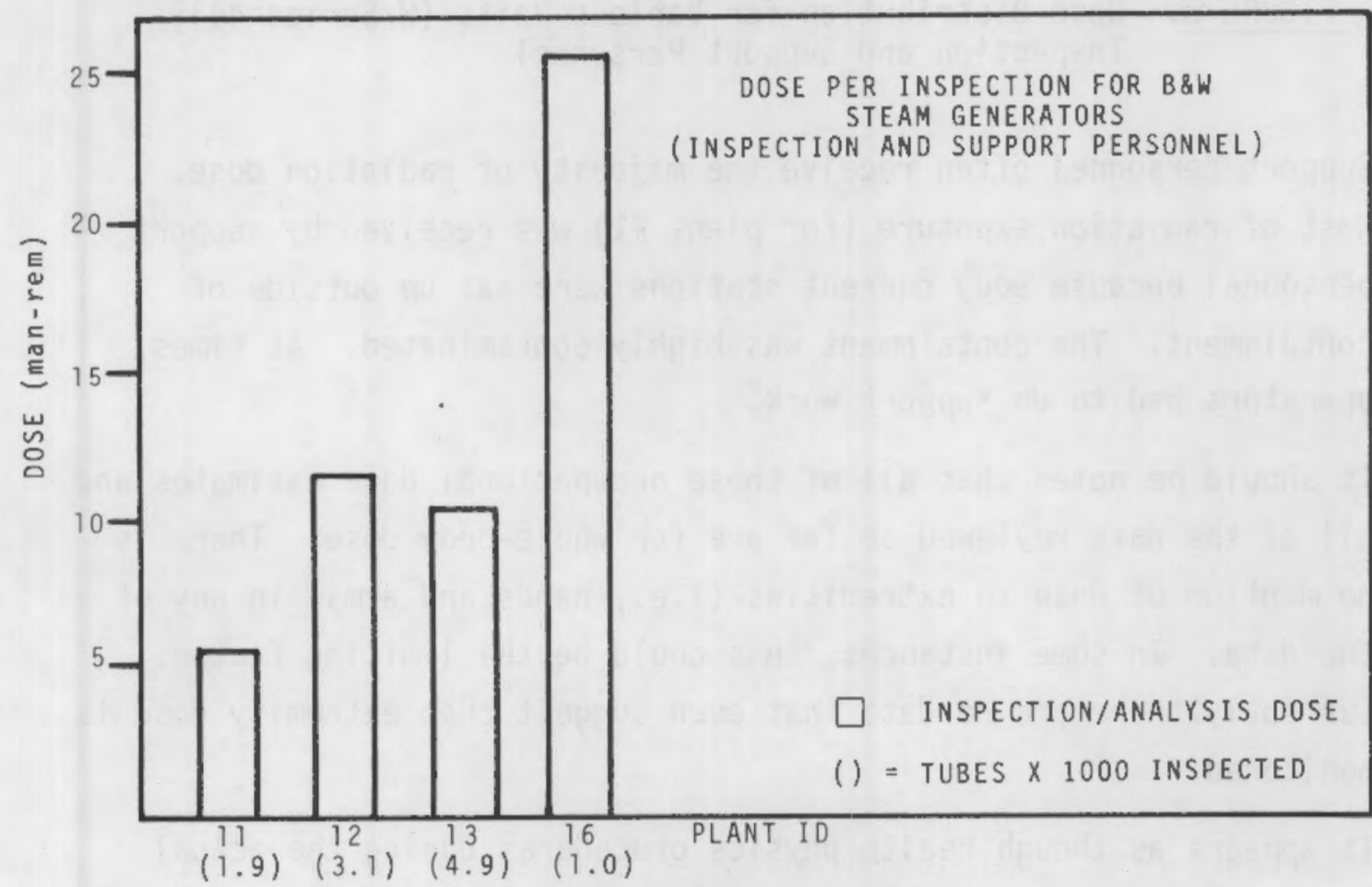

FIGURE 7. Dose Distribution for Various Units (B\&W); Inspection and Support Personnel 


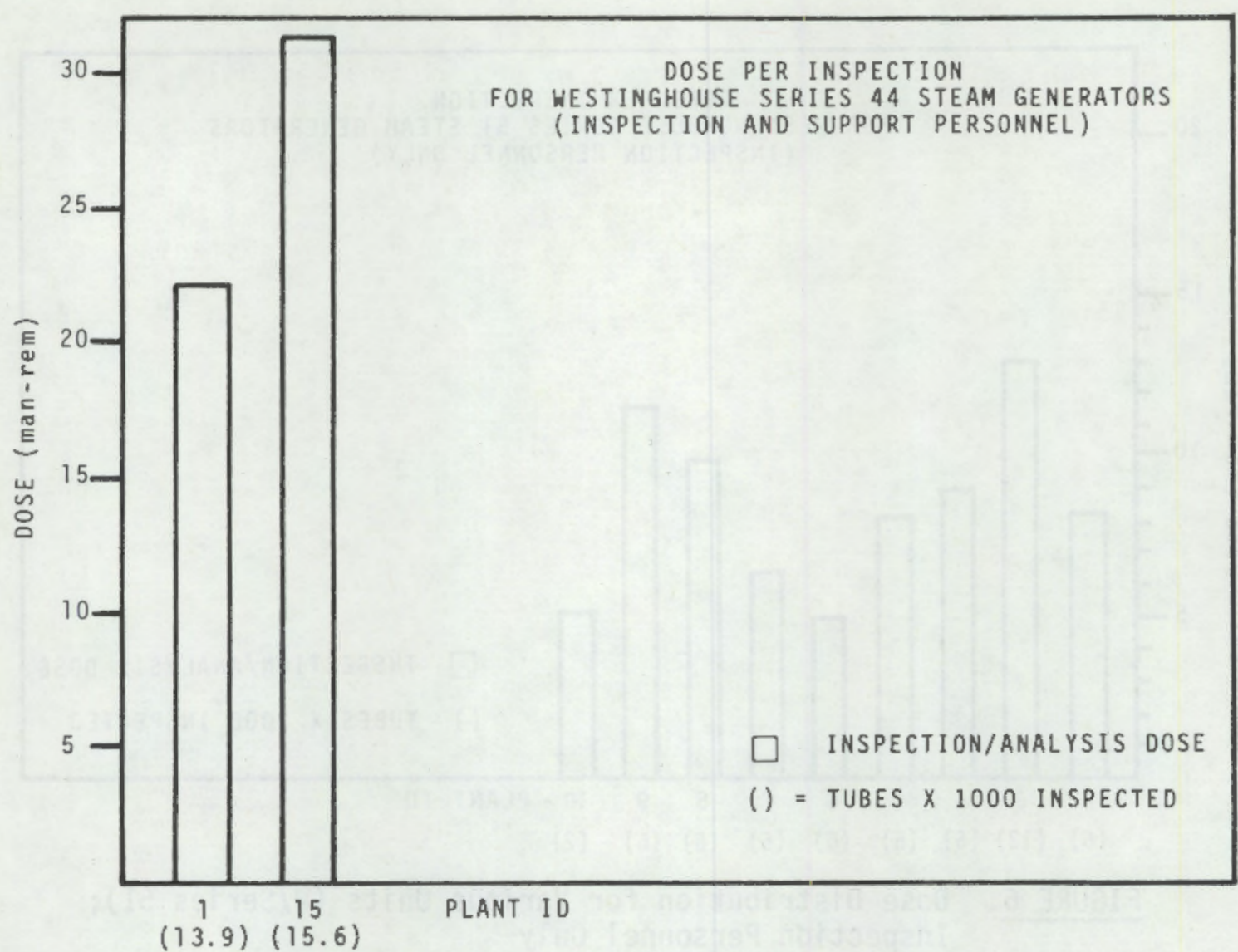

FIGURE 8. Dose Distribution for Various Units (W/Series 44); Inspection and Support Personnel

3. Support personnel often receive the majority of radiation dose. Most of radiation exposure (for plant \#1) was received by support personnel because eddy current stations were set up outside of containment. The containment was highly contaminated. At times, operators had to do support work.

4. It should be noted that all of these occupational dose estimates and all of the data reviewed so far are for whole-body dose. There is no mention of dose to extremities (i.e., hands and arms) in any of the data. In some instances, this could be the limiting factor. Currently there are no data that even suggest that extremity dose is monitored.

5. It appears as though health physics procedures during the actual inspection and setup time may actually cause increased occupational dose due to varying procedures by different health physics personnel 
TABLE 5. Occupational Doses for Inspection Team Only with No Support Personnel (see Figure 6)

\section{Man-Rem/}

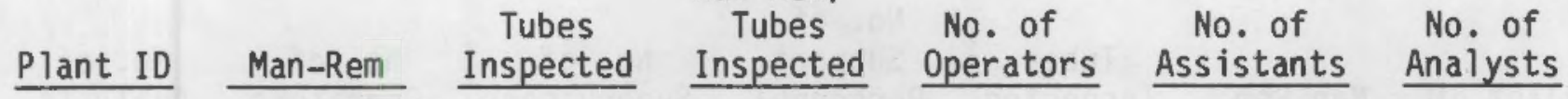

\begin{tabular}{|ccccccc}
2 & 8.337 & 6000 & $1.39(-3)$ & 4 & 0 & 1 \\
3 & 12.91 & 12000 & $1.08(-3)$ & 6 & 6 & 1 \\
4 & 8.895 & 6000 & $1.48(-3)$ & 4 & 4 & 1 \\
5 & 8.265 & 6000 & $1.38(-3)$ & 4 & 4 & 1 \\
6 & 4.974 & 6000 & $8.29(-4)$ & 3 & 2 & 1 \\
7 & 6.336 & 6000 & $1.06(-3)$ & 6 & 4 & 1 \\
8 & 9.772 & 6000 & $1.63(-3)$ & 5 & 1 & 1 \\
9 & 11.534 & 6000 & $1.92(-3)$ & 4 & 5 & 1 \\
10 & 5 & 2000 & $2.5(-3)$ & 5 & 0 & 1 \\
Average & $8.45 \pm 2.74$ & $6200 \pm 2500$ & $1.7(-3)$ & $4.6 \pm 1.0$ & $2.9 \pm 2.2$ & $1 \pm 0$
\end{tabular}

TABLE 6. Babcock \& Wilcox Occupational Doses for Inspection Plus Support Personnel (see Figure 7)

No. of

$$
\text { Tubes Support No. of No. of No. of }
$$

Plant ID Man-Rem Inspected Personnel Supervisors Operators Analysts

$\begin{array}{cllllll}11 & 5.51 & 1854 & 6 & 1 & 4 & 1 \\ 12 & 11.505 & 3094 & 8 & 2 & 4 & 1 \\ 13 & 10.57 & 4857 & 6 & 0 & 6 & 1 \\ 16 & 25.59 & 1006 & 8 & 0 & 4 & 1 \\ \text { Average } & 13.3 \pm 8.6 & 2700 \pm 1670 & 7.0 \pm 1.2 & 0.75 \pm 0.96 & 4.5 \pm 1.0 & 1\end{array}$


TABLE 7. Occupational Doses for Inspection Team Plus Support Personnel (Westinghouse Series 44) (see Figure 8)

\begin{tabular}{|c|c|c|c|c|c|c|}
\hline Plant ID & Man-Rem & $\begin{array}{c}\text { Tubes } \\
\text { Inspected }\end{array}$ & $\begin{array}{c}\text { No. of } \\
\text { Support } \\
\text { Personnel } \\
\end{array}$ & $\begin{array}{c}\text { No. of } \\
\text { Supervisors } \\
\end{array}$ & $\begin{array}{l}\text { No. of } \\
\text { Operators }\end{array}$ & $\begin{array}{r}\text { No. of } \\
\text { Anaiysts } \\
\end{array}$ \\
\hline 1 & 22 & 13,995 & 10 & 2 & 8 & 2 \\
\hline 15 & 31.192 & 15,637 & 8 & 0 & 8 & 1 \\
\hline Average & 26.2 & 14,816 & 9 & 1 & 8 & 1.5 \\
\hline
\end{tabular}

TABLE 8. Man-Rem Estimates for Setup and Removal Phases of Inspection

\begin{tabular}{|c|c|c|c|c|}
\hline Inspection Phases (a) & $\begin{array}{l}\text { Westinghouse } \\
\text { Series } 51 \\
\end{array}$ & $\begin{array}{c}\text { B\&W } \\
\text { Vertical } \\
\end{array}$ & $\begin{array}{r}\text { CE } \\
\text { Vertical } \\
\end{array}$ & U-Tube \\
\hline $\begin{array}{l}\text { Fixture Channel } \\
\text { Head Installation }\end{array}$ & $0.8-5.0$ & $0.8-6.0$ & 1.7 & -6.7 \\
\hline $\begin{array}{l}\text { Fixture Platform } \\
\text { Setup }\end{array}$ & $0.1-0.5$ & $0.1-0.75$ & 0.1 & -0.5 \\
\hline $\begin{array}{l}\text { Fixture Channel } \\
\text { Head Removal }\end{array}$ & $0.4-2.5$ & $0.4-3.0$ & 0.67 & -2.7 \\
\hline Total & $1.3-8.0$ & $1.3-9.8$ & 2.5 & -9.9 \\
\hline
\end{tabular}

(a) The NRC Oraft Regulatory Guide estimates 4.95 man-rem for these jobs.

TABLE 9. Information for Tube Plugging Operation

$\begin{array}{lc}\text { Exposive Rate } & 10-60 \mathrm{rem} / \mathrm{hr} \\ \text { Explosive } & 0.050-2.0 \text { man-rem } \\ \text { Mechanical } & 0.17-2.0 \text { man-rem } \\ \text { Welding } & 0.17-2400 \text { man-rem }\end{array}$


for the same job during the same shift. This problem is caused partially by the utility hiring contract technicans who have different training and backgrounds. One solution to this problem is to have written health physics procedures and train all personnel (eddy current personnel and health physics technicians) in these procedures. There will still be variations from plant to plant, however; and this too tends to increase occupational exposure during ISIs. This situation could be remedied by having the eddy current inspection contractors provide their own health physics procedures and personnel. Utilities would retain the right to review and amend these procedures if they did not comply with plant operating philosophy (i.e., ALARA).

\section{Fue 1 Outage ISI Opportunities}

The frequency and time window for ISI work provided by the fuel outages can be assessed from a recent report on LWR fuel outages. (1) This study includes all U.S. LWRs of greater than $150 \mathrm{MW}(\mathrm{e})$ rating over the period from January 1960 through June 1977.

Figure 9 summarizes the findings on the course of the fuel outage length with refueling number. (1) For the PWR units, the average curve shows that the first outage is about 13 weeks with a decrease to 7-8 weeks by the third outage. These authors ${ }^{(1)}$ state that the minimum fuel outage length under present design and testing conditions appears to be of the order of 4-6 weeks. A comparison of the overall outage times for U.S. and foreign LWR units is given in Figure 10.

The range of the interval between first criticality and the first fuel outage is given in Figure 11A. Figure $11 \mathrm{~B}$ shows the interval range between refuelings for first through the seventh refueling. As noted in the histograms, the mean time for the first fuel outage is 26 months, while the mean time between subsequent refuelings is about 12 months.

Using the mean data for the outage length and intervals, an ISI strategy based on fuel outages would have the frequency and work time windows shown in Figure 12. For comparison, frequencies under Regulatory Guide 1.83 recommendations for several problem cases are also given. With the possible exception 
of the first postcriticality inspection, it is seen that the nominal fuel outage schedule would generally be quite conservative relative to the Regulatory Guide 1.83 position.

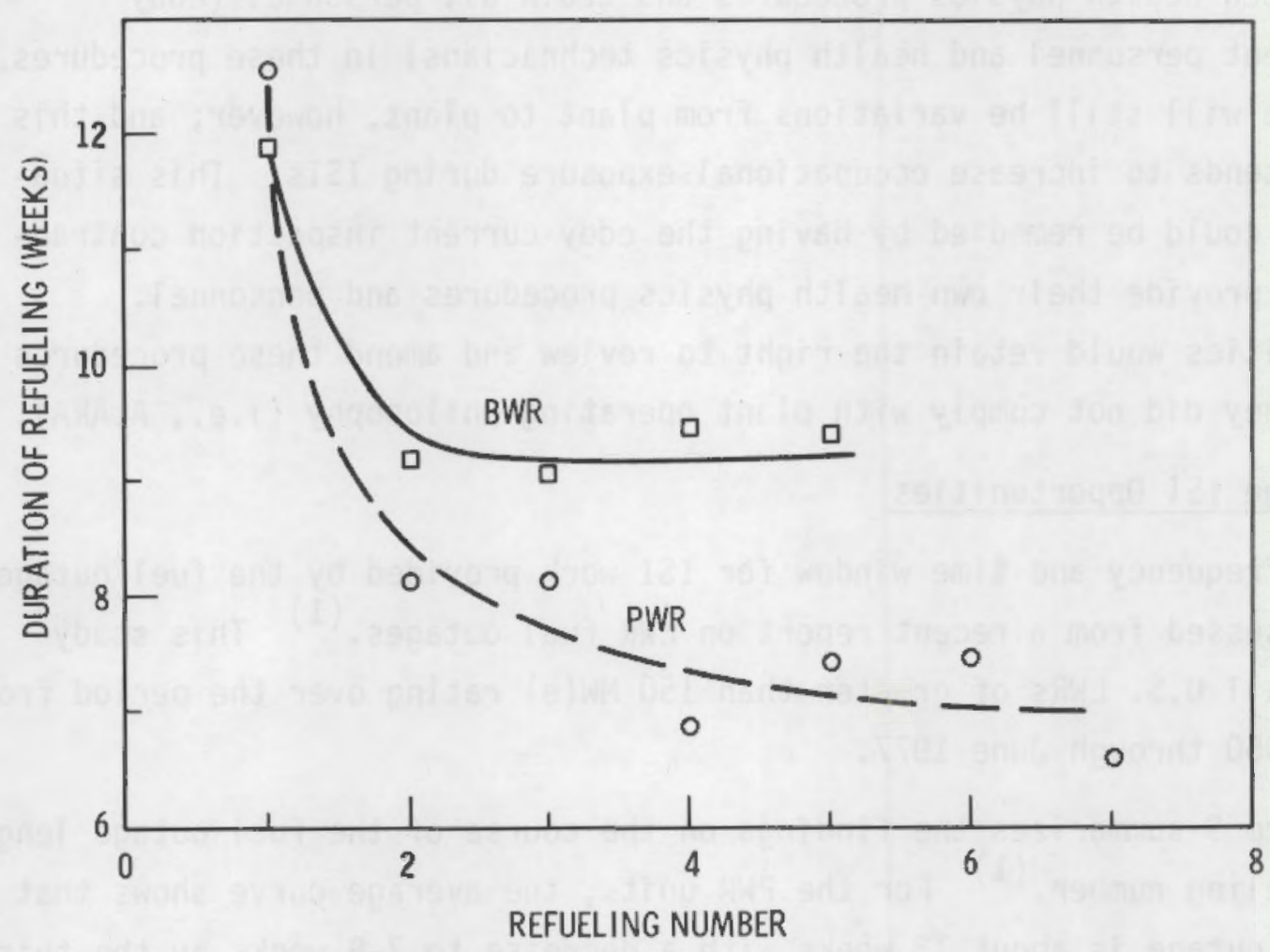

FIGURE 9. Refueling Outage Duration as a Function of the Number of Refuelings (Reference 1) 


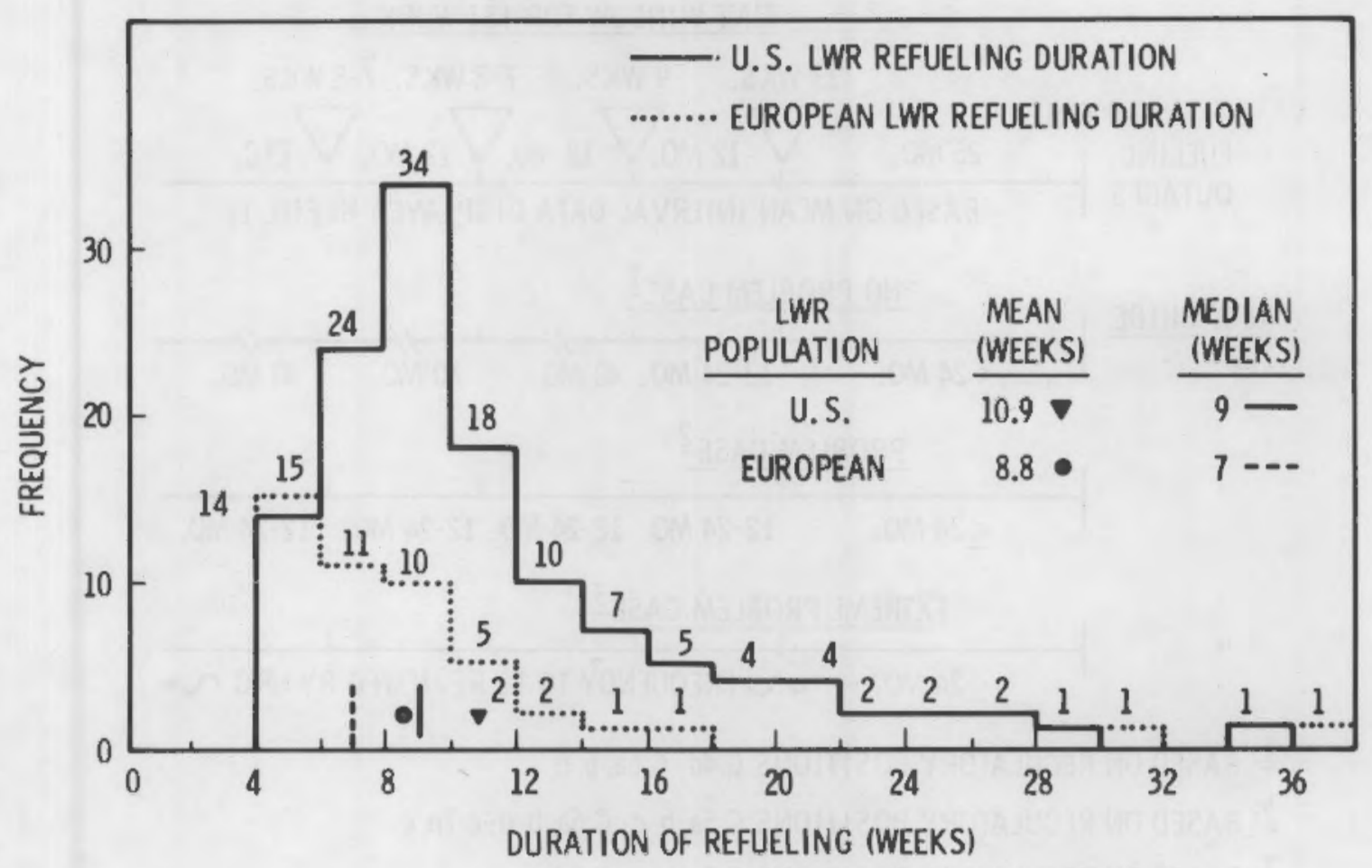

FIGURE 10. Refueling Durations: Comparison Between U.S. and European LWRs (Reference 1)

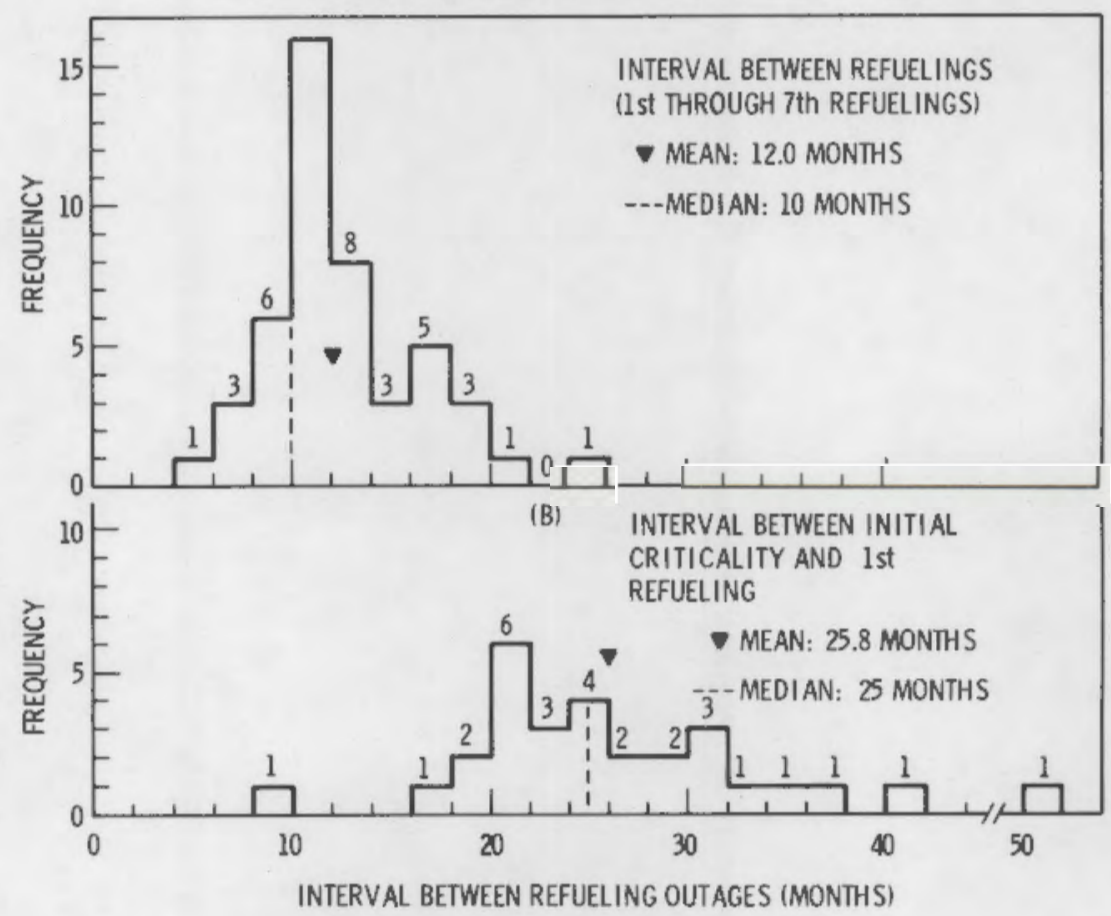

(A)

FIGURE 11. The Interval Between Refueling Outages (Reference 1) 
IIME WINDOW FOR ISI WORK

13 WKS. 9 WKS. 7-8 WKS. 7-8 WKS.
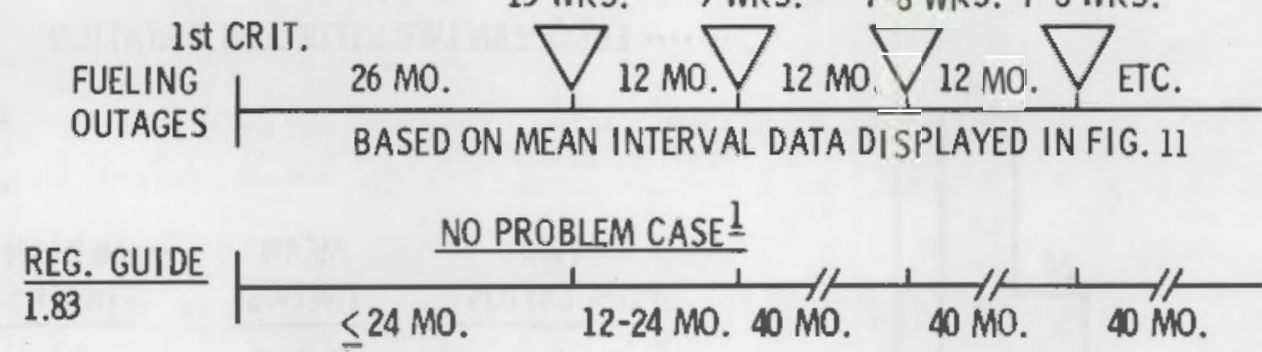

11

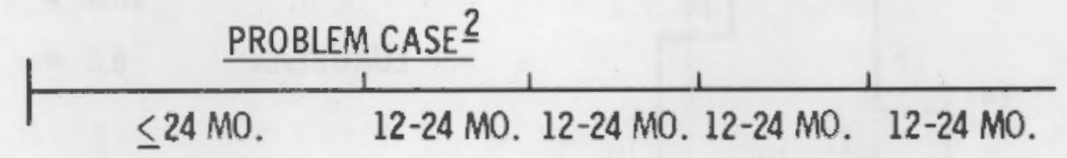

11

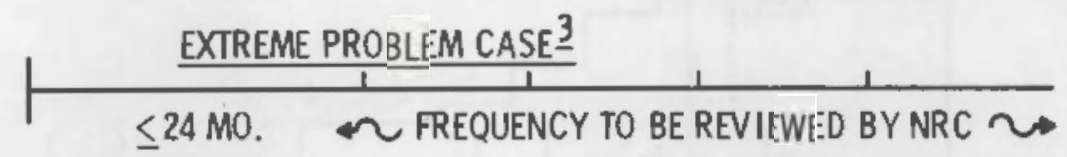

1: BASED ON REGULATORY POSITIONS C 4d; C 6a, b, d

2: BASED ON REGULATORY POSITIONS C 5a, b, c; C 6a, b, d; c 7b, c

3: BASED ON REGULATORY POSITIONS C 5a, b, c; C 7d

FIGURE 12. Comparison of ISI Frequencies Based on Fuel Outages with Regulatory Guide 1.83 


\section{COST OF DOWNTIME FOR NUCLEAR POWER PLANTS}

The C/B analysis of increased inspection of SG tubes in nuclear power plants must include an assessment of the cost of downtime of the power plant. The downtime cost is the difference between meeting the same demand with replacement power versus meeting it with electricity generated by the nuclear power plant. The downt ime cost can be separated into two parts. The first part to be discussed will be the cost of replacement power. The second part will be the cost or savings to the utility due to the forced outage. This opportunity cost is an implicit cost as opposed to the explicit replacement power cost.

The cost of replacement power is determined by the interaction among and between many factors. The following are some of the major factors causing the replacement of power to vary. The mix or type of power plants that any one utility system has will greatly affect the cost of replacement power. If a system has more base-load power available rather than intermediate or peaking load power, then the cost for replacement power will be less, all other factors being held constant. Not only the type of power plant but also the number available to supply power when one unit goes down will determine the cost of replacement power. If a utility system cannot obtain enough electricity from its own power plants or if the power can be purchased less expensively from another utility system, then the electricity will be "wheeled" in to replace the lost power. The price of this purchased power is also variable due to the same factors as discussed here.

In addition to the utility mix and the wheeling of power factors, the factor of time is very important. The utilities' power costs vary seasonally and diurnally. This can be seen in the company's load duration curve. The load duration curve charts the daily and/or seasonally varying load for the utility. At periods of high use of power, typically summer or winter depending on where the utility system is located (see Figure 22, p. 63, where the time of fuel outages is an inverse expression of this fact), the use of higher cost intermediate power and, perhaps, even peaking power may be necessary. If the utility is forced to purchase or produce power under these conditions, the price 
will be much higher. Thus, the time of year and the time of the day will also influence the cost of replacement power. The load duration curve is different for each utility depending on location and uses of the power. This variation again causes the replacement cost of power to vary considerably with different regions of the country having quite different load duration curves and, consequently, different costs.

In addition to the influence of the above factors on the cost of replacement power, the amount of power needed or size of outage will also cause the cost to vary. Even though a nuclear plant goes off-.line the amount of replacement power may be less because the nuclear plant may have been generating excess power for whatever reason. Also, the amount of power may be altered by actions the utility takes to reduce its load, i.e., stopping interruptible power sales. The cost of power may vary due to the amount needed to be purchased. A large amount of power may be less expensive on a per unit basis than a smaller amount. Thus, the firm's replacement power costs may vary considerably depending on external circumstances beyond the control of the utility.

To determine the cost of replacement power, historical cost data will have to be used. The reliability of these data is another factor influencing the cost of power. Given the rapid escalation in power costs over the past few years, any use of prior-year figures must be suspect. An escalation rate to adjust the cost of power leads to problems as to which rate to use and when to apply it. This entire issue, the reliability of data, will cause long-range forecasts of power costs to be much more suspect than at any time in the past.

All of the above factors interact with the others and make the estimation of replacement power costs for a utility at any one time in the future very difficult. As mentioned previously, the regions of the country have similar power costs due to the similarity of load duration curves and the fact that the plant mix of most of the utilities within a region will be similar. The wheeling of power between utilities within a region will, of course, also cause the replacement power costs to be the same. Usually a range of replacement power costs can be obtained for a region rather than a single-point estimate for one utility. This cost range would take jnto account all of the above factors; 
but, of course, the exact cost that any one utility would face at some point in time in the future would be almost impossible to estimate accurately.

With the above factors in mind, the following overall range of replacement costs were obtained from the Bonneville Power Administration (BPA) for electricity sold to utilities either within or out of their grid system. The overall range was from $4.5-85 \mathrm{mills} / \mathrm{kWh}$. The low end of the scale represents the use of hydroelectric generation on a massive scale in the Northwest. The upper end represents the use of gas/oil turbines of small capacity ( $\approx 25 \mathrm{MW}(\mathrm{e}))$. The BPA has set a limit of 4.5-20 mills/kWh on the sale cost of hydroelectric power from the Northwest dams. In addition to the lower cost hydroelectric power base-load plants and the expensive oil/gas turbine-produced power, the Northwest has two coal plants, Centralia and Boardman, that are or will be, respectively, selling power in the 10-16 mills/kwh range. This intermediate range of power costs makes the average range of power costs for the Northwest 15-30 mills/kwh.

The overall range of power costs $(4.5-85 \mathrm{mill} / \mathrm{s} / \mathrm{kWh})$ is the same for California. In California there is less of a hydroelectric base, which causes the average power cost to be between 20-50 mills/kWh. This is due to the use of more gas/oil turbines to generate electricity. The Northeast region of the country would have approximately the same average power costs as California due again to the reliance upon gas/oil-fired, electricity-generating units. The average replacement power costs for the rest of the nation would fall between the values for the Northwest and California. This is due to the use of coalfired units, which generate electricity that is priced less than the gas/oil turbine derived power but more than the hydroelectric power.

To determine the downtime cost due to SG failure, a value for the utility's added costs must be calculated. This cost consists of the replacement cost and an adjustment to the replacement cost to account for any savings or expenses due to the reactor being out of operation. When the reactor is operating, there are two main costs being incurred. The first is the fixed costs, which have to do with the investment of the capital; and the second is the variable costs, which include some of the operations and maintenance costs and fuel costs. When the reactor is not operating, the fixed costs are still being incurred but 
the variable costs are not. The difference between the costs when the reactor is operating and the costs when it is down is due to the variable cost differences. In this case it was assumed that the maintenance and operating costs would be the same and that the only difference would be the fuel costs. By not operating the reactor the fuel costs are not incurred.

From the viewpoint of the utility, the fuel costs are "saved" and the downt ime cost is simply the replacement cost minus the fue 1 cost "saved." The latest average fuel cost for nuclear reactors in the United States in 1979 is $5 \mathrm{mills} / \mathrm{kWh}$, obtained from the EPRI Report PS-1201-SR, Technical Assessment Guide July 1979. Thus, the cost of downtime is the cost over and above the regular cost of producing power.

The downtime costs can now be calculated for nuclear power plants in various regions of the United States. The average value for downtime in the Northwest is $17.5 \mathrm{mills} / \mathrm{kWh}(22.5-5)$. For California and the northeastern United States, the average cost of downtime is $30 \mathrm{mills} / \mathrm{kWh}$ (35-5). For the rest of the nation the average cost of downtime is $23.75 \mathrm{mills} / \mathrm{kWh}(28.75-5)$. These figures are, of course, quite approximate and vary with the factors mentioned above for replacement power costs. The downtime costs do not include the extra maintenance cost associated with increased inspection and repair of SG tubes. The downtime costs, as mentioned above, are the costs over and above the regular costs incurred in operating the nuclear power plant. The above outage cost estimates are sumarized below.

\begin{tabular}{ll}
\multicolumn{1}{c}{ Region } & $\begin{array}{c}\text { Approximate } \\
\text { Outage Cost }\end{array}$ \\
Northwest & $\begin{array}{l}17.5 \mathrm{mi} 11 \mathrm{~s} / \mathrm{kWh} \\
\text { California and } \\
\text { Northeast }\end{array}$ \\
Rest of Nation & $30.0 \mathrm{mills} / \mathrm{kWh}$
\end{tabular}

In the following section, very rough estimates are given of the $\$$ cost impact of various ISI strategies and of $\mathrm{USO}_{\mathrm{sg}}$. For the essentially illustrative purposes of these calculations a value of $21 \mathrm{mills} / \mathrm{kwh}$ was used for the 
lost power cost equivalent of outage time; for comparing the \& impact of various ISI strategies with the cost of $\mathrm{USO}_{\mathrm{Sg}} \mathrm{s}$ of various degrees of severity, a range of values of $15-27 \mathrm{mills} / \mathrm{kWh}$ was used. These values all fall within or are close to the outage cost data band given above and are probably well within this band considering possible uncertainties in the estimates. We regard a comprehensive analys is of outage costs for units of various rating and location to be indispensable to a significant $C / B$ analysis of SG ISI. Accordingly, this phase of the work is highlighted in the concluding section on proposed future work for this program. 
In this section several indices are suggested for characterization of ISIs, and they are applied to a number of ISI cases for three types of units. The indices can be used for individual inspections and for an ISI program extending over an arbitrary evaluation period for a given unit. The latter application is used in the present instance. For the purposes of this report, the inspections coincide with the inspection opportunities presented by the nominal fuel outages for PWR units. The section is concluded with a brief comparison between the costs of unscheduled outages attributable to SG problems (USO ${ }_{S g}$ ) and the costs of the most ambitious ISI case considered in this report, namely 100\% inspection scope over the evaluation period.

The NDT Information Index (Iisi)

An NDT information index is defined as follows for the individual and evaluation period ISI cases:

individual ISI:

$$
\text { I is } i^{*}=\frac{(\text { scope })_{i} \times U_{i}}{100}=\frac{s_{i} \times U_{i}}{100}
$$

evaluation period:

$$
\text { Iisi }=\sum_{i} \frac{\left(S_{i} \times U_{i}\right)}{100 \times \theta_{e v}}(\underline{y r})^{-1}
$$

where $(\text { scope })_{i}=S_{i}=\frac{\text { (number of tubes inspected) }}{\text { (total unit tubes) }} \times 100(\boldsymbol{q})$

$$
\begin{aligned}
& U_{i}= \text { the distribution factor (a measure of the size of the } \\
& \text { sample space available for selecting tubes for inspec- } \\
& \text { tion) }
\end{aligned}
$$




$$
\begin{aligned}
\theta_{\mathrm{ev}}= & \text { evaluation period }(\underline{\mathrm{yr}}) \geq 1 \mathrm{yr} \\
\hat{i}= & \text { sumation index over all inspections performed during } \\
& \text { evaluation period. }
\end{aligned}
$$

The range of the Iisi* and Iisi indices is indicated by the following minimum and maximum inspection cases:

$$
\begin{aligned}
& \text { Minimum } \\
& \text { Maximum } \\
& \text { Iisi*: } 3 \% \text { scope; } 1 \times 4 \text { SGs inspected } \\
& \text { Iisi* }=\left(\frac{3 \times 1}{4 \times 100}\right)=0.0075 \\
& 100 \% \text { scope; } 4 \times 4 \text { SGs inspected } \\
& \text { I is } i^{\star}=\left(\frac{100 \times 4}{4 \times 100}\right)=1.0 \\
& \text { Iisi: } 3 \% \text { scope all inspections } \\
& 1 \times 4 \text { SGs inspected each inspection } \\
& 1 \text { inspection every } 3 \text { years } \\
& \text { 9-year evaluation period } \\
& \text { Iisi }=\frac{1}{9}\left[\left(\frac{3 \times 1}{4 \times 100}\right) \times 3\right] \\
& \text { Iisi }=0.0025 \mathrm{yr}^{-1} \\
& 100 \% \text { scope all inspections } \\
& 4 \times 4 \text { SGs inspected each inspection } \\
& 1 \text { inspection every year } \\
& \text { 9-year evaluation period } \\
& \text { I isi }=\frac{1}{9}\left[\left(\frac{100 \times 4}{4 \times 100}\right) \times 9\right] \\
& \text { I is } i=1.0 \mathrm{yr}^{-1}
\end{aligned}
$$

The distribution factor (U) defined here gives no "information" credit for rotation of the SGS on successive partial (scope <100\%) inspections. While such rotation does improve the information somewhat, this increment becomes less significant the longer the interval between inspections. Rotation credit was considered an unnecessary elaboration for this preliminary analysis. For the ISI cases considered later in this section for three types of PWR units (2, 3 , and 4 SGs), the Iisi index ranges from 0.004 to $0.89--a$ max/min ratio of about 220 .

Rad Exposure Index (MAN-REM)

A rad exposure index (MAN-REM) is defined as follows for individual and evaluation period ISI cases:

individual ISI:

$$
\text { MAN-REM* }=(M R)_{n t i} \times n_{i}+(M R)_{t i} \times t_{i} \quad(\text { man-rem) }
$$


evaluation period:

$$
\begin{aligned}
& \text { MAN-REM }=\sum_{i}(M R)_{n t i} \times n_{i}+\sum_{i}(M R)_{t i} \times t_{i} \text { (man-ren) } \\
& \text { or MAN-REM }=(M R)_{n t} \sum_{i} n_{i}+(M R)_{t} \sum_{i} t_{i} \\
& \text { if average values of }(M R)_{n t i} \text { and }(M R)_{t i} \text { are used over } \theta_{\text {ev }}
\end{aligned}
$$

where $(M)_{n t i}=$ aggregate rad exposure for nontesting phases of inspection

(i) (NOT equipment setup and removal) (man-rem)

$$
\begin{aligned}
n_{i}= & \text { number of SGs involved in inspection }(i) \\
(M R)_{t i}= & \text { aggregate rad exposure per tube for the testing phase of } \\
& \text { inspection }(i) \text { (man-rem) } \\
t_{i}= & \text { no. of tubes involved in inspection }(i) \\
i= & \text { summation index over } \theta_{e v} .
\end{aligned}
$$

For the ISI cases, unit types, and rad field cases considered later in this section, the rad exposure index for the 9-year evaluation period ranges from 7.5 to 780 man-rem, giving a max/min ratio of about 100 .

$\$$ Impact Index (\$isi)

A \& impact index (\$isi) is defined as follows for individual and evaluation period ISI cases:

individual ISI:

$$
\$ i s i^{\star}=(\$ / \text { tube })_{i} \times t_{i}+F_{i} \times \theta_{i} \times \$_{0 i}\left(10^{6} \$\right)
$$

evaluation period:

$$
\text { sisi }=\sum_{i}(\$ / \text { tube })_{i} \times t_{i}+\sum_{i} F_{i} \times \theta_{i} \times \$_{0 i} \quad\left(10^{6} \delta\right)
$$

or $\quad$ sisi $=(\$ /$ tube $) \sum_{i} t_{i}+F \times \$ \sum_{i} \theta_{i}$

if average values of $(\$ / \text { tube })_{i}, F_{i}$, and $\$_{0 i}$ are used over $\theta_{e v}$ and where 
$(\$ / \text { tube })_{j}=$ the total cost of the inspection ( $i$ ) on a per tube tested

$$
\begin{aligned}
& \text { basis }\left(\underline{\left.10^{6} 8 / \text { tube }\right)}\right. \\
t_{i}= & \text { tubes tested during inspection }(i) \\
F_{i}= & \text { the interference factor, which with } \theta_{i} \text { gives the critical } \\
& \text { path } t \text { ime assignable to a given inspection (i) } \\
\theta_{i}= & \text { the nominal work time window for inspection (i) (day) } \\
\delta_{0 i}= & \text { the cost per day of outage at time of inspection }(i)\left(\underline{\left.10^{6} \$\right)}\right. \\
i= & \text { summation index over } \theta_{\text {ev }} .
\end{aligned}
$$

For the ISI cases, unit types, interference factors, inspection costs, work time windows, and outage costs considered later in this section, the \$isi index for the g-year evaluation period ranges from $3.7 \times 10^{-2}$ to 23 (millions of 8 ), giving a max/min ratio of about 620 .

Composite Indices $\left(C_{1}\right.$ and $\left.C_{2}\right)$

Several combinations of the above indices may have some utility as measures of the incentive for individual ISIs at given times and of the merit of various ISI strategies over an evaluation period. The $c_{1}$ index is defined as follows:

for individual ISI:

$$
c^{\star}{ }_{1}=\mathrm{I} \text { is } i \star /(\text { MAN }-R E M)^{\star} \quad\left(\underline{\text { man-rem }}^{-1}\right.
$$

evaluation period:

$$
C_{1}=\operatorname{Iisi} /\left(\text { MAN-REM) } \quad(\underline{\text { yr } \times \text { man-rem }})^{-1}\right.
$$

where, as noted, the Iisi and MAN-REM indices appropriate to the individual or evaluation period ISI cases are used.

For the various ISI cases considered in this section over a 9-year evaluation period, the $c_{1}$ index ranges from $1.0 \times 10^{-4}$ to $9.9 \times 10^{-3} c_{1}$ units $(y r \times \text { man-rem })^{-1}$, giving a max/min ratio of about 99 .

The $C_{2}$ index is defined as follows: 
for individual ISI:

$$
C_{2}^{\star}=\frac{\text { I isj* }}{(\text { MAN-REM })^{\star} \times \$ 15 i^{\star}} \quad\left(\text { man-rem } \times 10^{6} \$\right)^{-1}
$$

evaluation period:

$$
C_{2}=\frac{\text { Iisi }}{(\text { MAN-REM }) \times \$ i s i} \quad\left(\text { man-rem } \times y r \times 10^{6} \mathrm{~g}\right)^{-1}
$$

again using the indices appropriate to the ISI case.

In the following analysis for a 9-year evaluation period, the value of the $c_{2}$ index ranges from $9.6 \times 10^{-4}$ to $5.1 \times 10^{-3} c_{2}$ units $\left(y r \times \text { man-rem } \times 10^{6} \&\right)^{-1}$, giving a max/min ratio of about 5 .

Values of the above indices have been calculated for a number of ISI cases using the ground rules given in Table 10. The ISI cases are defined in Table 11. The values of the various parameters involved in calculation of the indices are given in Table 12. The various cases considered in the calculation are given in Table 13. Data from the calculation are given in Appendix B. Obviously, there is not necessarily a one-to-one relationship between the Iisi index and the other indices. The given value couplings between these indices result from the application of the arbitrary rules given in Table 10. A more general analysis of the functional relationship among these indices would be interesting but outside the scope of this report.

The MAN-REM index is given as a function of the Iisi index in Figures 13 and 14 for the high rad field and "zero $T$ " cases, respectively (see Table 13). The average MAN-REM/Iisi characteristics for the high field case all display a monotonical increase with Iisi, with magnitude of the MAN-REM index decreasing with unit type in the order: $2 S G, 4 S G, 3 S G$, for a given Iisi value above about 0.03. Below this Iisi value (in the regime of the $A$ and $B$ ISI cases, see Table 11) no distinction is made among the three unit types. The MAN-REM/Iisi characteristics for the zero $T$ case (Figure 14) all display a plateau over an Iisi range of about 0.01 to 0.1 . The characteristics for individual units are not well distinguished on this plot until the Iisi index reaches a value of about 0.1 . Above this I isi value, the MAN-REM index decreases with unit type 
TABLE 10. Ground Rules for Calculation of ISI Indices

1. The evaluation period is 9 years and starts with the beginning of cormercial operation.

2. The timing of the inspection opportunities is as follows:

lst opportunity: 2 years from date of commercial operation 2nd opportunity: 3 years from date of comercial operation 3rd opportunity: 4 years from date of commercial operation 4 th opportunity: 5 years from date of comercial operation 5th opportunity: 6 years from date of comercial operation 6th opportunity: 7 years from date of commercial operation 7th opportunity: 8 years from date of comercial operation 8th opportunity: 9 years from date of commercial operation

3. Indices are calculated for the following units:

4 SG unit: using Westinghouse SGs of 3,260 tubes/SG

3 SG unit: using Westinghouse SGs of 3260 tubes/SG

2 SG unit: using Babcock \& Wilcox SGs of 15,531 tubes/SG

4. Indices are calculated for 14 ISI cases; three representing minimum inspection under Regulatory Guide 1.83 rules (A cases), two representing minimum inspection under ASME Code XI rules ( $B$ cases), and nine representing arbitrary cases over a wide range of inspection scope ( $C$ cases).

5. The distribution of the inspection samples among the unit SGs is determined by Regulatory Guide 1.83 and Code XI rules for the A and B cases, respectively; for the $C$ cases, the number of $S G$ involved in a given inspection is determined as follows: $n_{i}=(\text { scope })_{i} \times N_{s g} \times 1 / 100$ (see nomenclature sheet, Appendix A). For noninteger values of $n_{j}$, use next highest integer; for the first inspection only for 4 and 3 SG units, the minimum value of $n_{j}$ is 2 .

6. The work time windows for the inspection opportunities are as follows: first: 13 weeks (91 days); second: 9 weeks (63 days); subsequent: 7.5 weeks (53 days). 
TABLE 11. Definition of ISI Cases

Description

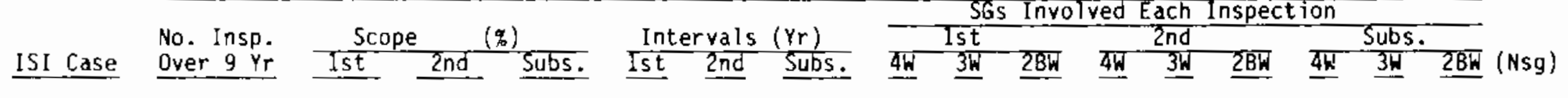

$\begin{array}{lllllllllllllllll}A-1 & 8 & 3 & 3 & 3 & 2 & 1 & 1 & 2 & 2 & 1 & 1 & 1 & 1 & 1 & 1 & 1 \\ \mathrm{~A}-2 & 5 & 3 & 3 & 3 & 2 & 1 & 2 & 2 & 2 & 1 & 1 & 1 & 1 & 1 & 1 & 1 \\ \mathrm{~A}-3 & 4 & 3 & 3 & 3 & 2 & 1 & 3 & 2 & 2 & 1 & 1 & 1 & 1 & 1 & 1 & 1 \\ \mathrm{~B}-1 & 8 & 3 & 1.5 & 1.5 & 2 & 1 & 1 & 4 & 3 & 2 & 1 & 1 & 1 & 1 & 1 & 1 \\ \mathrm{~B}-2 & 4 & 3 & 1.5 & 1.5 & 2 & 1 & 1 & 4 & 3 & 2 & 1 & 1 & 1 & 1 & 1 & 1 \\ \mathrm{C}-1 & 8 & 100 & 100 & 100 & 2 & 1 & 1 & 4 & 3 & 2 & 4 & 3 & 2 & 4 & 3 & 2 \\ \mathrm{C}-2 & 8 & 100 & 100 & 50 & 2 & 1 & 1 & 4 & 3 & 2 & 4 & 3 & 2 & 2 & 2 & 1 \\ \mathrm{C}-3 & 8 & 100 & 50 & 50 & 2 & 1 & 1 & 4 & 3 & 2 & 2 & 2 & 1 & 2 & 2 & 1 \\ \mathrm{C}-4 & 8 & 100 & 33.3 & 33.3 & 2 & 1 & 1 & - & 3 & - & - & 1 & - & - & 1 & - \\ \mathrm{C}-5 & 8 & 100 & 25 & 25 & 2 & 1 & 1 & 4 & 3 & 2 & 1 & 1 & 1 & 1 & 1 & 1 \\ \mathrm{C}-6 & 8 & 33.3 & 33.3 & 33.3 & 2 & 1 & 2 & - & 2 & - & - & 1 & - & - & 1 & - \\ \mathrm{C}-7 & 8 & 50 & 25 & 25 & 2 & 1 & 1 & 2 & 2 & 1 & 1 & 1 & 1 & 1 & 1 & 1 \\ \mathrm{C}-8 & 8 & 25 & 25 & 25 & 2 & 1 & 1 & 2 & 2 & 1 & 1 & 1 & 1 & 1 & 1 & 1 \\ \mathrm{C}-9 & 8 & 10 & 10 & 10 & 2 & 1 & 1 & 2 & 2 & 1 & 1 & 1 & 1 & 1 & 1 & 1\end{array}$

(a) Where less than $100 \%$ scope is involved, SGs are rotated for subsequent inspections to improve information for given scope limitation. 


\section{TABLE 12. Parameter Values Used for Calculation of Indices}

Index Parameter Values

I isi

$S_{j}:$ see Table 11

$U_{i}$ : see Table $11 ; U_{i}=n_{i} / N_{s g}$

${ }^{\theta}$ ev: 9 years (see Table 10); for number of inspections and inspection interval, see Table 11

MAN-REM (MR) ${ }_{n t}:$ high field case $=9.8 \mathrm{man}-\mathrm{rem} / \mathrm{SG}$ (see Table 8)

(MR) ${ }_{\mathrm{nt}}$ : low field case $=1.3 \mathrm{man}-\mathrm{rem} / \mathrm{Sg}$ ( see Table 8)

(MR) $)_{\mathrm{nt}}$ : average case $=5.6 \mathrm{man}-\mathrm{rem} / \mathrm{SG}$ (see Table 8)

$(M R)_{t}$ : high field case $=2.5 \times 10^{-3}$ man-rem/tube (see Table 5 )

$(M R)_{t}$ : low field case $=8.3 \times 10^{-4}$ man-rem/tube (see Table 5)

$\left(\right.$ (MR) $\mathrm{t}_{\mathrm{t}}$ : average case $=1.7 \times 10^{-3} \mathrm{man}-\mathrm{rem} /$ tube (see Tab le 5)

Sisi $\quad(\$ / \text { tube })_{i}:=$ see Figure 5

$$
\begin{aligned}
t_{i}: & =(\text { scope }) \times(\text { tubes } / S G) \times(\text { SGs } / \text { un } i t) \times(1 / 100) \\
& =S_{i} \times 130.4 \text { for } 4 \text { SG unit } \\
& =S_{i} \times 97.80 \text { for } 3 \text { SG unit }
\end{aligned}
$$

$=S_{i} \times 310.6$ for $25 G$ unit (see Tables 10 and 11)

$F_{j}$ : values of 0 and $F=0.1 \times$ (Iisi) are used

$\theta_{i}: \theta_{1}=91$ days; $\theta_{2}=63$ days; subsequent $=53$ days

$\$_{0}=\$_{0 i}:$ value equivalent to a lost power cost of $21.00 \mathrm{mi1ls} / \mathrm{kWh}$ is used for a unit of $1000-\mathrm{MW}(\mathrm{e})$ rating $(\$ 500,000$ per day)

time $\quad(M H)_{n t}: 315$ man-hour per SG (see Table 3)

$(\mathrm{MH})_{\mathrm{t}}: 2.9 \times 10^{-1}$ man-hr per tube (from plot of data for manhour for testing versus sample size given in Figures $4 \mathrm{~A}$ and $4 B$ ) 
TABLE 13. Cases Used for Calculation of Indices

Index

Case

Iisi

all ISI cases given in Table 11

MAN-REM (a): high field parameters; all ISI cases

(b): low field parameters; all ISI cases

(c): case assuming the "T" component of the rad exposure is zero due to use of remote analytical techniques; for this case the average value is used for (MR) ${ }_{n t}$ all ISI cases

Sisi

(a): no interference case $(F=0)$; all ISI cases

(b): proportional $F$ case; $F_{i}=F_{\max } \times(\text { Iisi })_{i} ; F_{\max }=0.1$; interference begins with second inspection and continues for all subsequent; all ISI cases

$C_{i}$ (a): the MAN-REM index used for $C_{1}$ is for the $T=0$ case; all ISI cases

$C_{2}$ (a): the MAN-REM index used for $C_{2}$ is the T=0 case; the \$isi index used for $C_{2}$ is for the $F=0$ case; all ISI cases

in the order: $4 \mathrm{SG}, 3 \mathrm{SG}, 2 \mathrm{SG}$, for a given Iisi. The latter order is an interesting cyclic permutation of the order given for the high field case (Figure 13). The difference in magnitude of the MAN-REM index between the high field and zero $T$ cases for a given I isi value is noteworthy and indicates the substantial rad exposure incentive for developing remote testing $(T)$ techniques for ISI of SGs.

The Sisi index is given as a function of the Iisi index in Figures 15 and 16 for the $F=0$ and the proportional $F$ cases (see Table 13), respectively. The $\$ i s i / I$ isi characteristics for the $F=0$ case (Figure 15) display a monotonical increase with Iisi over the range of Iisi calculation. Above an Iisi value of about 0.01 the characteristics for the three unit types are distinguishable on 


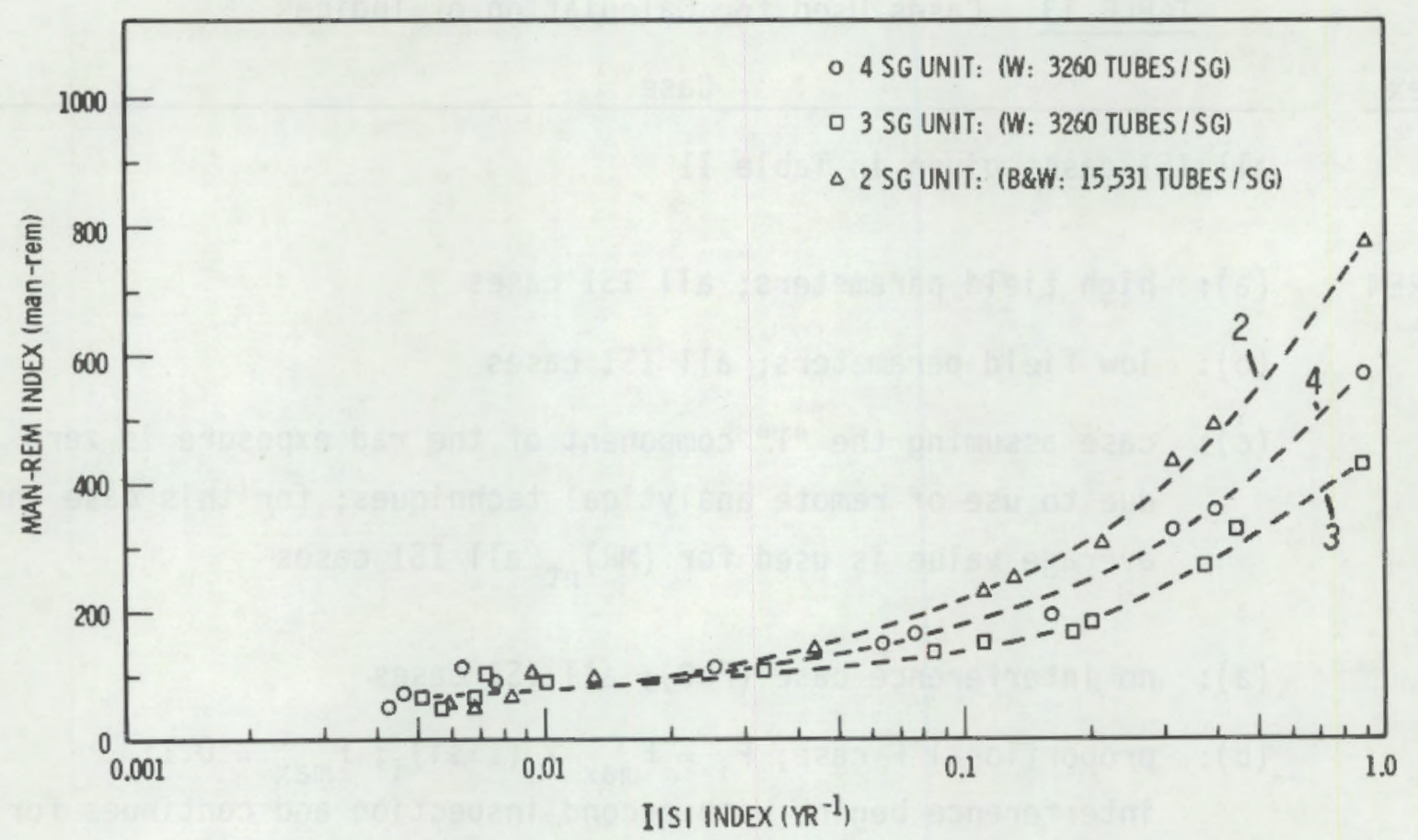

FIGURE 13. MAN-REM Index Versus Iisi; Index High Field Case

this plot, with the magnitude of the sisi index decreasing with unit type in the order: $2 S G, 4 S G, 3 S G$, for a given Iisi. The $3 S G$ and 4 SG characteristics are close over the full range of Iisi. All of the \$isi/Iisi characteristics for the proportional $F$ case (Figure 16) display a plateau within an Iisi range of about $0.09-0.2$. For this case, the 2 SG unit again gives the highest Sisi values, although the characteristics for all units are quite close. The difference in magnitude of the sisi index between the $F=0$ and the proportional $F$ cases for Iis $i$ values in excess of about 0.2 is noteworthy and affords some quantification of the importance of minimizing the interference factor $(F)$ in ISI operations where large nuclear units are involved.

The composite indices, $c_{1}$ and $C_{2}$, are given as a function of Iisi in Figures 17 and 18, respectively. As opposed to the MAN-REM and \$isi indices, it is desirable to maximize both of these indices, i.e., secure maximum NDT information with a minimum of rad exposure and $\$$ costs. As noted in Table 13 and on Figures 17 and 18, the MAN-REM component of these composite indices corresponds to the $T=0$ case. For the $C_{2}$ index, the additional sisi component 


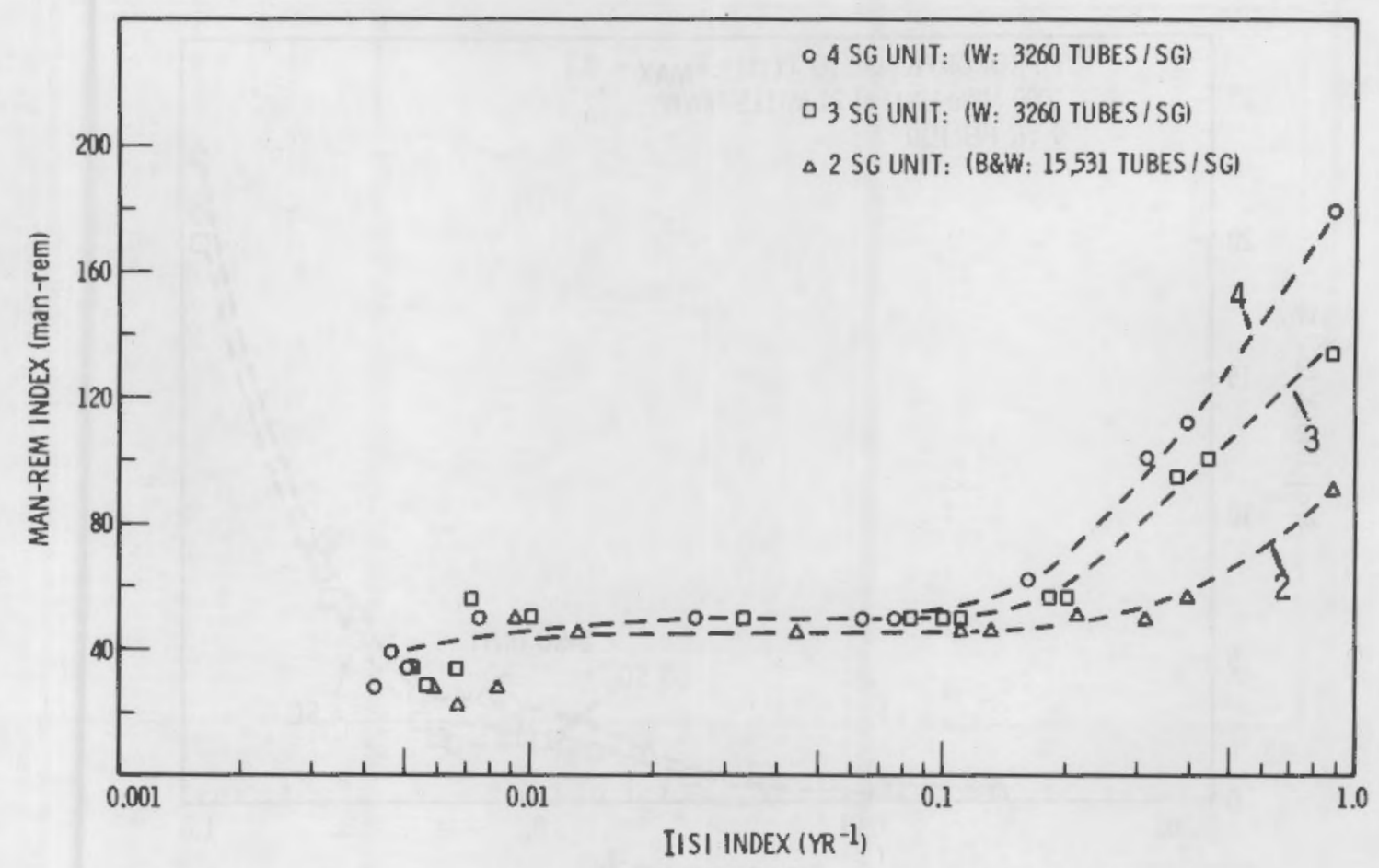

FIGURE 14. MAN-REM Index Versus Iisi; Index Zero $T$ Component Case

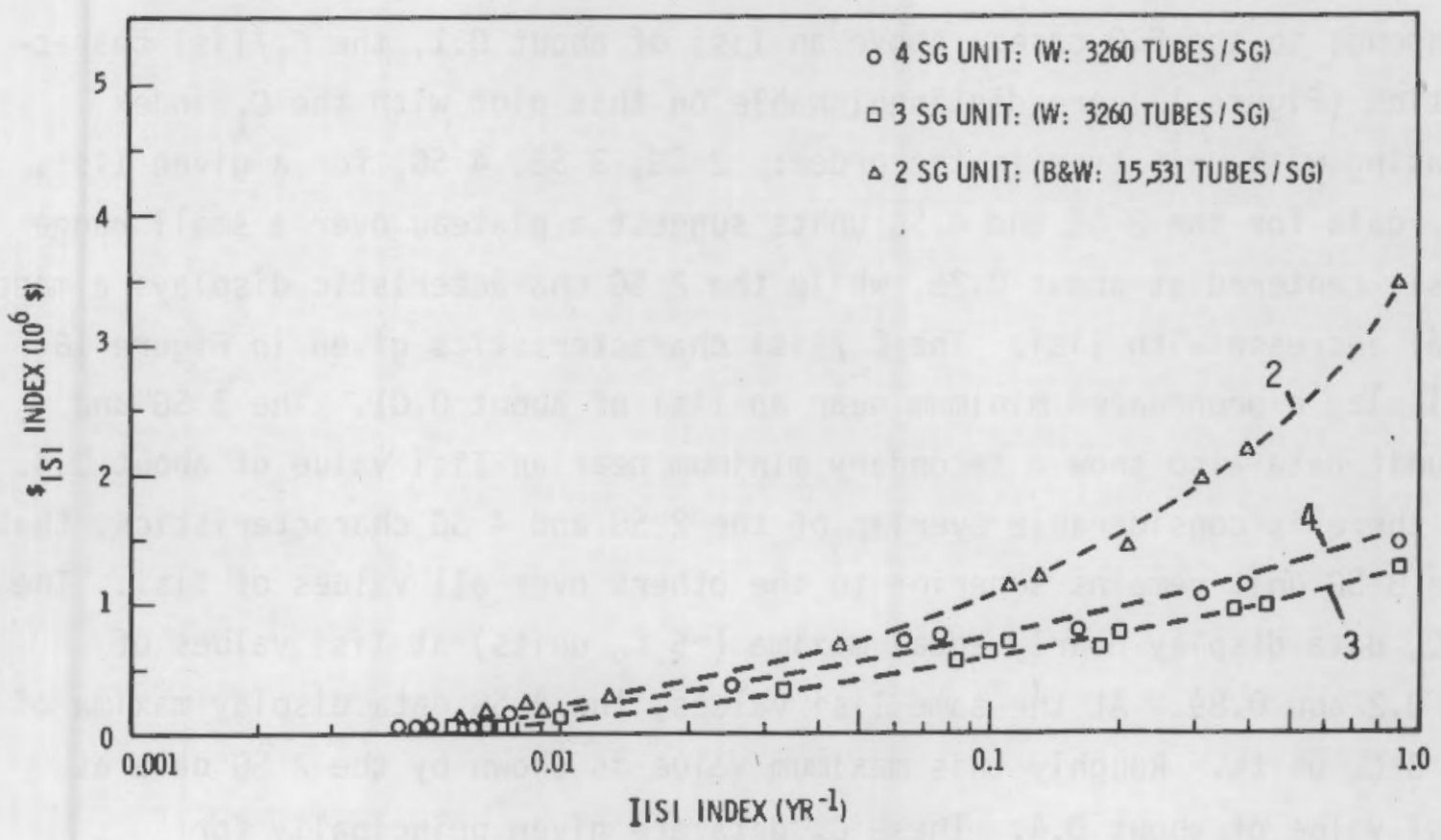

FIGURE 15. Sisi Index Versus Iisi Index; $F=0$ case 


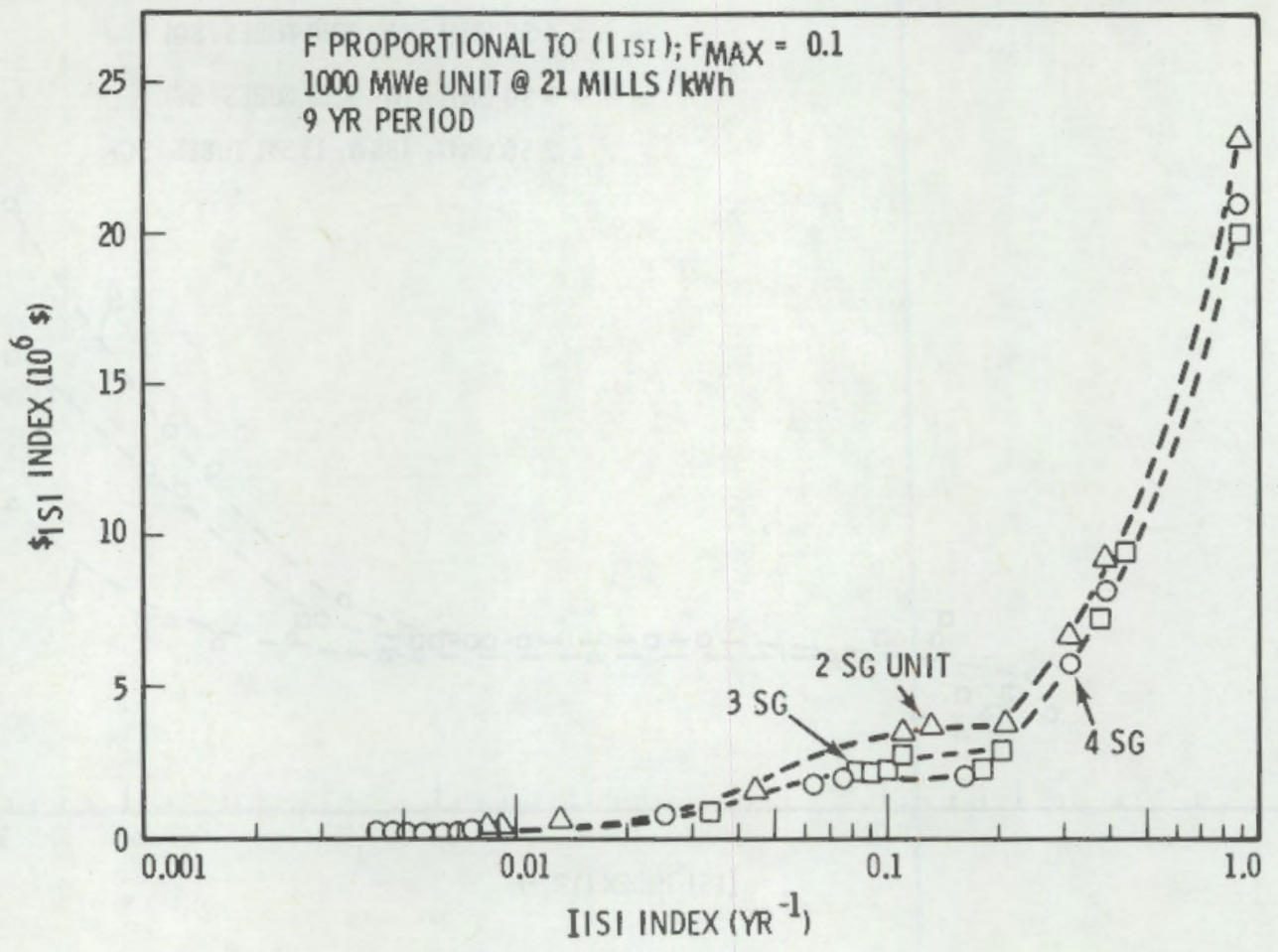

FIGURE 16. Sisi Index Versus I isi Index; Proportional $F$ Case $\left(F_{\max }=0.1\right)$

corresponds to the $F=0$ case. Above an Iisi of about 0.1 , the $C_{1} / I$ isi characteristics (Figure 17) are distinguishable on this plot with the $C_{1}$ index decreasing with unit type in the order: 2 SG, 3 SG, 4 SG, for a given Iisi. The $C_{1}$ data for the $3 S G$ and 4 SG units suggest a plateau over a small range of Iisi, centered at about 0.25 , while the 2 SG characteristic displays a monotonical increase with Iisi. The $\mathrm{C}_{2} / \mathrm{I}$ isi characteristics given in Figure 18 all display a pronounced minimum near an Iisi of about 0.01 . The 3 SG and 4 SG unit data also show a secondary minimum near an Iisi value of about 0.4. While there is considerable overlap of the 2 SG and 4 SG characteristics, that of the 3 SG unit remains superior to the others over all values of Iisi. The 3 SG $C_{2}$ data display nearly equal maxima ( $\sim 5 C_{2}$ units) at Iisi values of about 0.2 and 0.89 . At the same Iisi values, the 4 SG data display maxima of about $3 C_{2}$ units. Roughly this maximum value is shown by the $2 S G$ data at an Iisi value of about 0.4 . These $C_{2}$ data are given principally for 


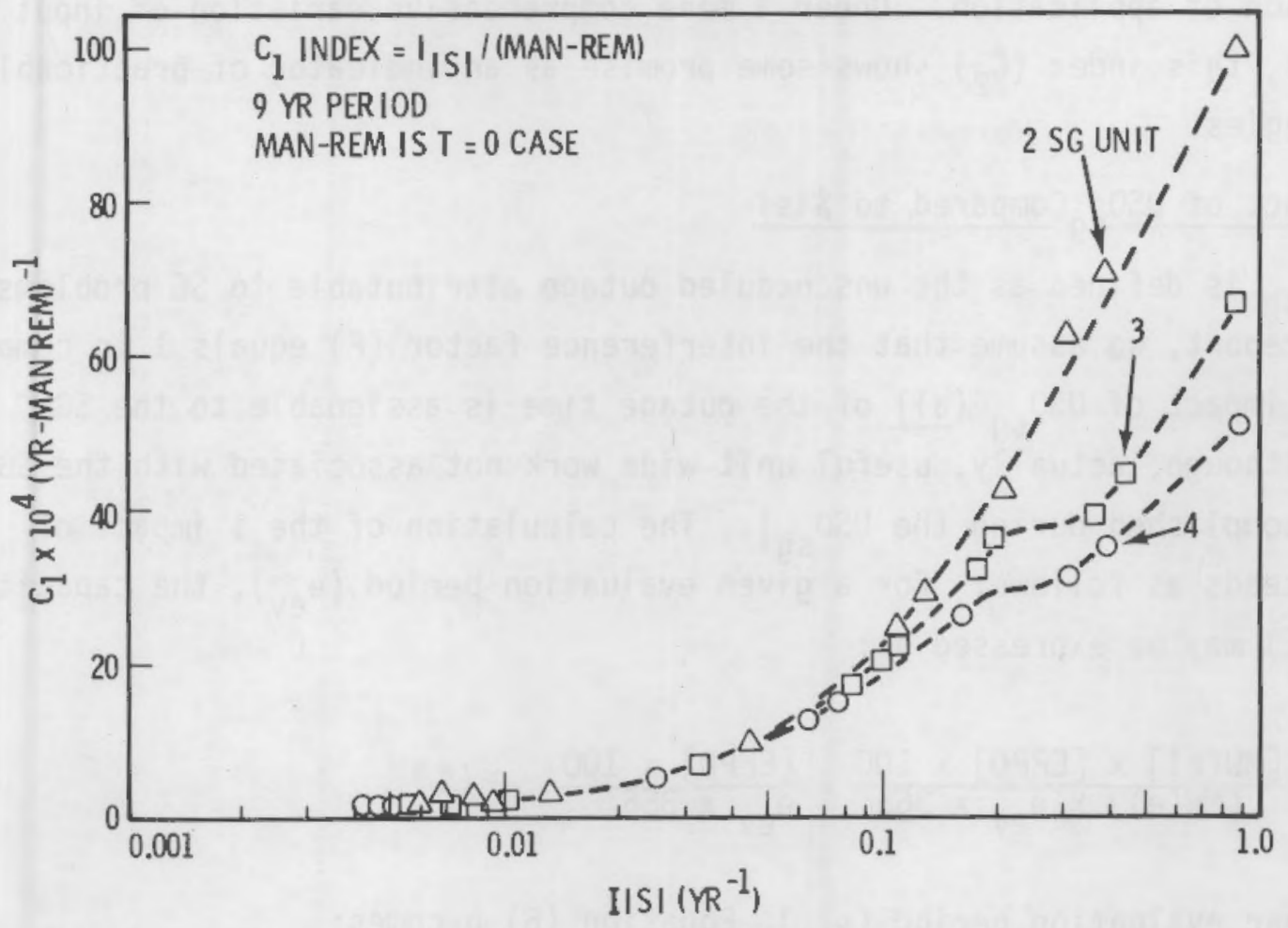

FIGURE 17. $C_{1}$ Index Versus Iisi Index

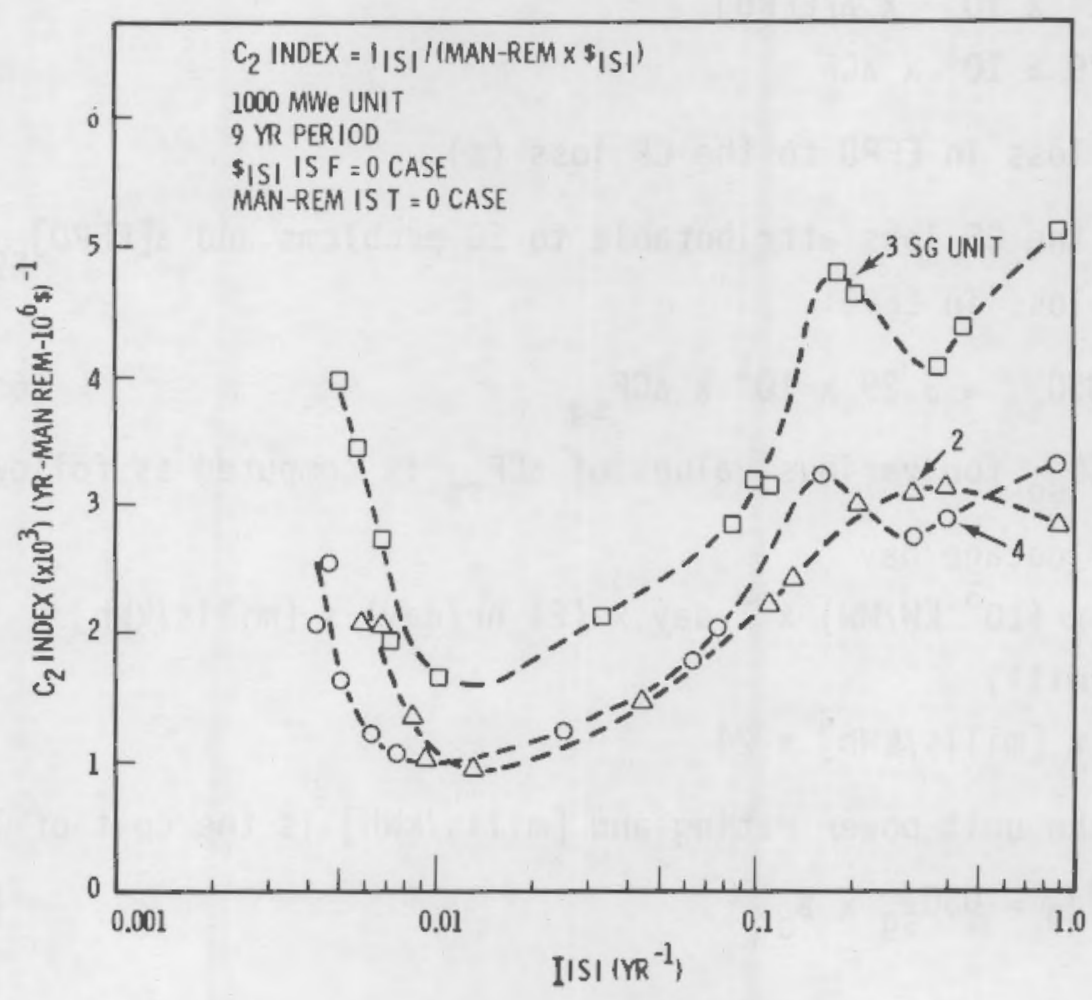

FIGURE 18. $C_{2}$ Index Versus Iisi Index 
illustration of application. Under a more comprehensive variation of input parameters, this index $\left(C_{2}\right)$ shows some promise as an indicator of practicable ISI strategies.

The \& Impact of USO ${ }_{\mathrm{Sg}}$ Compared to \&isi

USO $_{S g}$ is defined as the unscheduled outage attributable to SG problems. For this report, we assume that the interference factor $(F)$ equals 1 in computing the $\&$ impact of USO ${ }_{\text {sg }}$ (all of the outage time is assignable to the SG problem although, actualiy, useful unit-wide work not associated with the SGS may be accomplished during the USO $\left.{ }_{s g}\right)$. The calculation of the $\$$ impact of $\mathrm{USO}_{\mathrm{Sg}}$ proceeds as follows: For a given evaluation period $\left(\theta_{\mathrm{ev}}\right)$, the capacity factor (CF) may be expressed as:

$$
C F=\frac{[M W(e)] \times[E F P O] \times 100}{[M W(e)] \times \theta_{e v} \times 365}=\frac{[E F P O] \times 100}{\theta_{\mathrm{eV}} \times 365}
$$

For a 9-year evaluation period $\left(\theta_{\mathrm{ev}}\right)$, Equation (6) becomes:

and

$$
\mathrm{CF}=3.04 \times 10^{-2} \times[\mathrm{EFPO}]
$$

or $\Delta[E F P O]=3.29 \times 10^{1} \times \Delta C F$

which relates the loss in EFPD to the CF loss (\%).

Let $\triangle C_{S g}$ be the CF loss attributable to $S G$ problems and $\triangle[E F P O]_{S g}$, the corresponding loss in EFPD:

$$
\Delta[E F P D]_{S g}=U S O_{S g}=3.29 \times 10^{1} \times \Delta C F_{S g}
$$

The \& impact of $U_{S g}$ for various values of $\Delta C_{S g}$ is computed as follows:

$$
\begin{aligned}
\$_{0}= & \text { cost per outage day } \\
= & {[M W(e)] \times\left(10^{3} \mathrm{~kW} / \mathrm{MW}\right) \times 1 \text { day } \times(24 \mathrm{hr} / \text { day }) \times[\mathrm{mi} 11 \mathrm{~s} / \mathrm{kWh}] \times } \\
& \left(10^{-3} \$ / \mathrm{mi} 11\right) \\
= & {[\mathrm{MW}(\mathrm{e})] \times[\mathrm{mi} 11 \mathrm{~s} / \mathrm{kWh}] \times 24 }
\end{aligned}
$$

where $[M W(e)]$ is the unit power rating and $[\mathrm{mills} / \mathrm{kWh}]$ is the cost of lost power. $\mathrm{Now}, \mathrm{SUSO}_{\mathrm{Sg}}=\mathrm{USO}_{\mathrm{Sg}} \times \$_{0}$. 
Substituting for $\mathrm{USO}_{\mathrm{Sg}}$ and $\$_{0}$ from Equations (6c) and (7), respectively:

$$
\begin{aligned}
\text { sUSO }_{\text {Sg }} & =3.29 \times 10^{1} \times \Delta \mathrm{AF}_{\mathrm{Sg}} \times[\mathrm{MW}(\mathrm{e})] \times[\mathrm{mi} 11 \mathrm{~s} / \mathrm{kWh}] \times 24 \\
& =7.90 \times 10^{2} \times \Delta \mathrm{AF}_{\mathrm{Sg}} \times[\mathrm{MW}(\mathrm{e})] \times[\mathrm{mi} 11 \mathrm{~s} / \mathrm{kWh}] \\
& =7.90 \times 10^{-4} \times \Delta \mathrm{CF}_{\mathrm{Sg}} \times[\mathrm{MW}(\mathrm{e})] \times[\mathrm{mi} 11 \mathrm{~s} / \mathrm{kWh}]\left(10^{6} \$\right)
\end{aligned}
$$

Table 14 presents $\${ }^{4} S_{S g}$ data calculated from (8a) for a $1000-M W(e)$ unit for $\Delta C_{s g}$ values up to $6 \%$ and for three values of the $[\mathrm{mill} / \mathrm{s} / \mathrm{kWh}]$. These

\begin{tabular}{|c|c|c|c|c|}
\hline \multirow[b]{2}{*}{$\begin{array}{l}\Delta \mathrm{CF}_{\mathrm{Sg}} \\
(\%)\end{array}$} & \multirow{2}{*}{$\begin{array}{l}{ } \mathrm{SSO}_{\mathrm{Sg}} \\
\mathrm{EFPD} \\
\text { (day) } \\
\end{array}$} & \multicolumn{3}{|c|}{ suSO $_{\text {Sq }}$ 9-Year Period $\left(10^{6} \$\right)$} \\
\hline & & $\begin{array}{c}15 \text { mitाs } \\
\mathrm{kWh} \\
\end{array}$ & $\begin{array}{c}21 \text { mills } \\
\mathrm{kWh} \\
\end{array}$ & $\begin{array}{c}27.0 \mathrm{mi} T \mathrm{~s} / \\
\mathrm{kWh}\end{array}$ \\
\hline 1 & 32.9 & 11.9 & 16.6 & 21.3 \\
\hline 2 & 65.8 & 23.7 & 33.2 & 42.6 \\
\hline 3 & 98.7 & 35.6 & 49.8 & 64.0 \\
\hline 4 & 132 & 47.4 & 66.4 & 85.3 \\
\hline 5 & 165 & 59.3 & 83.0 & 107 \\
\hline 6 & 197 & 71.1 & 99.5 & 128 \\
\hline
\end{tabular}
data are plotted in Figure 19.

TABLE 14. USOSg \& Impact versus $\triangle C_{S g}$ for $1000-M W(e)$ Unit

Values of the \$isi index for the C-1 ISI case (see Table 11) were also calculated for the same (mills/kWh) values for a 1000-MW(e) unit. For comparison with SUSO $_{s g}$, the $F=0$ and $F=0.1$ cases were used for \$isi. Values of \$is $i$ were calculated for the three unit types (2, 3, and 4 SGs) and the unit average values were used for the USO ${ }_{\mathrm{Sg}}$ comparison. These \$isi data are superimposed on Figure 19.

The $\$$ isi data for the $\mathrm{F}=0$ case are trivial compared to $\mathrm{USO}_{\mathrm{Sg}}$ for $\mathrm{ACF}_{\mathrm{Sg}}$ in excess of roughily $0.5 \%$. For the $F=0.1$ case, the points of equivalence with ${ }^{\mathrm{SUSO}_{\mathrm{Sg}}}$ on the $\triangle \mathrm{CF}_{\mathrm{Sg}}$ axis are close to $1.3 \%$ for all power cost assumptions. 


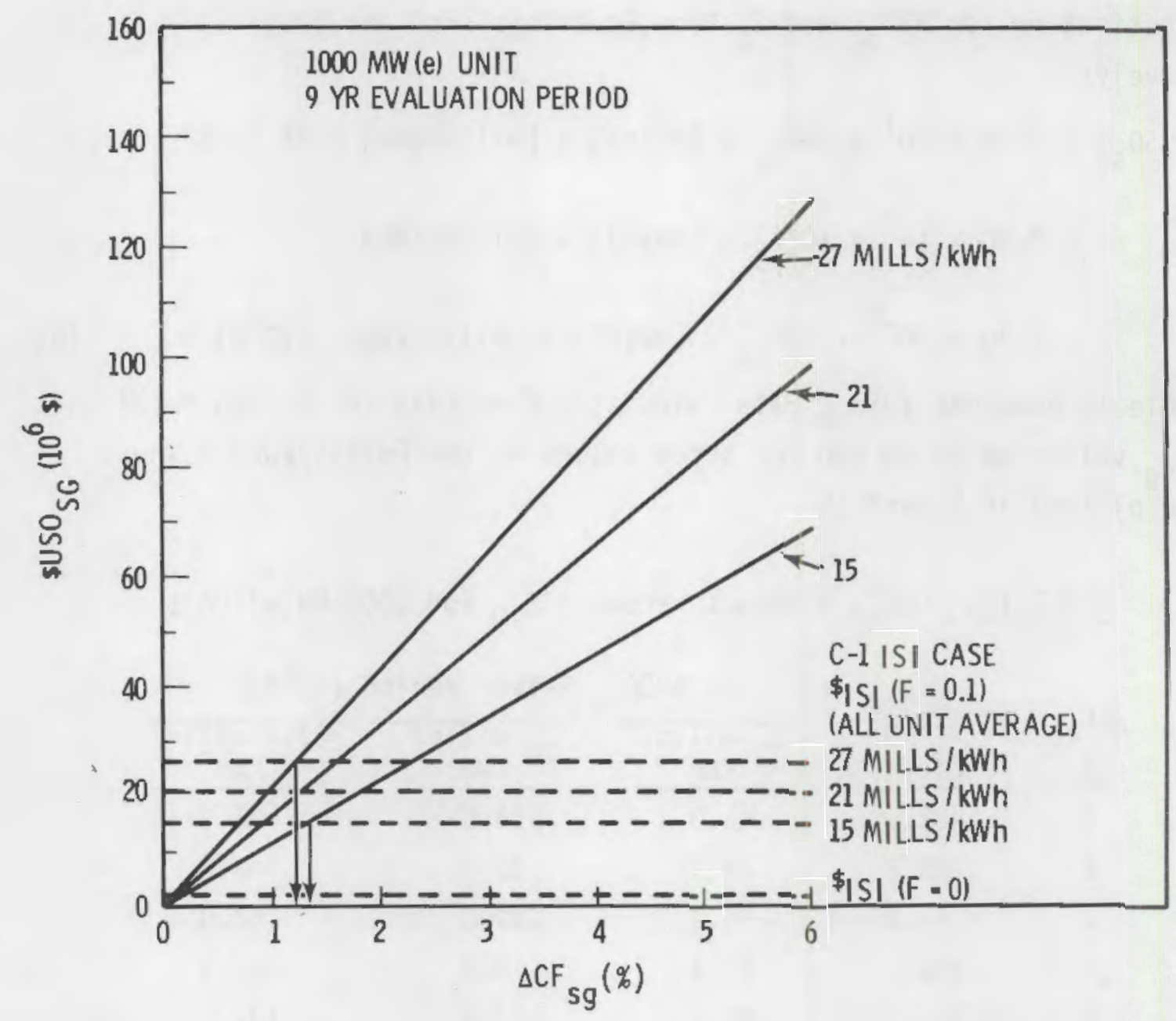

FIGURE 19. $\mathrm{SUSO}_{\text {sg }}$ Versus $\triangle \mathrm{CF}_{\mathrm{Sg}}$. $\mathrm{SUSO}_{\mathrm{Sg}}$ is compared with sisi for the C-1 ISI case (100\% inspection scope for each year of the evaluation interval) under $F=0.1$ and $F=0$ assumptions.

In other words, over a 9-year evaluation period and under the rather pessimistic assumption that the average $F=0.1$ the cost of the most ambitious ISI strategy considered in this report $(C-1,100 \%$ scope all inspections; see Table 11) would be exceeded by suSO $_{5 \mathrm{~g}}$ if the $\mathrm{ACF}_{\mathrm{sg}}$ exceeded about 1.3 . Earlier in this report, it was noted that a $\triangle C F$ value of about $3.6 \%$ was assignable to $S G$ problems over a 2-year period ending in June 1978. According to the data of Figure 19, the $8^{8} \mathrm{SO}_{\mathrm{Sg}}$ corresponding to this $\triangle C F$ level exceeds the cost of the C-1 ISI case $(F=0.1)$ by roughly a factor of three for all power cost levels. Under more careful management of the ISI work $(F \sim 0)$, the ISI cost would be trivial compared to $\mathrm{SUSO}_{\mathrm{sg}}$ for $\triangle \mathrm{CF}_{\mathrm{Sg}}$ in excess of about $0.5 \%$. 
IN-SERVICE INSPECTION TIME AND MANPOWER ESTIMATES FOR 40-UNIT PWR POPULATION

Estimates of the manpower requirements to perform ISI of SG tubes comprised by a given PWR unit population can be made on several bases; namely a minimum aggregate inspection crew for the population can be estimated using a maximum rad exposure allowance per man per year; a somewhat more realistic estimate of manpower requirements can be made by assuming a certain crew size for the nontesting (NT) and testing ( $T$ ) phases of the inspection per SG. The time for an inspection can be estimated using these crews, average man-hour values for NT and $T$ phases, and making assumptions as to the simultaneity of the work on the various phases of the inspection. The manpower and time data enable an assessment of practicable nationwide ISI campaigns for the current PWR population.

\section{Manpower Estimate--Rad Exposure Basis}

For the purpose of a rough estimate of the manpower requirement, it is assumed that the inspection scope is the same for all units for a given year $\left(S_{u}\right)$; and that the number of SGs involved per inspection per unit $\left(n_{u}\right)$ is proportional to the scope $\left(S_{u}\right)$, where, as previously, noninteger values of $n_{u}$ are taken as the next highest integer. (Men) ${ }_{n t}$ and (Men) $t$ may be expressed:

$$
\begin{aligned}
(\text { Men })_{n t} & =\frac{(M R)_{n t}}{R^{\star}} \times \sum_{u}\left(\frac{S_{u} \times N_{s g, u}}{100}\right)=\frac{(M R)}{R^{\star}} \times \sum_{u} n_{u} \\
(M e n)_{t} & =\frac{(M R)_{t} \times S_{u}}{100 \times R^{\star}} \times \sum_{u} N_{s g, u} \times t_{s g, u}
\end{aligned}
$$

where $R^{\star}=$ the maximum acceptable rad exposure per man per year

$u=$ the summation index over the units involved in a given inspection campaign and the other terms have been defined previously (see Appendix A).

For this manpower estimate, the following parameter values are used (see Table 12): 


$$
\begin{aligned}
(M R)_{n t} & =\text { average case }=5.6 \text { man-rem/SG } \\
(M R)_{t}= & \text { average case }=1.7 \times 10^{-3} \text { man-rem/tube } \\
R^{\star}= & 4 \text { rem per man per year }(5 \text { rem per man per year is current } \\
& \text { occupational maximum dose specified in } 10 \mathrm{CFR} 20, \mathrm{p} .20 .1) .
\end{aligned}
$$

The 40-unit PWR population considered here is given in Table 15. With the above assumptions for $(M R)_{n t},(M R)_{t}, R^{\star}$, and the unit population given in Table 15, the (Men) $n t$ and (Men) $t$ expressions become:

$$
\begin{aligned}
(\text { Men })_{n t} & =1.4\left[\left(\frac{s_{u} \times 4}{100}\right) \times 10+\left(\frac{s_{u} \times 3}{100}\right) \times 10+\left(\frac{s_{u} \times 2}{100}\right) \times 20\right] \\
(\text { Men })_{t} & =2.64 \times s_{u}
\end{aligned}
$$

where, for (Men) $n t$, actual or next highest integer values are used for the terms involving $\mathrm{S}_{\mathrm{u}}$. The (Men) $\mathrm{nt}_{\mathrm{t}}$ and $(\text { Men })_{\mathrm{t}}$ values were calculated for a number of $S_{u}$ values, and these data are given in Table 16 and plotted in Figure 20. Data for the $U=1.0$ case [all SGs are inspected each time irrespective of scope $\left.\left(S_{u}\right)\right]$ are also given in Table 16 but are not plotted. The manpower compliments shown in Figure 20 would be "perpetual" for inspection of the 40 units providing the 4 rem per man per yr 1 imit was observed.

Manpower Estimate--Crew Assumption Basis

To avoid assumptions as to the selection of the units for a given inspection campaign, the average unit identified in Table 15 will be used for the manpower estimate for this case. Accordingly, the unit referred to here has 15,500 tubes, 2.75 SGs (rounded to 3), and 5,600 tubes per SG.

It is assumed that the NT crew has five men per SG involved in inspection and the $T$ crew has five men per $S G$ involved in inspection, irrespective of scope, where, as noted previously, the NT crew is supplied by the utility and the $T$ crew, by the NDT contractor(s). The NT crew is largely confined to one or several units of a given utility whereas the $T$ crew would be expected to service the units on a nationwide basis. Because of the limited number of the 
TABLE 15. 40-Unit PWR Population Considered in In-Service Inspection Manpower and Time Estimates

2 SG Units

Arkansas $1(\mathrm{BW} / 15,500)^{(\mathrm{a})}$

Calvert Cliffs $1(C E / 8,500)$

Calvert Cliffs 2 (CE/8,500)

Crystal River $(B W / 15,500)$

Davis-Besse $1(B W / 15,500)$

Kewaunee $(W / 3,400)$

Ft. Calhoun $(C E / 5,000)$

Ginna $(W / 3,300)$

Oconee $1(\mathrm{BW} / 15,500)$

Oconee $2(\mathrm{BW} / 15,500)$

Oconee $3(\mathrm{BW} / 15,500)$

Palisades $(C E / 8,500)$

Point Beach $1(W / 3,300)$

Point Beach $2(w / 3,300)$

Prairie Is land $1(W / 3,300)$

Prairie Is land $2(W / 3,300)$

Rancho Seco $(B W / 15,500)$

St. Lucie $(C E / 8,500)$

3 Mile Island $1(B W / 15,500)$

Millstone 2 (CE/8,500)
3 SG Units

Beaver Valley $(W / 3400)$ Cook 1 (W/3400)

Maine Yankee (CE/5700) Haddam Neck (W/3400)

Robinson 2 ( $W / 3300) \quad$ Haddam Neck $(W / 3800)$

San Onofre $1(W / 3800)$ Indian Point $2(W / 3800)$

Surry $1(W / 3400)$

Surry $2(W / 3400)$

Turkey Point $3(W / 3300)$

Turkey Point 4 (W/3300)

North Anna 1 (W/3400)

Farley $1(W / 3400)$
4 SG Units

Indian Point $3(W / 3800)$

Salem 1 (W/3400)

Trojan (W/3400)

Yankee Rowe ( $W / 1620)$

Zion 1 (W/3300)

Zion $2(W / 3300)$

$\begin{aligned} \text { Summary: } & -40 \text { units } \\ & -620,000 \text { tubes } \\ - & 110 \text { SGs. }\end{aligned} \mid \begin{aligned} & \text { average unit of } 15,500 \text { tubes/unit; } \\ & 2.75 \text { SGs (rounded to 3.0)/unit; } \\ & 5,600 \text { tubes/SG }\end{aligned}$

(a) Information in parentheses indicates manufacturer and tubes per SG rounded to nearest 100 . 
TABLE 16. Manpower Estimate for 40-Unit Inspection;

Rad Exposure Basis

\begin{tabular}{|c|c|c|c|c|c|c|}
\hline , & prop & $\begin{array}{l}\text { iable } \\
\text { nsper } \\
\text { onal }\end{array}$ & cope) & & $\begin{array}{l}=1 \\
\text { s ins } \\
\text { scor }\end{array}$ & \\
\hline Scope (\%) & $M_{t}$ & $M_{n t}$ & $\sum M$ & $M_{t}$ & $M_{n t}$ & $\sum_{M}$ \\
\hline 3 & 8 & 56 & 64 & 8 & 150 & 160 \\
\hline 10 & 27 & 56 & 83 & 27 & 150 & 180 \\
\hline 25 & 66 & 56 & 120 & 66 & 150 & 220 \\
\hline 26 & 69 & 70 & 140 & 69 & 150 & .220 \\
\hline 33.3 & 88 & 70 & 160 & 88 & 150 & 240 \\
\hline 36 & 95 & 84 & 180 & 95 & 150 & 250 \\
\hline 50 & 130 & 84 & 220 & 130 & 150 & 290 \\
\hline 55 & 150 & 130 & 270 & 150 & 150 & 300 \\
\hline 66.6 & 180 & 130 & 300 & 180 & 150 & 330 \\
\hline 68 & 180 & 140 & 320 & 180 & 150 & 330 \\
\hline 75 & 200 & 140 & 340 & 200 & 150 & 350 \\
\hline 76 & 200 & 150 & 360 & 200 & 150 & 360 \\
\hline 100 & 260 & 150 & 420 & 260 & 150 & 420 \\
\hline
\end{tabular}

See Table 15 for unit population.

See Table 12 for average (MR) nt and (MR) T used.

Table entry is size of crew satisfying 4 rem/year dose limit ( $M_{t}=$ test $\mathrm{crew}$;

$M_{n t}=$ setup (rew).

latter specialized personnel, the $T$ crew requirements are of particular interest and the following discussion is so oriented. On the basis of the above crew assumptions, the (Men) $t$ requirement is as follows:

$$
\text { (Men) }{ }_{t}=Y_{u} \times \text { (SGs involved per unit) } \times 5=Y_{u} \times n_{u} \times 5
$$

where $Y_{u}$ is the number of units of a given type involved in a given campaign. For simplicity, it is assumed that $n_{u}$ is equal for all units for a given campaign. Let campaign refer to an ISI operation within a given year in which 


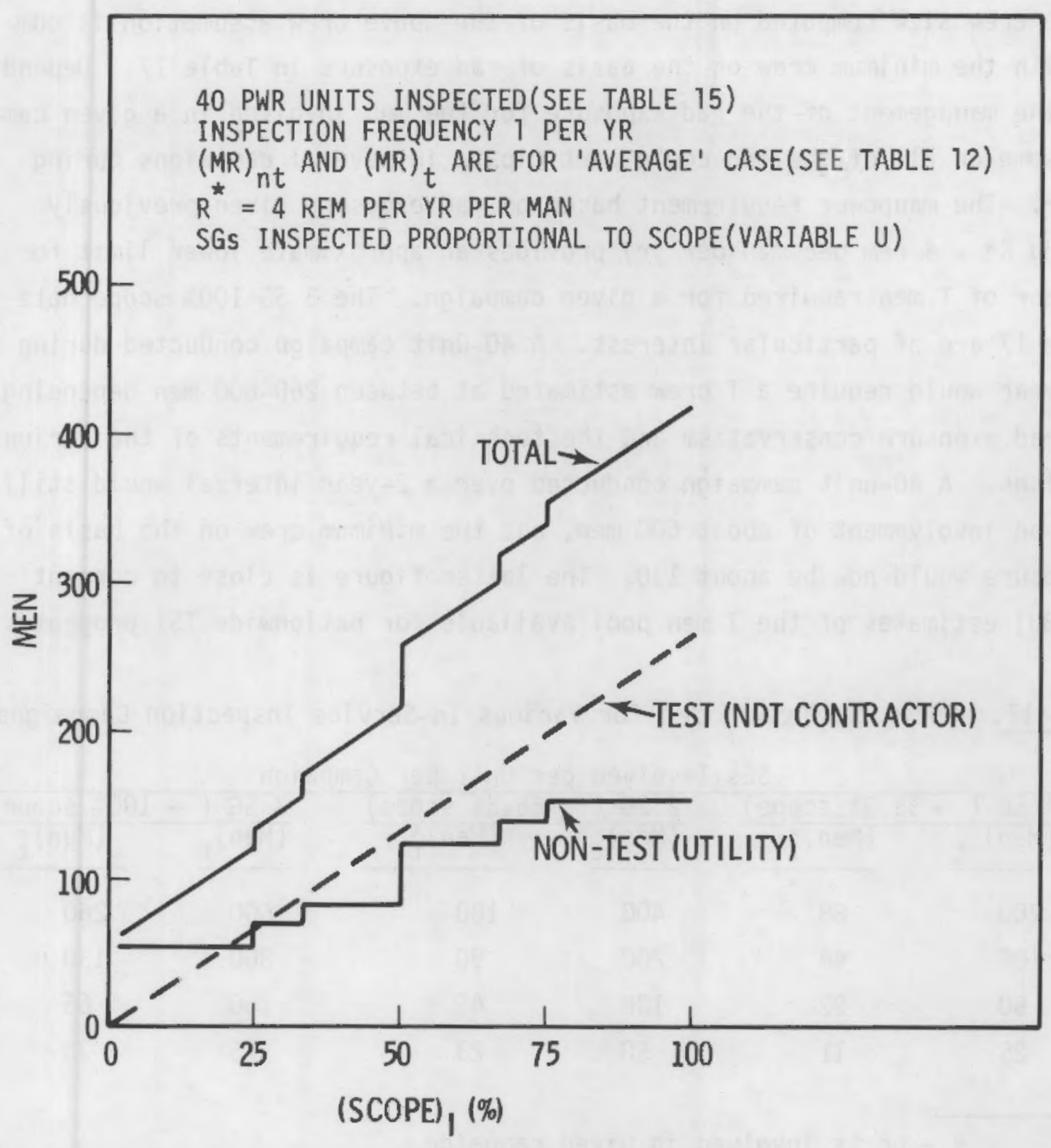

FIGURE 20. Minimum Personnel for Inspection of 40 PWR Units; Rad Exposure Basis

a given number of units is inspected in the most time- and cost-efficient manner. The campaign would, therefore, involve some simultaneous inspection, some overlap of inspections to various extents, and some isolated inspections that are fairly closely coupled in time to the rest of the campaign. 
The crew size computed on the basis of the above crew assumption is compared with the minimum crew on the bas is of rad exposure in Table 17 . Depending on the management of the rad exposure for the men involved in a given campaign, some or all of the men could participate in several campaigns during the year. The manpower requirement based on rad exposure given previously (assuming $R^{*}=4$ rem per man per $y r$ ) provides an approximate lower limit for the number of $T$ men required for a given campaign. The 3 SG $100 \%$ scope data of Table 17 are of particular interest. A 40-unit campaign conducted during a single year would require a $T$ crew estimated at between 260-600 men depending on the rad exposure conservatism and the technical requirements of the various inspections. A 40-unit campaign conducted over a 2-year interval would still require an involvement of about $600 \mathrm{men}$, but the minimum crew on the basis of rad exposure would now be about 130. The latter figure is close to current (May 1980) estimates of the T men pool available for nationwide ISI programs.

TABLE 17. Estimated Crew Sizes for Various In-Service Inspection Campaigns

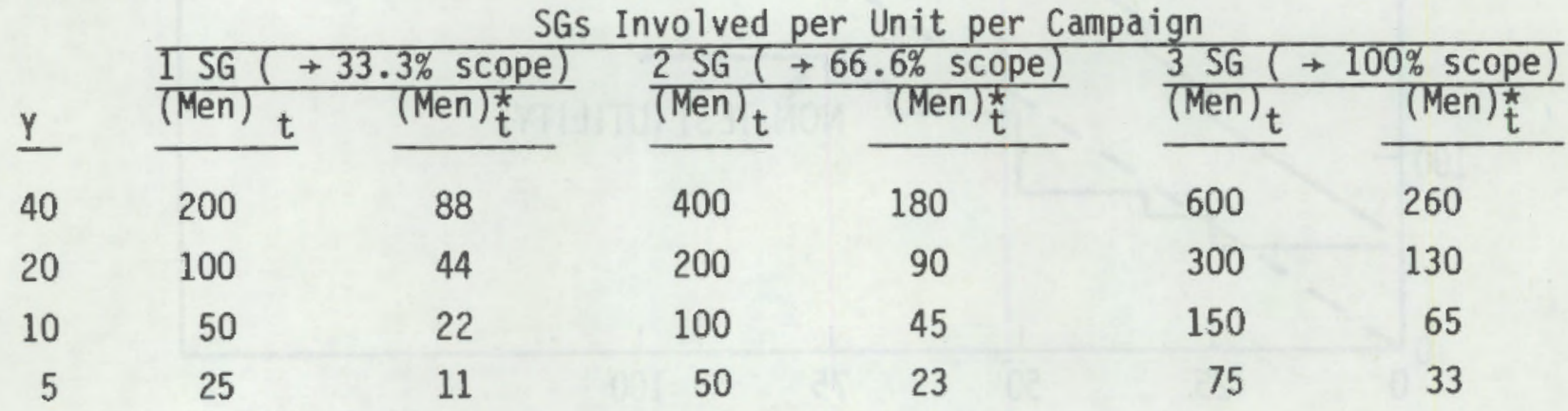

Notes: $\quad Y=$ units involved in given campaign

$(\text { Men })_{t}=T$ crew size, assuming a 5 -man crew per SG, irrespective of scope

$(\operatorname{Men})_{t}^{*}=T$ crew size for given maximum scope based on 4 rem per man per $\mathrm{yr}$ dose limit and average test rad field condition given in Table 12

$=$ (40-unit crew requirement for given maximum scope) $\times Y / 40$ (see Tabie 16)

Unit $=$ average unit given in Table 15. 


\section{Time Estimate for ISI}

An approximation of the time required for an inspection of given scope is obtained from the following expressions:

$$
\begin{aligned}
& (\text { Time })_{n t}=\alpha\left(\frac{S_{i} \times N_{s g}}{100}\right) \times\left(\frac{(M H)_{n t}}{C_{n t}}\right) \\
& (\text { Time })_{t}=\alpha\left(\frac{S_{i} \times N_{s g} \times t_{s g}}{100}\right) \times\left(\frac{(M H)_{t}}{C_{t}}\right)
\end{aligned}
$$

where, for (Time) $n t$, the next highest integer is taken for noninteger values of the term involving $S_{i}$. In the above expressions:

$\alpha=$ time efficiency factor ( $a$ value of $1.0=$ simultaneous work by all of crew; higher values mean less efficient work)

$$
\begin{aligned}
(M H)_{n t} & =\text { the man-hours per SG for NT work } \\
(M H)_{t} & =\text { the man-hours per tube for T work } \\
C_{n t} & =\text { the crew size for NT work; similiarly for } C_{t}
\end{aligned}
$$

and the other terms have been defined previously (see Appendix A).

For the time estimates of this section, the following parameter values are used:

$$
\begin{aligned}
\alpha & =1.0 \text { for both NT and } T \text { work } \\
(M H)_{n t} & =315 \text { man-hours per SG (see Table 12) } \\
(M H)_{t} & =2.9 \times 10^{-1} \text { man-hours per tube (see Table 12) } \\
C_{n t} & =5 \text { men per SG } \\
C_{t} & =5 \text { men per SG irrespective of inspection scope. }
\end{aligned}
$$

Values of the (Time) $n t$ and (Time) $t$ are given for the average unit (see Table 15) and for several specific units in Tables 18 and 19, respectively. The variable $U$ case is used for the specific units. The variable $U$ and $U=1.0$ cases are computed for the average unit. The total time value 
TABLE 18. In-Service Inspection Time Values for Average Unit

\begin{tabular}{|c|c|c|c|c|c|c|c|c|}
\hline \multirow[b]{2}{*}{ Scope (x) } & \multicolumn{4}{|c|}{ Variable U Case } & \multicolumn{4}{|c|}{$U=1.0$ Case } \\
\hline & $\begin{array}{c}\begin{array}{c}\text { (Time) } \\
(\mathrm{hr})\end{array} \\
\end{array}$ & $\begin{array}{r}\text { (Time) } \\
(\mathrm{hr}) \mathrm{t} \\
\end{array}$ & $\begin{array}{l}\text { ETime } \\
\text { (hr) }\end{array}$ & $\begin{array}{r}\text { ETime } \\
(\text { wk) } \\
\end{array}$ & $\begin{array}{c}\text { (Time) } \\
(\mathrm{hr})^{\mathrm{nt}} \\
\end{array}$ & $\begin{array}{c}(\text { Time) } \\
(\mathrm{hr}) \mathrm{t}\end{array}$ & $\begin{array}{l}\begin{array}{c}\text { ET ime } \\
(\mathrm{hr})\end{array} \\
\end{array}$ & $\begin{array}{r}\begin{array}{r}\text { ETime } \\
(w \mathrm{k})\end{array} \\
\end{array}$ \\
\hline 100 & 190 & 900 & 1090 & 6.5 & 190 & 900 & 1090 & 6.5 \\
\hline 66.7 & 130 & 600 & 730 & 4.3 & 190 & 600 & 790 & 4.7 \\
\hline 50 & 130 & 460 & 590 & 3.5 & 190 & 460 & 650 & 3.9 \\
\hline 33.3 & 60 & 300 & 360 & 2.1 & 190 & 300 & 490 & 2.9 \\
\hline 25 & 60 & 240 & 300 & 1.8 & 190 & 240 & 430 & 2.6 \\
\hline 10 & 60 & 90 & 150 & 0.9 & 190 & 90 & 280 & 1.7 \\
\hline 3 & 60 & 30 & 90 & 0.5 & 190 & 30 & 220 & 1.3 \\
\hline
\end{tabular}

Notes: Variable $U$ case - number of SGs involved depends on scope. $U=1.0$ case - all SGs involved in inspection irrespective of scope. See Table 15 for definition of average unit.

given in Tables 18 and 19 assumes that there is no simultaneity between the NT and $T$ phases of the inspections, which is not necessarily true. The time data for the average unit are plotted in Figure 21 against the scope for both the variable $U$ and the $U=1.0$ cases. Comparing the conservative total ISI time given in Table 18 for $100 \%$ scope ( 6.5 weeks) with the average work time windows given in Figure 12 for the fuel outages ( $7-13$ weeks), it appears that the time factor should present no problem for well-organized ISIs.

Information on both the frequency and work time window opportunities presented by the fuel outages for ISI activity was given previously in this report. It was also noted that certain calendar periods are favorable to ISI activity on the basis of expected power demand. Some further comment on the latter fact is appropriate to this section. The calendar period favorability is quantified somewhat in Figure 22, where a histogram is presented of the beginning calendar date of fuel outages for U.S. PWR units. These data were obtained from a computer analys is of the NRC SISOR data base. There are several reservations about the data from which Figure 22 was obtained, namely the data are reported monthly and since a normal fuel outage lasts from 6-8 weeks, there was some data manipulation involved in identifying the beginning of the outage. 
TABLE 19. In-Service Time Values for Specific Units (Variable U) ${ }^{\text {(a) }}$

\begin{tabular}{|c|c|c|c|c|c|c|c|c|c|c|c|c|c|c|c|}
\hline \multirow[b]{2}{*}{ Type of Unit } & \multicolumn{3}{|c|}{ 100x Scope } & \multicolumn{3}{|c|}{ 66.7x Scope } & \multicolumn{3}{|c|}{$50 \%$ Scope } & \multicolumn{3}{|c|}{ 33.3\% Scope } & \multicolumn{3}{|c|}{ 10x Scope } \\
\hline & $\begin{array}{l}\text { (Time) } \\
(\mathrm{hr})^{\mathrm{nt}}\end{array}$ & $\begin{array}{c}\text { (Time) } \\
(\mathrm{hr})^{\mathrm{t}}\end{array}$ & $\begin{array}{l}\text { ET ime } \\
(\mathrm{hr})\end{array}$ & $\begin{array}{l}\text { (Time) } \\
(\mathrm{hr})^{\mathrm{nt}} \\
\end{array}$ & $\begin{array}{r}(f \mathrm{im}) \\
(\mathrm{hr}) \mathrm{t}\end{array}$ & $\begin{array}{l}\text { ET ime } \\
\text { (hr) }\end{array}$ & $\begin{array}{c}\text { TTime }) \\
(\mathrm{hr})^{\mathrm{nt}} \\
.\end{array}$ & $\begin{array}{c}\text { (Time) } \\
(\mathrm{hr})^{\mathrm{t}} \\
\end{array}$ & $\begin{array}{l}\text { Efime } \\
(\mathrm{hr})\end{array}$ & $\begin{array}{c}\text { Time }) \\
(\mathrm{hr})^{\mathrm{nt}}\end{array}$ & $\begin{array}{l}\text { (Time) } \\
(\mathrm{hr}) \\
\end{array}$ & $\begin{array}{l}\text { ET ime } \\
\text { (hr) } \\
\end{array}$ & $\begin{array}{c}\text { Time) } \\
(\mathrm{hr})^{\mathrm{nt}} \\
\end{array}$ & $\begin{array}{c}(\mathrm{Time}) \\
(\mathrm{hr})^{\mathrm{t}}\end{array}$ & $\begin{array}{l}\text { ET Time } \\
\text { (hr) }\end{array}$ \\
\hline $2 \mathrm{SG}$ & & & & & & & & & & & & & & & \\
\hline $\begin{array}{c}\text { B\&H }(15,500 \\
\text { Tubes/SG) }\end{array}$ & 130 & 1800 & 1930 & 130 & 1200 & 1320 & 60 & 900 & 960 & 60 & 600 & 660 & 60 & 180 & 240 \\
\hline CE $(8,500)$ & 130 & 980 & 1110 & 130 & 660 & 780 & 60 & 500 & 560 & 60 & 320 & 380 & 60 & 100 & 160 \\
\hline$W(3,300)$ & 130 & 380 & 510 & 130 & 260 & 380 & 60 & 200 & 260 & 60 & 130 & 190 & 60 & 40 & 100 \\
\hline 3 SG & & & & & & & & & & & & & & & \\
\hline$W(3,400)$ & 190 & 600 & 790 & 130 & 400 & 520 & 130 & 300 & 430 & 60 & 200 & 260 & 60 & 60 & 120 \\
\hline 4 SG & & & & & & & & & & & & & & & \\
\hline$w(3,400)$ & 260 & 780 & 1040 & 130 & 540 & 660 & 130 & 400 & 530 & 130 & 260 & 390 & 60 & 80 & 140 \\
\hline
\end{tabular}

(a) Variable U case (SGs inspected proportional to scope) 


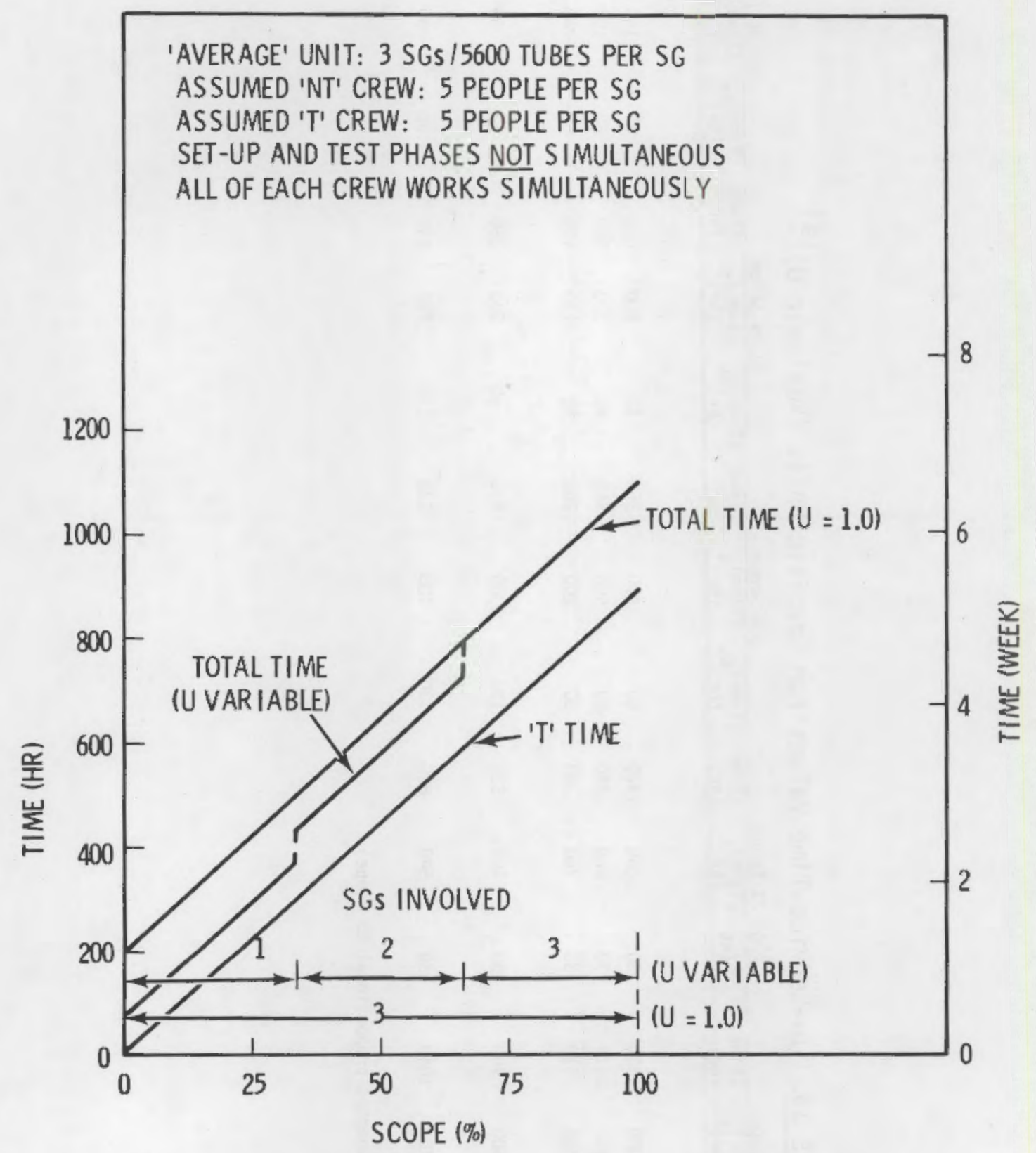

FIGURE 21. ISI Time Versus Scope for Average Unit

The bimodal characteristic of Figure 22 suggests that a two-campaign-peryear ISI strategy involving a unit population appropriate to the current ISI manpower situation would be feasible. 


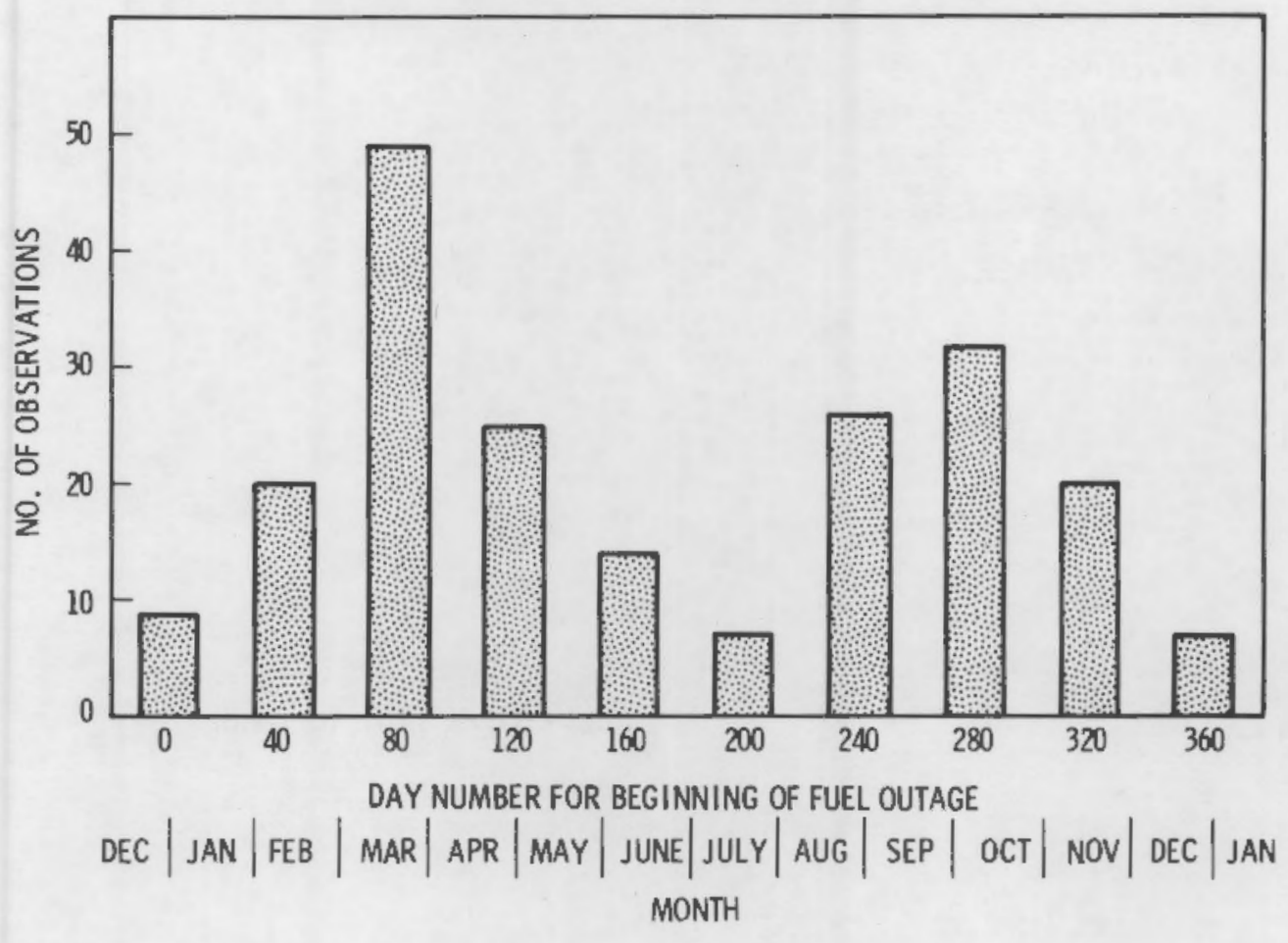

FIGURE 22. Beginning Dates of Fuel Outages 



\section{COMMENTS ON PROBABILISTIC ANALYSIS OF STEAM GENERATOR TUBING PROBLEMS}

The fundamental relationship in the ISI C/B analysis is:

$$
\left[\mathrm{USO}_{\mathrm{sg}}\right]=\mathrm{f}([\mathrm{ISI}])
$$

where $\left[\mathrm{USO}_{\mathrm{Sg}}\right.$ ] is the intensity of $\mathrm{SG}$ attributed unscheduled outages, measured by the number and length of the outages over some evaluation period and [1SI] is the intensity of the $S G$ inspection program, measured by the scope and frequency of the inspections (or more generally by the NOT information developed over the evaluation period).

ISIs can influence tubing failure in two ways: 1) by providing guidance to unit $0 / 0 / M$ practice that will tend to minimize tubing failure and 2) by censoring those tubes that are within an arbitrary degradation regime (as defined by the "plugging limit").

The second influence is the principal concern of this report. It will be successful only to the extent that uncensored tubes are not degraded to "leaker" status in the interval between inspections. This condition depends on: the validity of the criteria used to identify unacceptable tubes (as summarized by the plugging limit); the sensitivity of the NDT technique(s) to significant structural change; and the rate of deterioration of the tubing containment ability, which could vary substantially with time over the tubing population of a given SG and from zone-to-zone for a given tube of a single SG.

Corrosion attack (e.g., pitting, cracking, erosion-corrosion, or "uniform" attack from oxidation or other chemical action) may be accelerated as the degradation progresses, depending on the local physico.chemical and stress situation. Judging the conservatism of a given plugging limit is therefore difficult unless there is good knowledge of the rates of all operable degradation processes as a function of the defect state of the tubing. For the following necessarily qualitative discussion, let $D$ be some measure of the degradation state of a tube. $D$ is a monotonically increasing characteristic of various extent for all working tubes of the unit population and is difficult to quantify even for very simple cases involving a single structural defect, well-characterized metallurgical conditions adjoining the defect, and a good 
knowledge of the nominal local working conditions. The success of a given ISI strategy, in the sense of the second (censoring) ISI influence noted above, depends on all tubes of the unit satisfying the relationship:

$$
\theta_{f}>\theta_{o p}
$$

where $\theta_{f}$ is the time to failure of a given tube measured from the last inspection and $\theta_{o p}$ is the unit operating time between ISIs. $\theta_{f}$ and 0 are related by the following expression:

$$
D+\int_{0}^{\theta_{f}} \dot{D} d \theta=D+\Delta D=D_{f}
$$

where $\dot{D}=$ the instantaneous rate of the tubing degradation

$D=$ the degradation state of the tubing at the start of the operating period

$\Delta D=$ the degradation increment realized at time of tube failure

$\mathrm{D}_{\mathrm{f}}=$ the degradation state corresponding to tube failure under the working and metallurgical conditions specific to the tube.

The degradation rate $(\dot{0})$-operating time characteristic may be expected to vary widely over the unit tubing population and, in fact, over the length of a given tube for those cases where the tube is subject to various significant degradation processes (see Figure 23). Quantitative knowledge of the $\dot{D}-\theta$ characteristic is, in general, quite limited. Let $D_{p l}$ represent the degradation state corresponding to the plugging 1 imit (the current plugging limit is based on the penetration of a detectable degradation effect through the tube wall, i.e., on the percent of wall penetration by the defect). The success criterion expressed by Equation (2) can be recast in terms of $\theta_{\mathrm{op}}$ and $\mathrm{D}_{\mathrm{pl}}$ as follows:

$$
\begin{aligned}
& D+\int_{0}^{\theta_{f}} \dot{D} d \theta>0+\int_{0}^{\theta}{ }_{0 p}^{\theta} \dot{D} d \theta \quad\left(0<D_{p 1}\right) \\
& \text { or } \int_{0}^{\theta_{f}} \dot{D d \theta}>\int_{0}^{\theta_{0 p}^{o p}} \dot{D d \theta}
\end{aligned}
$$



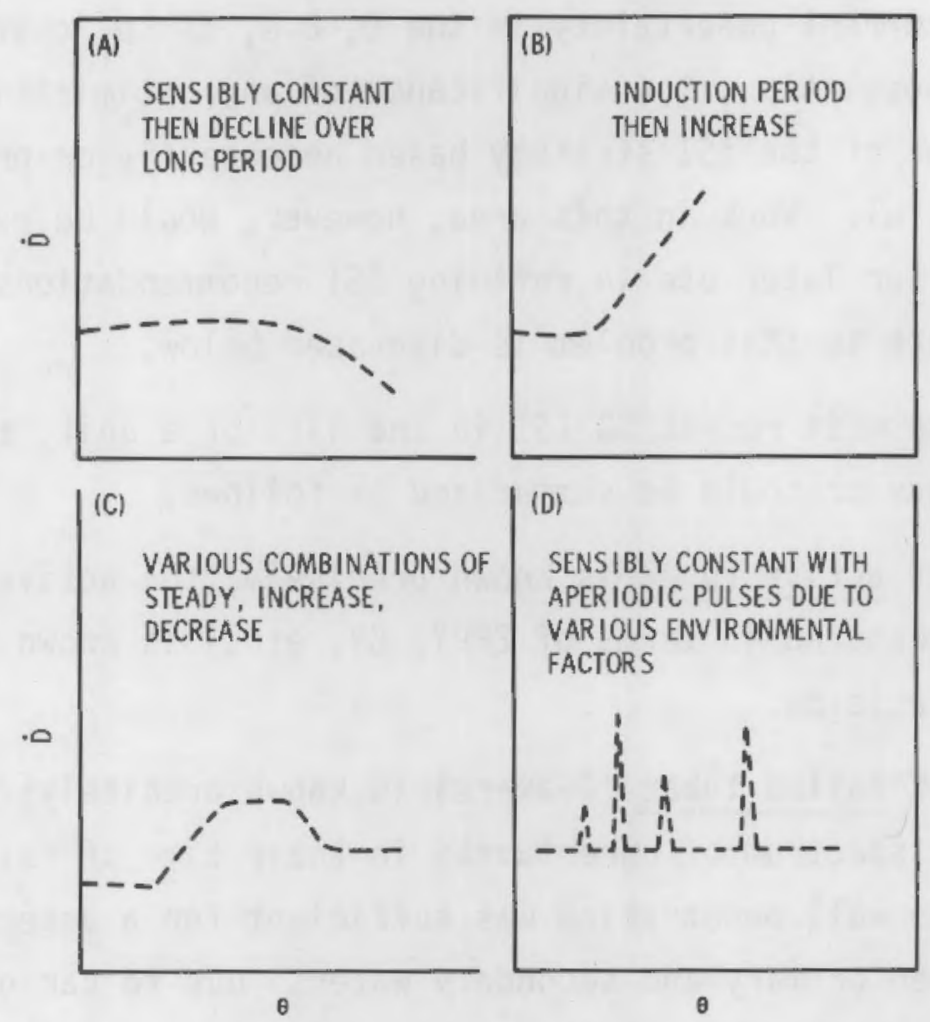

FIGURE 23. Schematics of Conceivable D- $\theta$ Characteristics for Steam Generator Tubing

Considering the possible complexity of the $\dot{D}-\theta$ relationship, Equation (4) is left in integral form.

Easterling ${ }^{(10)}$ has analyzed the NOT uncertainty with respect to simple defect conditions. This is obviously an important factor in establishing censoring limits that can maximize the number of tubes satisfying criterion (4) for practicable values of $\theta_{o p}$. It is also obvious that the further the departure of the ISI scope (percent of unit tubing population inspected during an ISI) from $100 \%$, the greater the possibility of tubes not satisfying criterion (4). Easterling ${ }^{(10)}$ has also addressed the implications of partial sampling to some extent. Problems arising from partial sampling may be expected to decrease in importance as better knowledge is acquired of the degradation of a unit tubing population with operating time. 
In view of current uncertainty in the $\mathrm{D}, \dot{\mathrm{D}}-\theta$, and $\mathrm{D}_{f}$ characteristics for the unit tubing population, the significance of any optimization of the $\theta_{\text {op }}$ (frequency) factor of the ISI strategy based necessarily on probabilistic analysis is doubtful. Work in this area, however, would be expected to yield valuable insight for later use in refining ISI recommendations for specific units. An approach to this problem is discussed below.

Following the most recent SG ISI in the life of a unit, the knowledge of the SG tubing behavior could be summarized as follows.

- The number of active tubes is known precisely; the active tube service life (measured in terms of EFPY, CY, etc.) is known within an arbitrary precision.

- The number of failed tubes (leakers) is known precisely; there is a fairly broad spectrum of uncertainty in their time of failure (the time when the wall penetration was sufficient for a detectable interchange between primary and secondary waters) due to various problems of leak detection and identification of leakers.

- The number of unfailed plugged tubes is presumably known precisely; while the time of plugging is known precisely (hence the corresponding service life), these tubes represent a spectrum of residual life expectancy whose range is dependent on the conservatism of the plugging practice. The plugging of these tubes is, therefore, a statistical life censoring act that may pose some difficulty in tubing reliability analysis considering the difficulty in relating residual life expectancy to a specific defect state. Studies of defected SG tubing will contribute to a practical resolution of the latter problem. (11)

The above tubing information represents a complex, unplanned censored data situation that may be treated in the literature although a review of this analysis has been outside the scope limitations of this report. A reliability analysis technique for multiple time-censored data satisfying certain statistical requirements has been discussed in several reports by $W$. B. Nelson of General Electric. (12) An associated computer program for the calculation and 
plotting of the cumulative failure rate function is reported by Nelson and Hendrickson. (13) The elements of this technique are outlined in Appendix $C$.

The limits of application of the above technique to the SG tubing data situation remain to be studied theoretically and by some application of the technique to tubing data from several units. Any practicable technique should be capable of accomnodating both the long-term tubing performance history as we 11 as recent trends in performance within some arbitrary evaluation period. It should also be readily assimilated into an overall SG ISI C/B code for analys is of the ISI frequency factor, along with the various costs of ISI strategies discussed previously in this report.

A useful quantification of the fundamental relationship (1) appears to be largely inaccessible at this time considering its complexity and the limited scope of information pertaining to the two ISI influences noted on p. 65. knowledge of this relationship will be served by good reporting of comprehensive ISI strategies and careful correlation of this ISI information with unit D/0/M practice that affects So tubing performance. 



\section{ESTIMATED COSTS FOR OISPOSAL OF SOLID WASTES ASSOCIATED WITH}

\section{PRIMARY TO SECONDARY LEAKAGE IN PWR STEAM GENERATORS}

Leaks in the SG tubing of a PWR result in the transfer of radionuclides in the primary coolant to the secondary system water. When the radionuclide content of the secondary system water exceeds a value of $1 \times 10^{-7}{ }_{\mu \mathrm{Ci} / \mathrm{ml} \text {, it }}$ is necessary to treat this water if it is removed for discharge to the environment. In order to maintain a high level of water quality in the SG, a portion of this water is normally removed continuously as a blowdown stream. When the radionuclide content exceeds the discharge limit, the blowdown stream is typi-cally routed through an ion exchange treatment system. When the ion exchange capacity of the resin is exhausted, the spent resin is removed and discarded as solid waste. Until recently, it has been common practice to decant as much water from the spent resin as possible and package the resin with some free water remaining for disposal. A new regulatory stance will require complete removal of any free water from the resin before shipment and disposal. This may be accomplished by various fixation techniques such as the cement silicate system.

The conventional approach to ion exchange treatment of the SG blowdown has involved a deep bed of mixed cation and anion exchange resins. There are no firm data available on the quantity of this resin discarded as waste per unit of reactor operating time, although it has been estimated to be about $4500 \mathrm{ft}^{3}$ per year for a typical PWR.

An alternate approach to treatment of SG blowdown involves the use of full-flow condensate treatment with Powdex ion exchange resins. This approach is expected to keep secondary system water pure enough to avoid blowdown from the SG. One operating reactor reported that a retrofit Powdex system for PWR condensate included blending of the blowdown with the condensate before treatment, thereby avoiding discharge of the blowdown. The Powdex resin is disposed of as radioactive waste and is estimated to be about the same order of magnitude as the volume given above.

\footnotetext{
Graver Water Conditioning Co., Division of Ecodyne Corporation, Union, New Jersey.
} 
The volume of spent Powdex resin is normally not related to the radionuclide content of the secondary system condensate or blowdown. The resin is used for both ion exchange and filtration, and it is the latter (high-pressure differential buildup) that determines the life of the resin and, therefore, the volume of resin used.

The cost of disposing spent ion exchange resin from SG blowdown and/or condensate treatment can vary widely depending principaily on whether or not it is considered radioactive. The lowest cost was estimated for unrestricted release of the resin for disposal to a local sanitary landfill $(\$ 15,000$ annually). The highest cost was estimated for disposal as solidified waste to a radwaste burial site located 1000 miles from the reactor ( $\$ 164,000$ annually). Al1 cost figures were based on January 1980 prices. The following text examines the costs associated with treatment of water contaminated by primary to secondary leaks. Results are placed into a matrix that lists costs as a function of leakage activity.

The following economic analys is evaluates the costs associated with treatment of radwastes from the secondary heat exchange fluid loop. This fluid is periodically contaminated by primary fluid passing through breaks in the tubes of the $S G$ heat exchanger.

The basis of the analysis is from an interoffice memorandum (IOM) from the Washington Public Power Supply System (by Steen) dated April 5, 1979. The IOM reports on the costs associated with various treatment methods for secondary fluids in the SG. It was recommended that the standard ureaformaldehyde (UF) radwaste solidification system be replaced by a more efficient and less expensive cement-sodium silicate system. This report will assume use of the cementsodium solicate system and will, as the reference report did, assume retrofit capital costs for the conversion of the UF system to the cement-sodium silicate system. Oata used from the IOM are extrapolated to reflect on the treatment of radwastes associated with SG reakage. The analysis results in a range of values $(\$ / y r)$ associated with treatment of secondary rad-contaminated waters from nuclear SGs.

The assumptions used in this analysis are presented below. Facility life expectancy is 15 years and the interest rate used is $10 \%$. The burial site used 
is Hanford, Washington, except for Cases $A$ and $K$ (see Table 20). It was calculated that $45 \%$ of the spent resin generated in the reference study $\left(5300 \mathrm{ft}^{3}\right.$ by volume) was due to $S G$ leakage. This $f$ act was verified in a de minimus study $(14)$ that estimated the quantity of spent resin at $4500 \mathrm{ft}^{3} / \mathrm{yr}$. Therefore, the analysis shouid be conservative.

\section{Assumptions}

1. Liners (a) used by the plants under construction (WNP 1/4) will accommodate waste of the following radiation ranges:

a) $20 \%$ of the wastes will have been contaminated to 1-5 rem/hour

b) $35 \%$ of the wastes will have been contaminated to 200 mrem-1 rem/hour

c) $45 \%$ of the wastes will have been contaminated to $0-200 \mathrm{mrem} /$ hour.

2. Liners of $100-\mathrm{ft}^{3}$ capacity will be used for solidification of wastes.

3. Approximately $8,400 \mathrm{ft}^{3} / \mathrm{yr}$ of waste must be solidified per facility.

4. Shipping charges are $95 \$ /$ mile or $\$ 100 /$ shipment, whichever is higher.

5. Liners cost $\$ 650$ each.

6. Liners with dose rates 1-5 rem/hour are shipped one per truck; all others are shipped two per truck.

7. Burial charges for secure radwaste burial are based upon Nuclear Engineering Companies, Hanford, Washington, charge-out rates (see attachment).

8. Modification capital and installation cost for cement-sodium silicate systern will be $\$ 1,050,000$. Keeping the old UF system will have no capitai costs (basis, July 1978).

9. Interest rate on capital costs is $10 \% / \mathrm{yr}$.

10. Life expectancy of solidification process is 15 years.

11. Cost data basis: July 1978 and January 1980.

(a) Liner is the container for the waste, exclusive of shielding. 
TABLE 20. Summary of Annual Operating Costs

\begin{tabular}{|c|c|c|c|c|c|c|c|c|c|c|c|}
\hline Case & A & $B$ & $C$ & $\mathrm{D}$ & $E$ & $F$ & $\mathrm{G}$ & $\mathrm{H}$ & I & $\mathrm{J}$ & $k$ \\
\hline $\cos$ & $\begin{array}{c}40,660 \\
(45,540)\end{array}$ & $\begin{array}{c}83,115 \\
(93,090)\end{array}$ & $\begin{array}{c}83,390 \\
(93,400)\end{array}$ & $\begin{array}{c}84,065 \\
(94,150)\end{array}$ & $\begin{array}{c}86,990 \\
(97,430)\end{array}$ & $\begin{array}{c}87,865 \\
(98,410)\end{array}$ & $\begin{array}{c}88,440 \\
(99,050)\end{array}$ & $\begin{array}{c}100,280 \\
(112,310)\end{array}$ & $\begin{array}{l}100,665 \\
(112,740)\end{array}$ & $\begin{array}{c}101,230 \\
(113,380)\end{array}$ & $(14,850)$ \\
\hline
\end{tabular}

\section{Case}

A Radwaste at $0-0.005 \mathrm{rem} / \mathrm{hour}$, buried onsite (negligibie burial costs).

Radwaste at 0-0.200 rem/hour, buried at Hanford, Washington, travel distance maximum of 50 miles. Radwaste at $0-0.200$ rem/hour, buried at hanford, washington, travel distance maximum of 500 miles. Radwaste at 0-0.200 rem/hour, buried at Hanford, Washington, travel distance maximum of 1000 miles. Radwaste at 0.200-1 rem/hour, buried at Hanford, washington, travel distance maximum of 50 miles. Radwaste at $0.200-1 \mathrm{rem} /$ hour, buried at Hanford, Washington, travel distance maximum of 500 miles. Radwaste at 0.200-1 rem/hour, buried at Hanford, washington, travel distance maximum of 1000 miles Radwaste at 1-5 rem/hour, buried at Hanford, Washington, travel distance maximum of 500 miles. Radwaste at 1-5 rem/hour, buried at Hanford, Washington, travel distance maximum of 500 miles. Radwaste at 1-5 rem/hour, buried at Hanford, Washington, travel distance maximum of 1000 miles. Radwaste below de minimus levels, buried in sanitary landfill, travel distance maximum of 50 miles.

$n=$ basis July 1978

$(n)=$ basis January 1980 
Table 20 presents initial operating costs for operating this facility under a variety of conditions (cases $A$ through $K$ ). Conditions varied including transportation charges (mileage to secure radwaste site) and levels of radwaste contamination. Initial operating costs varied from $\$ 15.8 \mathrm{~K}$ to $\$ 101.2 \mathrm{~K}$. The charge associated with initial capital expenditure is $\$ 69.6 \mathrm{~K}$ over the 15 -year lifetime of the facility (see Table 21 ).

Table 22 presents a breakdown of the total cumulative costs of the various options over the lifetime of the plant. A $10 \%$ annual inflation rate on annual operating costs is included in the computation, and a sample calculation is provided.

\section{TABLE 21. Capital Costs (January 1980 Basis)}

Cost of Equipment and Installation: $\$ 1,050,000$-- July 1978 Basis $(\$ 1,176,000)$-- January 1980 Basis

Assume Facilities Life Span of 15 Years, No Salvage Value. Assume Interest Rate of $10 \%$.

$\therefore$ Capital Costs/yr

$$
\begin{aligned}
\text { of Operation } & =(\$ 1,176,000)\left(\frac{i(1+i)^{n}}{(1+i)^{n-1}}\right) \begin{array}{l}
\text { Capital Recovery } \\
\text { Factor (n) }
\end{array} \\
& =(\$ 1,176,000)(0.13147) \\
& =\$ 155,000 / \mathrm{yr} \text { for Entire Facilities Wastes } \\
& =(\$ 155,000)\left(\frac{5,300}{11,800}\right)=\begin{array}{l}
\$ 69,600 / y r \text { for } \\
\begin{array}{l}
\text { Steam Generator } \\
\text { Waste Solidification }
\end{array}
\end{array}
\end{aligned}
$$

Next, it was necessary to determine which of the options (A-K) reflect both the actual state-of-the-art operating conditions and the projected operating conditions. To obtain these data, several organizations were contacted, including the Washington Public Power Supply System, Trojan Power reactor of Pacific Gas and Electric (PGE), and NRC. A de minimus study on wastes from Powdex systems (which are comonly used for secondary, SG, and waste water treatment) was also referenced. Results from these sources were two-fold. 
TABLE 22. Total Costs Associated with Oecontamination of Steam Generator Water (January 1980 Bas is)

Total cost of System up to $X$ Years (\$)

10

\begin{tabular}{rrrrr} 
& \multicolumn{1}{c}{$G$} & & $H$ & \multicolumn{1}{c}{$I$} \\
\cline { 5 - 5 } & 168,650 & & 181,910 & 182,340 \\
5 & 347,210 & & 375,050 & 375,950 \\
10 & 952,700 & & $1,033,650$ & $1,036,280$ \\
15 & $2,274,560$ & $2,485,880$ & $2,492,740$ \\
& $4,191,020$ & $4,612,310$ & $4,625,980$
\end{tabular}

A

$$
115
$$

234,830

626,020

$1,421,770$

$2,490,900$

$$
2,179,580
$$$$
4,001,660
$$

$2,184,520$

$4,011,500$
Case

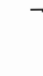

$4,035,330$

$\frac{J}{182,980}$

377,300

$\frac{K}{15,840}$

$1,040,180$

$2,502,940$

$4,646,310$

\begin{tabular}{rr}
$\frac{E}{}$ & \multicolumn{1}{c}{$F$} \\
167,030 & 168,010 \\
343,800 & 345,860 \\
942,810 & 948,790 \\
$2,248,740$ & $2,264,360$ \\
$4,134,670$ & $4,170,680$
\end{tabular}

33,260

96,700

252,440

503,270

EX: Year 2, Case A

Tota1 Cost $=n(69,600)+\left[\left(\frac{(1+i)^{n}-1}{i}\right)(45,540)\right]=234,830$
$n=2 ; i=0.1$

First, the utilities expect the resin will normally be low enough in radwaste contamination that it could be sent to sanitary landfills. In the worst case, contaminated resin would have to be taken to a secure radwaste landfill, without contamination penalties. However, apparently many utilities will send these spent resins to secure radwaste disposal facilities due to public pressure. Therefore, cases $A, B, C, D$, and $K$ reflect the situations and ranges of costs expected. First-year total costs ranged from $\$ 15.8 \mathrm{~K}$ to $\$ 163.7 \mathrm{~K}$ and increase substantially if the contaminated resin must be solidified due to capital costs associated with solidification equipment. cost data are given in Appendix $D$, which also gives calculations of the annual operating costs presented in this section. 
Possible costs associated with storage of solid wastes pending offsite shipping arrangements would be quite site-specific and were not considered at this stage of the $C / B$ analysis. 



\section{FURTHER COST/BENEFIT ANALYSIS OBJECTIVES}

A practicable C/B analysis technique for SG ISI will require a synthesis of many technical, personnel, and $\$$ cost factors, some of which have been given only a very cursory review in this report. Several further work areas for the subject program are briefly discussed here.

\section{Analys is of Outage Costs for PWR Units}

The critical path time cost for large nuclear units is a strong constraint on the scope and frequency parameters of ISI strategies. Some of the factors affecting this cost were discussed briefly in this report. $A C / B$ analysis technique for appraising SG ISIs, both individual inspections and an inspection program over an evaluation period, must be able to accommodate the complex of outage cost factors specific to a given unit at a given time. The purpose of this task is to perform an in-depth analysis of outage cost factors of PWR units and to evolve a technique for incorporating successively refined elements of this analysis into an overall $C / B$ code.

Analysis of SG Tubing Performance

The success of any C/B analysis code for SG ISI will be measured by the service it can render to units on a nationwide basis. Accordingly, a practicable code must accommodate a wide range of tubing performance, considering both overall and recent trend behavior. Ultimately, the purview of the C/B code could conceivably include the influence of various $0 / 0 / M$ factors on tubing performance. The current state of the information on tubing performance (i.e., the accessibility, the quality and scope of the data, and its relationship to pertinent unit $\mathrm{D} / \mathrm{O} / \mathrm{M}$ factors) does not appear adequate for the tubing reliability analysis needed for prudent specification of inspection intervals for specific units. This task would have several concomitant efforts: 1) participation with the cognizant public and private organizations in improving the scope, codification, and dissemination of performance data for PWR SG tubes and 2) study of the current tubing data bank with the objective of identifying practicable techniques for probabilistic analysis of tubing performance. In 
accordance with progress in the latter phase of this task, the probabilistic component (as related to tubing performance) would be incorporated in the overall $C / B$ analysis code.

Analysis of Foreign SG ISI Strategies and Related PWR SG Performance

While the focus of this program is on PWR units in the United States, it is expected that much valuable information on ISI strategies and the related PWR SG tubing experience could be obtained from foreign sources. The purpose of this task is to review relevant foreign SG ISI practice and the related SG tubing performance. Coordination of this work with the parent U.S. program would be expected to add both scope and authority to recommendations forthcoming from the program. 


\section{REFERENCES}

1. Electric Power Research Institute. August 1978. Refueling Outage Trends in Light Water Reactors. EPRI NP-842, Palo Alto, California.

2. Electric Power Research Institute. Apri1 1978. Major Outage Trends in Light Water Reactors. EPRI NP-755, Palo Alto, California.

3. Electric Power Research Institute. September 1979. Nuclear and Large Fossil Unit Operating Experience. EPRI NP-1191, Palo Alto, California.

4. Whooley, J. P., and E. E. Haddad. 1978. "The Application of Econometrics to Nuclear Power Plant Reliability." In Reliability Problems of Reactor Pressure Components, Vol. 1, p. 63. International Atomic Energy Agency Symposium, Vienna, Austria.

5. Electric Power Research Institute. August 1979. Limiting Factor Analysis of High Availability Nuclear Plants, Vol. 1. EPRI NP-1139, Palo Alto, California.

6. Electric Power Research Institute. September 1979. Limiting Factor Analys is of High Availability Nuclear Plants. EPRI NP-1138, Palo Alto, California.

7. Electric Power Research Institute. August 1979. Limiting Factor Analysis of $[-E$ Nuclear Plants, Vol. 1. EPRI NP-1137, Palo Alto, California.

8. Pathania, R. S., and 0. S. Tatone. September/0ctober 1979. "SteamGenerator Tube Performance: World Experience with Water-Cooled Nuclear Power Reactors During 1977." Nuclear Safety 20(5) (and other reports in the AECL series on SG tubing performance).

9. Nuc lear Power Experience, Inc. 1980. Nuc lear Power Experience - Vol. PWR-2, (late 1970 through January 1980), Encino, California.

10. Easterling, R. G. August 1980. Steam Generator Inspection Plans. NUREG/ CR-1282, Sandia Laboratories, A1buquerque, New Mexico.

11. Alzheimer, J. M., et a1. September 1979. Steam Generator Tube Integrity Program Phase I Report. NUREG/CR-0718, Pac if ic Northwest Laboratory, Richland, Washington.*

12. Neison, W. B. November 1972. "Theory and Applications of Hazard Plotting for Censored Failure Data." Technometrics 14(4):945.

13. Nelson, W. 8., and R. Hendrickson. 1969. PROPLOT - A Versatile TimeSharing Program for Probability Plotting and Analys is of Data. General Electric Research and Development Center, TIS Report 69-C-203. 
14. Rodger, W. A., et al. April 1978. De Minimus Concentration of Radionuclides in Solid Wastes. AIF/NESP-016.

15. Marsh, L. B. March 1980. Evaluation of Steam Generator Tube Rupture Events. NUREG-0651, Nuclear Regulatory Commission.*

\#Available for purchase from the NRC/GPO Sales Program, U.S. Nuclear Regulatory Commission, Washington, DC 20555, and/or the National Technical Information Service, Springfield, VA 22161. 
APPENDIX A

NOMENCLATURE 
APPENDIX A

NOMENCLATURE

\begin{tabular}{|c|c|c|}
\hline Symbol & Identification & Units \\
\hline ALARA & as low as reasonably achievable & \\
\hline$\alpha$ & time efficiency factor for given inspection phase & \\
\hline $\mathrm{CF}$ & capacity factor & \\
\hline CTF I & cumulative tube failure index & $(S G E F P Y)^{-1}$ \\
\hline$c_{1}$ & composite index for evaluation period [I isi/(MAN-REM)] & (yr man-rem $)^{-1}$ \\
\hline$C_{1}$ & composite index for individual inspection [Iisj*/(MAN-REM*)] & $(\operatorname{man}-r e m)^{-1}$ \\
\hline $\mathrm{C}_{2}$ & composite index for evaluation period [Iisi/(MAN-REM \&isi)] & $\left(y r \text { man-rem } \times 10^{6} \$\right)^{-1}$ \\
\hline $\mathrm{C}_{2}$ & composite index for individual inspection [Iis $i^{*} /($ MAN-REM* $\left.\$ i s i *)\right]$ & $\left(\operatorname{man}-r e m \times 10^{6} \$\right)$ \\
\hline$c_{t}$ & nominal crew size for testing phase of inspection & \\
\hline$c_{n t}$ & nominal crew size for nontesting phase of inspection & \\
\hline D & symbol of degradation state of $S G$ tubing & \\
\hline $\mathrm{D}$ & rate of change of 0 & \\
\hline 8 isi & $\$$ impact index for evaluation period & $\left(10^{6} \$\right)$ \\
\hline$\$ i s i^{\star}$ & 8 impact index for individual inspection & $\left(10^{6} \$\right)$ \\
\hline$\delta_{0 i}$ & outgage cost per day for unit at time of inspection (i) & $\left(10^{6} 8 /\right.$ day $)$ \\
\hline
\end{tabular}




\begin{tabular}{|c|c|c|}
\hline Symbol & Identification & Units \\
\hline$(\$ /$ tube $) ;$ & total cost of ISI on a per tube inspected basis & $\left(10^{6} \$ /\right.$ tube $)$ \\
\hline $\mathrm{SuSO}_{\mathrm{sg}}$ & $\$$ impact of unscheduled outage attributable to SG problems & $\left(10^{6} \$\right)$ \\
\hline EFPY & effective full power year & \\
\hline$f$ & number of tubes failed (plugged) & \\
\hline $\mathrm{F}_{\mathbf{i}}$ & time interference factor for inspection (i) & \\
\hline$f(\theta)$ & probability density for tube failure & \\
\hline$F(\theta)$ & cumulative failure probability & \\
\hline$i$ & sumnation index over inspections for given unit & \\
\hline ISI & in-service inspection & \\
\hline$[\mathrm{ISI}]$ & intensity of an in-service inspection program & \\
\hline I isi & NDT information index for evaluation period for given unit & $(y r)^{-1}$ \\
\hline $\begin{array}{l}\operatorname{Iisi*} \\
\lambda(\theta)\end{array}$ & $\begin{array}{l}\text { information index for individual inspection } \\
\text { tube failure rate }\end{array}$ & \\
\hline$\Lambda(\theta)$ & cumulative tube fajlure rate & \\
\hline$(M R)_{t}$ & aggregate rad exposure for testing phase per tube tested & (man-rem/tube) \\
\hline$(M R)_{n t}$ & aggregate rad exposure for nontesting phase per SG involved & (man-rem/SG) \\
\hline MAN-REM & rad exposure index for evaluation period & (man-rem) \\
\hline MAN-REM* & rad exposure index for individual inspection & (man-rem) \\
\hline
\end{tabular}




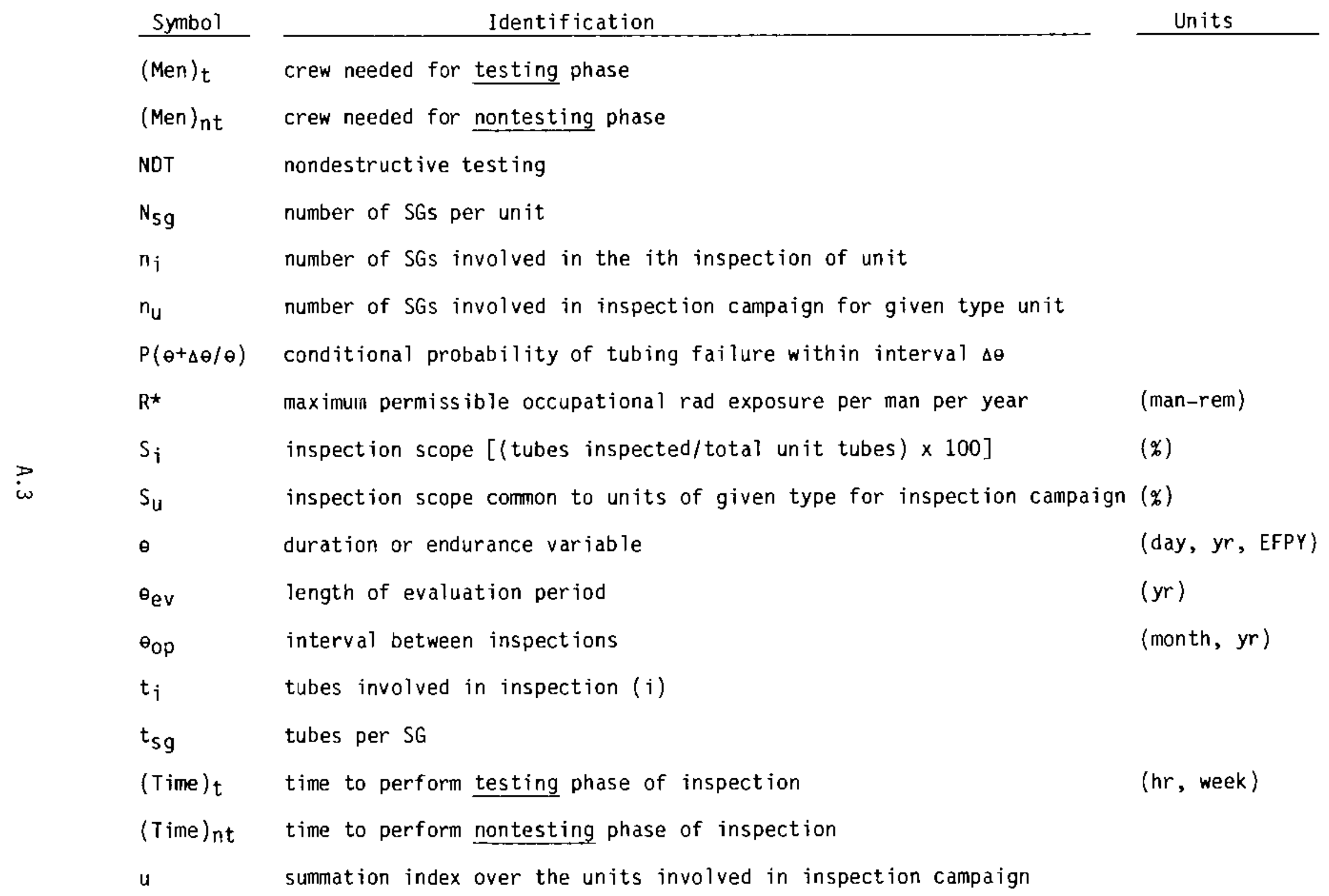


Symbol

Identification

$U_{i}$ distribution factor (SGs involved in inspection/total SGs in unit)

unit a PWR power plant in present context

$\mathrm{USO}_{\mathrm{Sg}} \quad$ unscheduled outage attributable to $S G \operatorname{problem}(\mathrm{s})$

$\left[\mathrm{USO}_{\mathrm{sg}}\right]$ intensity of unscheduled outages attributable to SG problems

$Y_{U}$ number of units of given type involved in inspection campaign
Units

(day) 
APPENDIX B

DATA FOR CHARACTERIZATION INDICES 
TA8LE B.1. Values of Indices for ISI Cases

\section{4-SG Unit}

\begin{tabular}{|c|c|c|c|c|c|c|c|c|}
\hline ISI Case & I isi & $\begin{array}{l}\text { MAN-REM } \\
(\mathrm{High}) \\
\end{array}$ & $\begin{array}{l}\text { MAN-REM } \\
\text { (LOW) }\end{array}$ & $\begin{array}{l}\text { MAN-REM } \\
(T=0)\end{array}$ & $\begin{array}{c}\$ i s i \\
(F=0) \\
\end{array}$ & $\begin{array}{c}\text { Sisi } \\
\text { Proportional } \mathrm{F} \\
\left(\mathrm{F}_{\max }=0.1\right)\end{array}$ & $\begin{array}{c}(a) \\
C_{1}^{(y r x M R)^{-1}} \\
\end{array}$ & $\begin{array}{c}(\mathrm{b}) \\
\mathrm{C}_{2} \\
\left(\operatorname{yr} \times M R \times 10^{6} \$\right)^{-1} \\
\end{array}$ \\
\hline & $\left(Y r^{-1}\right)$ & (man-rem) & & & $\left(10^{6} 8\right)$ & & & \\
\hline $\begin{array}{l}A-1 \\
A-2 \\
A-3\end{array}$ & $\begin{array}{l}7.5(-3)(c) \\
5.0(-3) \\
4.2(-3)\end{array}$ & $\begin{array}{l}96 \\
64 \\
53\end{array}$ & $\begin{array}{r}14 \\
9.4 \\
7.8\end{array}$ & $\begin{array}{l}50 \\
34 \\
28\end{array}$ & $\begin{array}{l}1.4(-1) \\
9.0(-2) \\
7.2(-2)\end{array}$ & $\begin{array}{l}2.9(-1) \\
1.7(-1) \\
1.4(-1)\end{array}$ & $\begin{array}{l}1 \cdot 5(-4) \\
1 \cdot 5(-4) \\
1 \cdot 5(-4)\end{array}$ & $\begin{array}{l}1.1(-3) \\
1.6(-3) \\
2.1(-3)\end{array}$ \\
\hline $\begin{array}{l}B-1 \\
B-2\end{array}$ & $\begin{array}{l}6.3(-3) \\
4.6(-3)\end{array}$ & $\begin{array}{r}112 \\
71\end{array}$ & $\begin{array}{c}16 \\
9.9\end{array}$ & $\begin{array}{l}62 \\
39\end{array}$ & $\begin{array}{l}8.4(-2) \\
4.6(-2)\end{array}$ & $\begin{array}{l}1.6(-1) \\
7.8(-2)\end{array}$ & $\begin{array}{l}1.0(-4) \\
1.2(-4)\end{array}$ & $\begin{array}{l}1.2(-3) \\
2.6(-3)\end{array}$ \\
\hline $\begin{array}{l}C-1 \\
C-2 \\
C-3 \\
C-4\end{array}$ & $\begin{array}{l}8.9(-1) \\
3.9(-1) \\
3.1(-1)\end{array}$ & $\begin{array}{l}574 \\
359 \\
323\end{array}$ & $\begin{array}{r}129 \\
80 \\
72\end{array}$ & $\begin{array}{l}179 \\
112 \\
101\end{array}$ & $\begin{array}{l}1.5 \\
1.2 \\
1.1\end{array}$ & $\begin{array}{l}2.1(+1) \\
8.3 \\
5.9\end{array}$ & $\begin{array}{l}5.0(-3) \\
3.5(-3) \\
3.1(-3)\end{array}$ & $\begin{array}{l}3.3(-3) \\
2.9(-3) \\
2.8(-3)\end{array}$ \\
\hline $\begin{array}{l}C-4 \\
C-5 \\
C-6\end{array}$ & $1.6(-1)$ & 198 & 44 & 62 & $8.0(-1)$ & 2.0 & $2.6(-3)$ & $3.2(-3)$ \\
\hline $\begin{array}{l}C-7 \\
C-8 \\
C-9\end{array}$ & $\begin{array}{l}7.6(-2) \\
6.3(-2) \\
2.5(-2)\end{array}$ & $\begin{array}{l}161 \\
153 \\
114\end{array}$ & $\begin{array}{l}36 \\
34 \\
21\end{array}$ & $\begin{array}{l}50 \\
50 \\
50\end{array}$ & $\begin{array}{l}7.5(-1) \\
7.0(-1) \\
3.9(-1)\end{array}$ & $\begin{array}{l}2.0 \\
1.9 \\
8.7(-1)\end{array}$ & $\begin{array}{l}1.5(-3) \\
1.3(-3) \\
5.0(-4)\end{array}$ & $\begin{array}{l}2.0(-3) \\
1.8(-3) \\
1.3(-3)\end{array}$ \\
\hline
\end{tabular}

(a) $\mathrm{C}_{1}=$ I isi/MAN-REM, $T=0$ case

(b) $\mathrm{C}_{2}=$ Iisi/ (MAN-REM $\times \$$ isi); $T=0$ for MAN-REM, $F=0$ for $\$$ isi

(c) $7.5(-3)=7.5 \times 10^{-3}$, etc. 
TA8LE B.1. (contd)

3-SG Unit

\begin{tabular}{|c|c|c|c|c|c|c|c|c|}
\hline \multirow[t]{2}{*}{ ISI Case } & Iisi & $\begin{array}{l}\text { MAN-REM } \\
\text { (High) }\end{array}$ & $\begin{array}{l}\text { MAN-REM } \\
\text { (LOW) } \\
\end{array}$ & $\begin{array}{l}\text { MAN-REM } \\
(T=0)\end{array}$ & $\begin{array}{c}\text { Sisi } \\
(\mathrm{F}=0)\end{array}$ & $\begin{array}{c}\text { Sisi } \\
\text { Proportional F } \\
\left(\mathrm{F}_{\max }=0.1\right)\end{array}$ & $\begin{array}{c}c_{1} \\
\text { (yrxMR)-1 } \\
\end{array}$ & $\begin{array}{c}C_{2} \\
\left(y r \times M R \times 10^{6} \$\right)^{-1}\end{array}$ \\
\hline & $\left(\mathrm{Yr}^{-1}\right)$ & (man-rem) & & & $\left(10^{6} \$\right)$ & & & \\
\hline $\begin{array}{l}A-1 \\
A-2 \\
A-3\end{array}$ & $\begin{array}{l}1.0(-2) \\
6.7(-3) \\
5.6(-3)\end{array}$ & $\begin{array}{l}94 \\
63 \\
52\end{array}$ & $\begin{array}{l}14 \\
9 \\
7.5\end{array}$ & $\begin{array}{l}50 \\
34 \\
28\end{array}$ & $\begin{array}{l}1.2(-1) \\
7.2(-2) \\
5.8(-2)\end{array}$ & $\begin{array}{l}3.1(-1) \\
1.8(-1) \\
1.4(-1)\end{array}$ & $\begin{array}{l}2.0(-4) \\
2.0(-4) \\
2.0(-4)\end{array}$ & $\begin{array}{l}1.7(-3) \\
2.7(-3) \\
3.5(-3)\end{array}$ \\
\hline $\begin{array}{l}\text { B-1 } \\
\text { B-2 }\end{array}$ & $\begin{array}{l}7.2(-3) \\
5.0(-3)\end{array}$ & $\begin{array}{r}101 \\
61\end{array}$ & $\begin{array}{l}14 \\
8.4\end{array}$ & $\begin{array}{l}56 \\
34\end{array}$ & $\begin{array}{l}6.6(-2) \\
3.7(-2)\end{array}$ & $\begin{array}{l}1.6(-1) \\
7.9(-2)\end{array}$ & $\begin{array}{l}1.3(-4) \\
1.5(-4)\end{array}$ & $\begin{array}{l}2.0(-3) \\
4.0(-3)\end{array}$ \\
\hline $\begin{array}{l}C-1 \\
C-2 \\
C-3 \\
C-4 \\
C-5 \\
C-6 \\
C-7 \\
C-8 \\
C-9\end{array}$ & $\begin{array}{l}8.9(-1) \\
4.4(-1) \\
3.7(-1) \\
2.0(-1) \\
1.8(-1) \\
1.1(-1) \\
1.0(-1) \\
8.3(-2) \\
3.3(-2)\end{array}$ & $\begin{array}{l}431 \\
323 \\
277 \\
180 \\
166 \\
153 \\
143 \\
137 \\
108\end{array}$ & $\begin{array}{l}96 \\
72 \\
59 \\
40 \\
36 \\
34 \\
30 \\
28 \\
19\end{array}$ & $\begin{array}{r}134 \\
101 \\
95 \\
56 \\
56 \\
50 \\
50 \\
50 \\
50\end{array}$ & $\begin{array}{l}1.3 \\
9.9(-1) \\
9.5(-1) \\
7.7(-1) \\
6.7(-1) \\
7.0(-1) \\
6.3(-1) \\
5.8(-1) \\
3.1(-1)\end{array}$ & $\begin{array}{l}2.0(+1) \\
9.5 \\
7.4 \\
2.9 \\
2.3 \\
2.8 \\
2.2 \\
2.2 \\
9.4(-1)\end{array}$ & $\begin{array}{l}6.6(-3) \\
4.4(-3) \\
3.9(-3) \\
3.6(-3) \\
3.2(-3) \\
2.2(-3) \\
2.0(-3) \\
1.7(-3) \\
6.6(-4)\end{array}$ & $\begin{array}{l}5.1(-3) \\
4.4(-3) \\
4.1(-3) \\
4.6(-3) \\
4.8(-3) \\
3.1(-3) \\
3.2(-3) \\
2.9(-3) \\
2.1(-3)\end{array}$ \\
\hline
\end{tabular}


TABLE B.1. (contd)

\section{2-SG Unit}

8 isi

\begin{tabular}{|c|c|c|c|c|c|c|c|c|}
\hline \multirow[t]{2}{*}{ ISI Case } & Iisi & $\begin{array}{l}\text { MAN-REM } \\
\text { ( } \mathrm{High)}\end{array}$ & $\begin{array}{l}\text { MAN-REM } \\
(\text { LOW }) \\
\end{array}$ & $\begin{array}{l}\text { MAN-REM } \\
(T=0)\end{array}$ & $\begin{array}{c}\text { \$isi } \\
\langle F=0)\end{array}$ & $\begin{array}{c}\text { Proportional } \mathrm{F} \\
\left(\mathrm{F}_{\max }=0.1\right)\end{array}$ & $\begin{array}{c}C_{1} \\
(y r \times M R)^{-1} \\
\end{array}$ & $\begin{array}{c}\mathrm{C}_{2} \\
\left(\mathrm{yr} \times M R \times 10^{6} \phi\right)^{-1} \\
\end{array}$ \\
\hline & $\left(Y_{r^{-1}}\right)$ & (man-rem) & & & $\left(10^{6} 8\right)$ & & & \\
\hline $\begin{array}{l}\mathrm{A}-1 \\
\mathrm{~A}-2 \\
\mathrm{~A}-3\end{array}$ & $\begin{array}{l}1.3(-2) \\
8.3(-3) \\
6.7(-3)\end{array}$ & $\begin{array}{l}97 \\
61 \\
48\end{array}$ & $\begin{array}{l}16 \\
10 \\
8.3\end{array}$ & $\begin{array}{l}45 \\
28 \\
22\end{array}$ & $\begin{array}{l}3.0(-1) \\
2.2(-1) \\
1.5(-1)\end{array}$ & $\begin{array}{l}5.8(-1) \\
3.9(-1) \\
2.8(-1)\end{array}$ & $\begin{array}{l}2.9(-4) \\
3.0(-4) \\
3.1(-4)\end{array}$ & $\begin{array}{l}9.6(-4) \\
1.4(-3) \\
2.0(-3)\end{array}$ \\
\hline $\begin{array}{l}\text { B-1 } \\
\text { B-2 }\end{array}$ & $\begin{array}{l}9.2(-3) \\
5.8(-3)\end{array}$ & $\begin{array}{l}99 \\
55\end{array}$ & $\begin{array}{l}16 \\
8.4\end{array}$ & $\begin{array}{l}50 \\
28\end{array}$ & $\begin{array}{l}1.8(-1) \\
1.0(-1)\end{array}$ & $\begin{array}{l}3.3(-1) \\
1.6(-1)\end{array}$ & $\begin{array}{l}1.8(-4) \\
2.1(-4)\end{array}$ & $\begin{array}{l}1.0(-3) \\
2.1(-3)\end{array}$ \\
\hline $\begin{array}{l}C-1 \\
C-2 \\
C-3 \\
C-4\end{array}$ & $\begin{array}{l}8.9(-1) \\
3.9(-1) \\
3.1(-1)\end{array}$ & $\begin{array}{l}778 \\
486 \\
438\end{array}$ & $\begin{array}{l}227 \\
142 \\
128\end{array}$ & $\begin{array}{l}90 \\
56 \\
50\end{array}$ & $\begin{array}{l}3.5 \\
2.2 \\
2.0\end{array}$ & $\begin{array}{l}2.3(+1) \\
9.3 \\
6.7\end{array}$ & $\begin{array}{l}9.9(-3) \\
7.0(-3) \\
6.2(-3)\end{array}$ & $\begin{array}{l}2.8(-3) \\
3.2(-3) \\
3.1(-3)\end{array}$ \\
\hline $\begin{array}{l}C-5 \\
C-6\end{array}$ & $2.1(-1)$ & 302 & 83 & 50 & 1.4 & 3.8 & $4.2(-3)$ & $3.0(-3)$ \\
\hline $\begin{array}{l}C-7 \\
C-8 \\
C-9\end{array}$ & $\begin{array}{l}1.3(-1) \\
1.1(-1) \\
4.4(-2)\end{array}$ & $\begin{array}{l}253 \\
233 \\
140\end{array}$ & $\begin{array}{l}68 \\
62 \\
31\end{array}$ & $\begin{array}{l}45 \\
45 \\
45\end{array}$ & $\begin{array}{l}1.2 \\
1.1 \\
6.7(-1)\end{array}$ & $\begin{array}{l}3.6 \\
3.5 \\
1.6\end{array}$ & $\begin{array}{l}2.9(-3) \\
2.4(-3) \\
9.8(-4)\end{array}$ & $\begin{array}{l}2.4(-3) \\
2.2(-3) \\
1.5(-3)\end{array}$ \\
\hline
\end{tabular}



APPENDIX C

A RELIABILITY ANALYSIS TECHNIQUE 
APPENDIX C

\section{A RELIABILITY ANALYSIS TECHNIQUE}

The failure rate $\lambda(\theta)$ is a prominent element of current reliability analysis. It is a conditional failure probability defined as:

$$
\lambda(\theta)=\frac{f(\theta)}{1-f(\theta)}
$$

where $f(\theta)$ is the probability density for failure at time $\theta$ and $F(\theta)$ is the cumulative failure probability at time $\theta . \lambda(\theta)$ is, therefore, a measure of the probability of failure at time $\theta$ given that a component has survived up to time $\theta$. The cumulative failure rate $\Lambda(\theta)$ is the integral of $\lambda(\theta)$ over the period of interest:

$$
\Lambda(\theta)=\int_{0}^{\theta} \lambda(\theta) d \theta
$$

Substituting the above definition of $\lambda(\theta)$ into Equation (2):

$$
\Lambda(\theta)=-\ln [1-F(\theta)]
$$

Hence,

$$
F(\theta)=1-e^{-\Lambda(\theta)}
$$

Relationship (3a) between $F(\theta)$ and $\Lambda(\theta)$ is independent of an assumption as to the statistical model of failure (exponential, lognormal, Weibu11, etc.).

The conditional probability of failure of a component within an arbitrary interval, given survival up to the interval, is a statistical finding of immediate interest to the steam generator (SG) in-service inspection (ISI) problem. 
This probability is a measure of the safety of a given interval between inspections, assuming the statistical analys is is appropriate to the current tube failure situation for the unit under study. This conditional probability may be expressed:

$$
P(\theta+\Delta \theta / \theta)=1-\frac{1-F(\theta+\Delta \theta)}{1-F(\theta)}
$$

Substituting for $F(\theta)$ from Equation (3a)

$$
\left.P(\theta+\Delta \theta / \theta)=1-e^{-[\Lambda(\theta+\Delta \theta)}-\Lambda(\theta)\right]
$$

W. B. Nelson ${ }^{(12)}$ has discussed a graphical procedure for evaluating Equation (4a), and Nelson and Hendrickson ${ }^{(13)}$ discussed a time-sharing computer program for deriving the cumulative fajlure rate function from multiple time-censored failure data and computing the statistical values of interest. The problem of analyzing existing SG tubing data was discussed briefly in the text of this report. While it appears that some of the statistical prerequisites for applying the technique discussed by Nelson may not be satisfied by the current SG tubing data bank, it is of some interest to demonstrate this technique using very 1 imited data for the $\mathrm{Palisades}$ pressurized water reactor (PWR) obtained from References 8 and 9 . For this illustration, the effective fuel power year (EFPY) is used for the endurance variable ( $\theta$ ) (see Table C.1). In Table C.2 the data are restated together with the number of tubes surviving at a given cumulative EFPY level. The failure rate at a given EFPY level is:

$$
\lambda(E F P Y)=\frac{\text { tubes failing at EFPY level }}{\text { tubes surviving }} \times 100
$$

The fajlure rate $(\lambda)$ and the cumulative failure rate $(\Lambda)$ data are given in Table C.2. Failure plotting paper is available for a number of failure statistical models (normal, exponential, lognormal, Weibu1), extreme value, etc.). The basic characteristics of these papers are: 1) a plot of the endurance variable (e.g., EFPY) versus the cumulative failure function $(\Lambda)$ will yield a 
TABLE C.1. Tubing Performance Data for Palisades

PWR Unit through 1977

$\begin{array}{lr}\frac{\sum \text { EFPY }}{0.5} & \text { Tubes Plugged } \\ 0.7 & 0 \\ 1.2 & 1,700 \\ 1.6 & 1,260 \\ 2.1 & 285 \\ 2.14 & 711 \\ & \frac{16}{3,972} \\ 17,038 \text { tubes in unit }\end{array}$

TABLE C.2. Failure Rate and Cumulative Failure Rate Data from Table C.1 Data

\begin{tabular}{|c|c|c|c|c|}
\hline EEFPY & Tubes Plugged & Reverse Rank (a) & $\begin{array}{l}\lambda(\text { EFPY }) \\
(\%) \\
\end{array}$ & $\begin{array}{l}\Lambda \text { (EFPY) } \\
-(\%)\end{array}$ \\
\hline 0.5 & 0 & 17,038 & -- & -- \\
\hline 0.7 & 1,700 & 15,338 & 11.08 & 11.08 \\
\hline 1.2 & 1,260 & 14,078 & 8.95 & 20.03 \\
\hline 1.6 & 285 & 13,793 & 2.07 & 22.10 \\
\hline 2.1 & 711 & 13,082 & 5.44 & 27.54 \\
\hline 2.14 & 16 & 13,066 & 0.12 & 27.66 \\
\hline
\end{tabular}

(a) Number of tubes surviving up to given EFPY total.

straight line if the paper statistics are valid, and 2) the cumulative failure probability $(F)$ corresponding to a given cumulative failure rate $(\Lambda)$ is obtained from the upper horizontal scale on the plot. For illustration purposes only, the data of Table C.2 are plotted on a smallest extreme value paper in Figure $C .1$ and a straight line is fitted to the points by eye. The conditional failure probability within an interval $\Delta \theta$ after a period $\theta$ is obtained as follows from such a plot: 


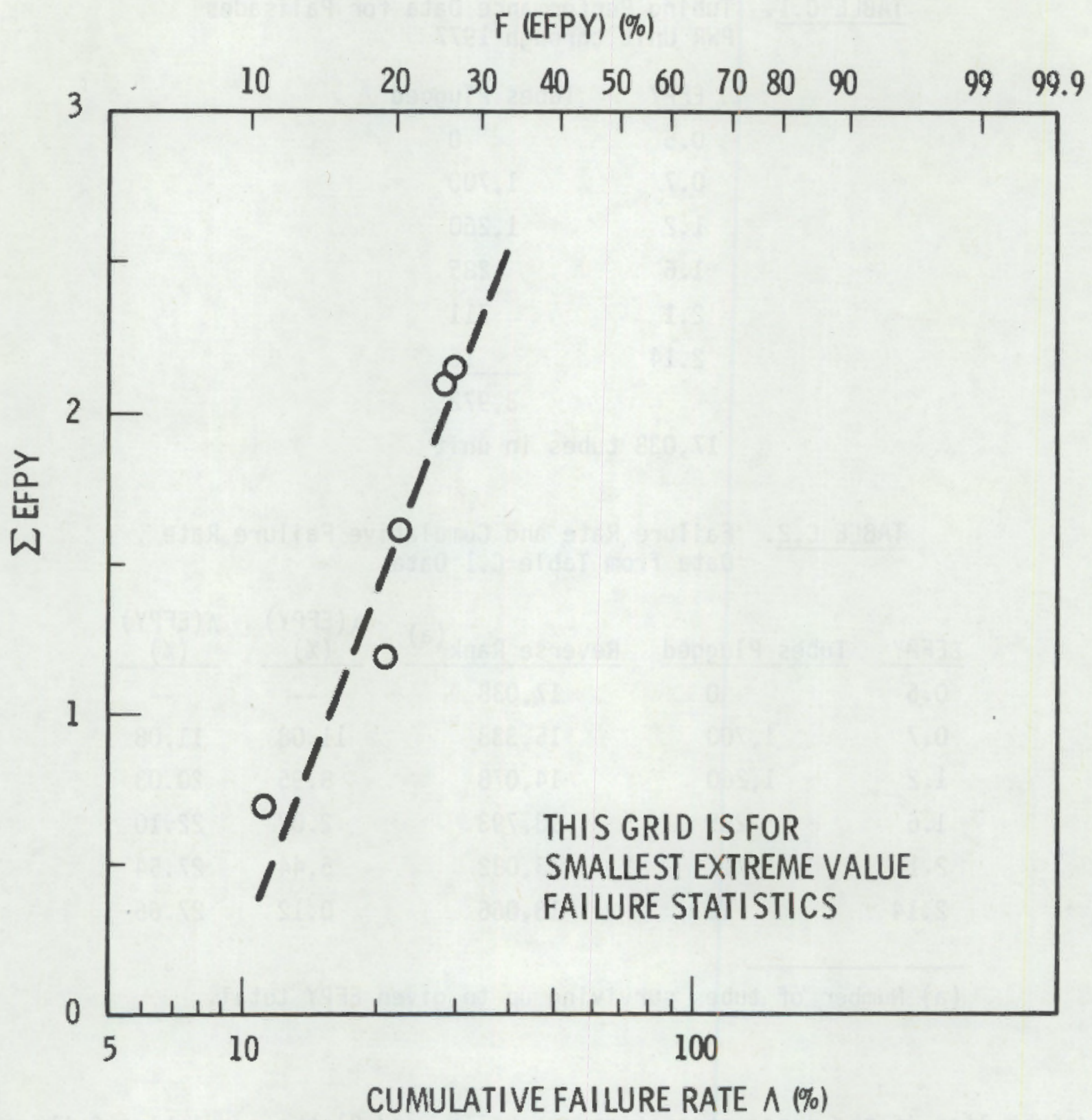

FIGURE C.1. Cumulative Failure Rate Versus Cumulative EFPY

- find the $\Lambda$ value corresponding to $\theta$ (current tube life in EFPY)

- find the $\Lambda$ value corresponding to $\theta^{+} \Delta \theta$ (life plus inspection interval measured in EFPY) 
- calculate $\Delta \Lambda=\Lambda(\theta+\Delta \theta)-\Delta(\theta)$

- enter plot at $\Delta \Lambda$ and read the cumulative failure probability (F) on the upper scale, which is the desired conditional failure probability. For example, using the characteristic line of Figure C.1:

- $\Lambda$ at a life of 1 EFPY $\approx \sim 16 \%$

- $\Lambda$ at 1 EFPY + a l-EFPY interval $=\sim 28 \%$

- $\Delta \Lambda=\sim 12 \%$

- $F($ EFPY $)$ from upper scale $=\sim 13 \%$.

Hence, according to this analysis there is a conditional probability of tubing failure of about $13 \%$ within the next 1 EFPY past a tube life of 1 EFPY. One interpretation of this is that about 2,200 out of 17,038 tubes would be expected to fail within a l-EFPY interval after a life of 1 EFPY.

Fortunately, the eariy Palisades data used for this illustration represent a very extreme case of poor tubing performance and are far from representative of current general tubing performance. Providing reasonably good applicability to current, or obtainable, tubing data can be demonstrated, the computerassisted technique outlined here may prove a usefui step toward incorporating probabilistic analysis of tubing performance into overall cost/benefit (C/B) analysis of SG ISI. 

APPENDIX 0

DATA FOR COSTING SOLID WASTE DISPOSAL 
TABLE 0.1. Cost 0ata from IOM Report ${ }^{\text {(a) }}$

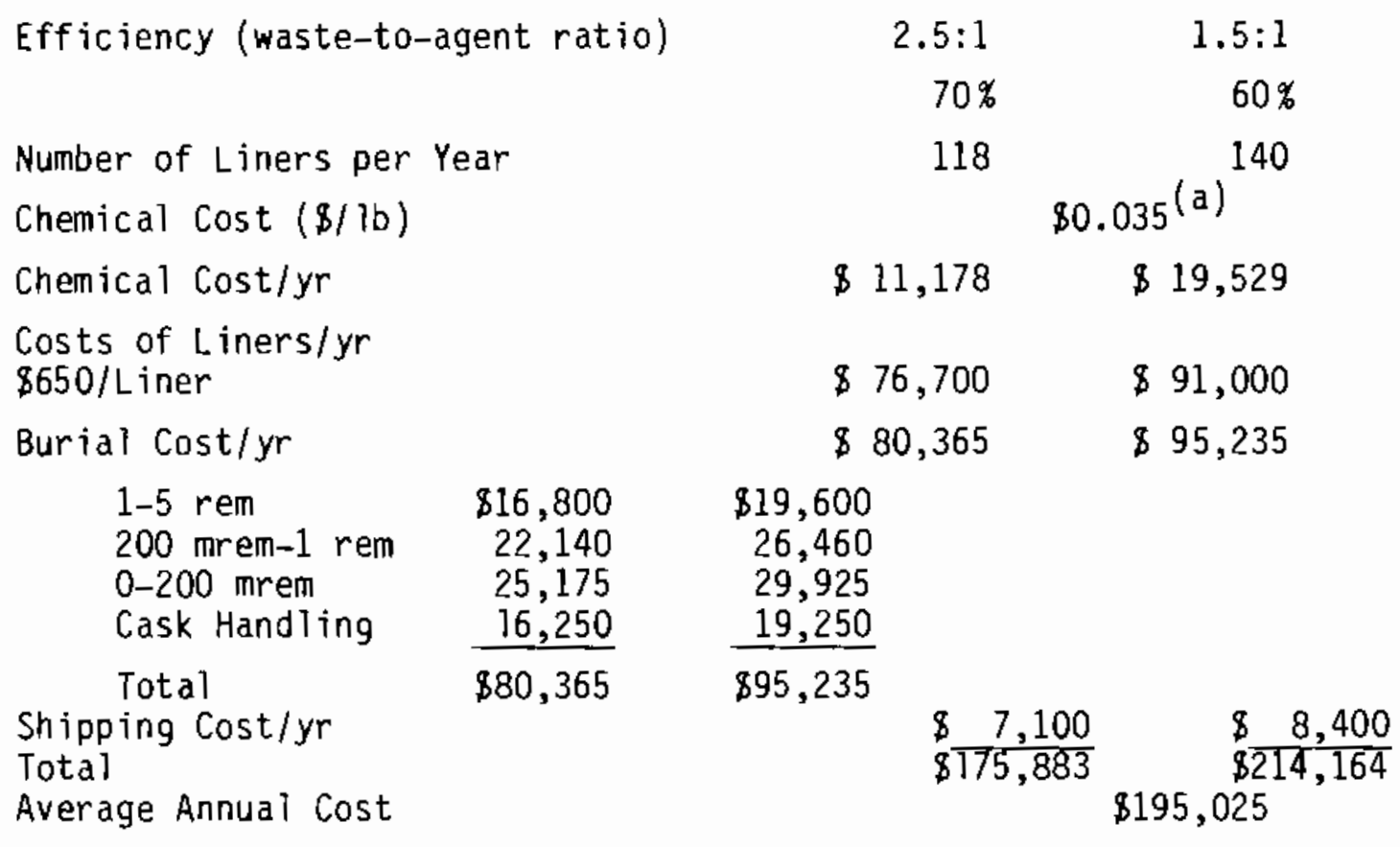

(a) Cement $=\$ 0.03 / 1 \mathrm{~b}$

Sodium silicate $=\$ 0.035 / \mathrm{lb}$

Calculations to Approximate Percent of Total Radwaste Decontamination Costs Oue to Steam Generator Leakages

1) $8400 \mathrm{ft}^{3}=$ unsolidified waste $/ \mathrm{yr}=\frac{8400}{\mathrm{x}}=\frac{2.5}{3.5} \mathrm{x}$

$$
=11,760 \mathrm{ft}^{3} \text { of 'Solidified waste per year }
$$

2) $x_{1}=$ cubic feet of $0.00-0.2 \mathrm{rem} /$ hour material (cost $\$ 4.75 / \mathrm{ft}^{3}$ ) $x_{2}=$ cubic feet of $0.201-1.0 \mathrm{rem} /$ hour material (cost $\$ 5.20 / \mathrm{ft}^{3}$ ) $x_{3}=$ cubic feet of $1-5$ rem/hour material (cost $\$ 7.10 / \mathrm{ft}^{3}$ )

$$
\begin{aligned}
& x_{1}+x_{2}+x_{3}=11,760 \mathrm{ft}^{3} \\
& \left(x_{1}\right)(\$ 4.75)=\$ 25,175 \quad x_{1}=5,300 \mathrm{ft}^{3} \\
& \left(x_{2}\right)(\$ 5.20)=\$ 22,140 \quad x_{2}=4,260 \mathrm{ft}^{3} \\
& \left(x_{3}\right)(87.20)=\$ 16,800 \quad x_{3}=\frac{2,330 \mathrm{ft}^{3}}{11,800-11,760 \mathrm{ft}^{3} \text { as expected }}
\end{aligned}
$$

(a) Interoffice memorandum from Washington Public Power Supply System (by Steen), April 5, 1979. 


\section{TABLE 0.1. (contd)}

3) Assuming that the $\left(x_{1}\right)$ component comes from the steam generator, the figure of $5300 \mathrm{ft}^{3}$ should be conservative. In other words, this is a maximum waste/yr/reactor to be expected.

4) Generate annual operating costs $(A O C)$ based upon this figure (i.e., ratio of volumes for associated costs):

$$
\frac{5,300}{11,800}=0.45
$$

Cases

A) Radwaste at 0-0.005 rem/hour, buried ons ite--min imum.

B) Radwaste at $0-0.200 \mathrm{rem} / \mathrm{hour}$, buried $<50 \mathrm{miles}$ away.

C) Radwas te at 0-0.200 rem/hour, buried 200-500 miles away.

D) Radwaste at $0-0.200 \mathrm{rem} / \mathrm{hour}$, buried $\sim 1000 \mathrm{miles}$ away.

E) Radwaste at $0.2-1 \mathrm{rem} / \mathrm{hour}$, buried $<50 \mathrm{miles}$ away.

F) Radwaste at $0.2-1 \mathrm{rem} / \mathrm{hour}$, buried $\sim 500$ miles away.

G) Radwas te at 0.2-i rem/hour, buried 1000 miles away.

H) Radwaste at 1-5 rem/hour, buried $\leq 50$ miles away.

I) Radwaste at 1-5 rem/hour, buried 500 miles away.

J) Radwaste at 1-5 rem/hour, buried 1000 miles away.

K) Disposal to municipal landfill.

All calculations assume $45 \%$ of given total volume $=\left(11,800 \mathrm{ft}^{3} / \mathrm{yr}\right.$ or $14,000 \mathrm{ft}^{3}(\mathrm{yr})$. 
TABLE 0.2. Calculations for Annual Operating Costs (AOC)

CASE A

\begin{tabular}{lrrr} 
& Efficiency & $\frac{2.5: 1}{1.5: 1}$ \\
\cline { 1 - 1 } a) Number of Liners & & 63 \\
b) Chemical Cost, $\$ / y r$ & 5,030 & 8,790 \\
c) Cost of Liners, $\$ / y r$ & 34,500 & 41,000 \\
d) Burial Cost, $\$ / y r$ & 0 & 0 \\
e) Shipping Cost, $\$ / y r$ & 0 & 0 \\
Total Cost, $\$ / y r$ & 39,530 & $\frac{49,790}{2}$ \\
Average AOC & \multicolumn{2}{c}{$\$ 40,660$}
\end{tabular}
(a) $x=(0.45) y$
$x_{1}=(0.45)(118)=53$
$x_{2}=(0.45)(140)=63$
(b) 0.45 of reference studies
(c) 0.45 of reference
(d) Onsite burial, assume no cost

\section{CASE B}

\section{Efficiency}

a) Number of Liners

b) Chemical cost, $\$ / y r$

c) Cost of Liners, $\$ / y r$

d) Burial Cost, $\$ / y r$

e) Shipping Cost, $\$ / y r$ Total Cost, $\$ / y r$ Average AOC $\underline{2.5: 1} \quad \underline{1.5: 1}$

$5,030 \quad 8,790$

$34,500 \quad 41,000$

$32,500 \quad 38,600$

$\frac{2,660}{74,690} \quad \frac{3,150}{91,540}$

$\$ 83,115$

(a-c) Same as Case A

(d) Fraction (0.45) of original; for example,

$2.5: 1=25,175+(0.45)(16,250)$
(e) Shipping Costs: $37.5 \%$ due to $x_{1}$ $39.0 \%$ due to $x_{2}$

Only have type one for Case $B$. $33.0 \%$ due to $x_{3}$ 
TABLE D.2. (contd)

CASE $\underline{C}$

\begin{tabular}{lrrr}
\multicolumn{1}{c}{ Efficiency } & $\frac{2.5: 1}{53}$ & $1.5: 1$ \\
\cline { 1 - 2 } a) Number of Liners & & 63 \\
b) Chemical Cost, $\$ / y r$ & 5,030 & 8,790 \\
c) Cost of Liners, $\$ / y r$ & 34,500 & 41,000 \\
d) Burial Cost, $\$ / y r$ & 32,500 & 38,600 \\
e) Shipping Cost, $\$ / y r$ & 3,135 & 3,425 \\
Total Cost, $\$ / y r$ & 74,965 & 91,815 \\
Average AOC & \multicolumn{2}{c}{$\$ 83,390$}
\end{tabular}

(a-d) Same as for Case B

(e) Add cost of $95 \$ / \mathrm{mile}$ at 500 miles

CASE D

Efficiency

a) Number of Liners

b) Chemical Cost, $\$ / y r$

c) Cost of Liners, $\$ / y r$

d) Burial Cost, $\$ / y r$

e) Shipping Cost, $\$ / y r$ Total Cost, $\$ / y r$ Average $A O C$ $\underline{2.5: 1} \quad \underline{1.5: 1}$

$53 \quad 63$

$5,030 \quad 8,790$

$34,500 \quad 41,000$

$32,500 \quad 38,600$

$\frac{3,610}{75,640} \quad \frac{4,100}{92,490}$

$\$ 84,065$

(a-d) Same as for Case B

(e) Add cost of $95 \$ / \mathrm{mile}$ at 1000 miles

\section{CASE E}

\section{Efficiency}

a) Number of Liners

b) Chemica 1 Cost, $\$ / y r$

c) Cost of Liners, $\$ / y r$

d) Burial Cost, $\$ / y r$

e) Shipping Cost, $\$ / y r$ Total Cost, $\$ / y r$ Average AOC $\underline{2.5: 1} \quad \underline{1.5: 1}$

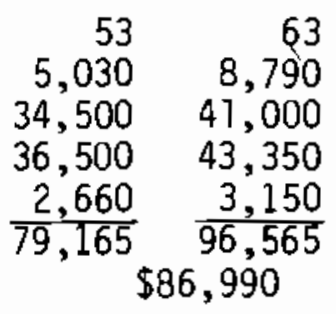

(a-c) Same as for Case B

(d) $\left(5,300 \mathrm{ft}^{3}\right)\left(\$ 5.20 / \mathrm{ft}^{3}\right)+(0.55)(16,250)=\$ 36,500$

$\left(6,300 \mathrm{ft}^{3}\right)\left(\$ 5.20 / \mathrm{ft}^{3}\right)+(0.55)(19,250)=\$ 43,350$ 
TABLE 0.2. (contd)

CASE F

Efficiency

a) Number of Liners

b) Chemical Cost, $\$ / y r$

c) Cost of Liners, $8 / \mathrm{yr}$

d) Burial Cost, $\$ / y r$

e) Shipping Cost, $8 / y r$ Total Cost, $8 / y r$ Average $A O C$
$2.5: 1 \quad 1.5: 1$

$53 \quad 63$

$5,030 \quad 8,790$

$34,500 \quad 41,000$

$36,500 \quad 43,350$

$\frac{3,135}{79,165} \quad \frac{3,425}{96,565}$

887,865

(a-d) Same as for Case $E$

(e) Add cost of $95 \$ / \mathrm{mile}$ at $500 \mathrm{miles}$

CASE G

\section{Efficiency}

a) Number of Liners

b) Chemical Cost, $\$ / y r$

c) Cost of Liners, $\$ / y r$

d) Burial cost, $8 / y r$

e) Shipping Cost, $\$ / \mathrm{yr}$ Total Cost, $\$ / y r$ Average AOC $\underline{2.5: 1} \quad \underline{1.5: 1}$

$53 \quad 63$

$5,030 \quad 8,790$

$34,500 \quad 41,000$

$36,500 \quad 43,350$

$3,610 \quad 4,100$

$79,640 \quad 97,240$

(a-d) Same as for Case $E$

(e) Add cost of $95 \% / m i l e$ at 1000 miles

CASE H

\section{Efficiency}

a) Number of Liners

b) Chemical Cost, $8 / y r$

c) Cost of Liners, $8 / \mathrm{yr}$

d) Burial cost, $\$ / y r$

e) Shipping Cost, $\$ / y r$

Total $\$ / \mathrm{yr}$

Average $\$ / \mathrm{yr}$ $\underline{2.5: 1} \quad \underline{1.5: 1}$

$5,030 \quad 8,790$

$34,500 \quad 41,000$

$48,190 \quad 57,240$

$\frac{2,660}{90,380} \quad \frac{3,150}{110,180}$

$\$ 100,280$

(a-c) Same as for Case $B$

(d) $\left(5,300 \mathrm{ft}^{3}\right)\left(\$ 7.10 / \mathrm{ft}^{3}\right)+(0.65)(16,250)=\$ 48,190$

$\left(6,300 \mathrm{ft}^{3}\right)\left(\$ 7.10 / \mathrm{ft}^{3}\right)+(0.65)(19,250)=\$ 57,240$ 



\section{OISTRIBUTION}

No. of

Copies

OFFSITE

A. A. Churm

DOE Patent Division

9800 S. Cass Avenue

Argonne, IL 60439

265 U.S. Nuclear Regulatory Comission

Division of Technical Information and Document Control

7920 Norfolk Avenue

Bethesda, MO 20014

2 DOE Technical Information Center

10 U.S. Nuclear Regulatory Comisission

Office of Nuclear Reactor Regulation

Division of Safety Technology

Washington, DC 20555
No. of

Copies

ONSITE

49 Pacific Northwest Laboratory

J. A. Alzheimer

C. H. Bloomster

O. B. Cearlock

R. A. Clark

F. M. Cummings

S. D. Dahlgren

D. E. Deonigi

R. L. Dillon

P. G. Doctor

L. G. Faust

A. F. Gasper ino

W. A. Glass

D. L. Hall

C. R. Hann

A. J. Haverfield

G. R. Hoenes

H. V. Larson

G. H. Lyon

B. W. Mercer

C. J. Morr is

D. E. Olesen

S. E. Petty

G. J. Posakony

A. M. Sutey

S. A. Weakley

W. R. Wiley

L. O. Williams

G. E. Zima (15)

Technical Information (5)

Publishing Coordination (2) 



\begin{tabular}{|c|c|c|c|}
\hline \multicolumn{2}{|c|}{ 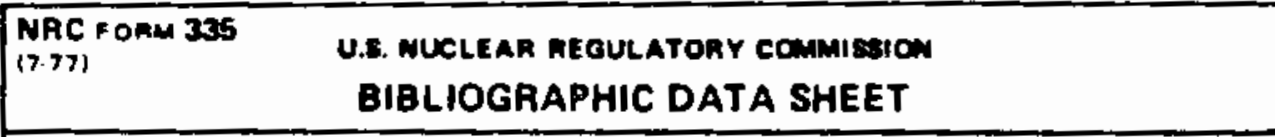 } & \multicolumn{2}{|c|}{ 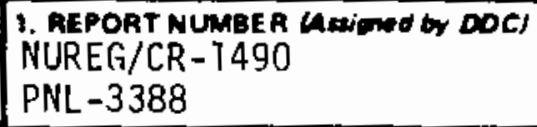 } \\
\hline \multirow{2}{*}{\multicolumn{2}{|c|}{$\begin{array}{l}\text { 4. TITLE AND SUBTITLE Mod Volume No. if popropriagl } \\
\text { Some Aspects of Cost/Benefit Analysis for Inservice } \\
\text { Inspection of PIIR Steam Generators }\end{array}$}} & \multicolumn{2}{|l|}{ 2. (tano bienk) } \\
\hline & & \multicolumn{2}{|c|}{ 3. RECIPIENTS ACCESSION MO. } \\
\hline \multicolumn{2}{|c|}{$\begin{array}{l}\text { 7. AUTMORIS } \\
\text { G.E. Zima, G.H. Lyon, P.G. Doctor, G.R. Hoenes, S.E. Petty, }\end{array}$} & \multicolumn{2}{|c|}{$\begin{array}{l}\text { 5. DATE REPORT COMPLETED } \\
\text { YONTH } \\
\end{array}$} \\
\hline \multirow{3}{*}{\multicolumn{2}{|c|}{$\begin{array}{l}\text { 9. PE RFORMING ORGANIZATION NAME AND MAILING ADDRESS Uneiuct Zip Codel } \\
\text { PaCif ic Nor thwest Laboratory } \\
\text { P.O. Box } 999 \\
\text { Richland, WA } 99352\end{array}$}} & \multicolumn{2}{|c|}{\begin{tabular}{|l|r|} 
DATE REPORT ISSUED & \\
MONTH & YEAA \\
MaY & 1981 \\
\end{tabular}} \\
\hline & & \multicolumn{2}{|l|}{ 6. (Leene brenk) } \\
\hline & & \multicolumn{2}{|l|}{ 8. Heen werkt } \\
\hline \multirow{2}{*}{\multicolumn{2}{|c|}{$\begin{array}{l}\text { 12. SPONSORING ORGANIZATION NAME AND MAILING ADDAESS Inciud Zio Cool } \\
\text { Division of Reactor Safety Research } \\
\text { Office of Nuclear Regulatory Research } \\
\text { U.S. Nuclear Regulatory Commission } \\
\text { Washington, DC } 20555\end{array}$}} & \multicolumn{2}{|c|}{ 10. PAOUECT/TASKIMOAK UNIT NO. } \\
\hline & & \multicolumn{2}{|l|}{ FIN B23I5 } \\
\hline \multicolumn{4}{|c|}{\begin{tabular}{l|l|l} 
13. TYPE OF REPOAT & PE RIOO COVEAED Anctusin dows) \\
Technical &
\end{tabular}} \\
\hline \multicolumn{2}{|l|}{ 15. SUPPLEMENTAAY NOTES } & \multicolumn{2}{|l|}{ 14. (Leme ank) } \\
\hline \multicolumn{4}{|c|}{ 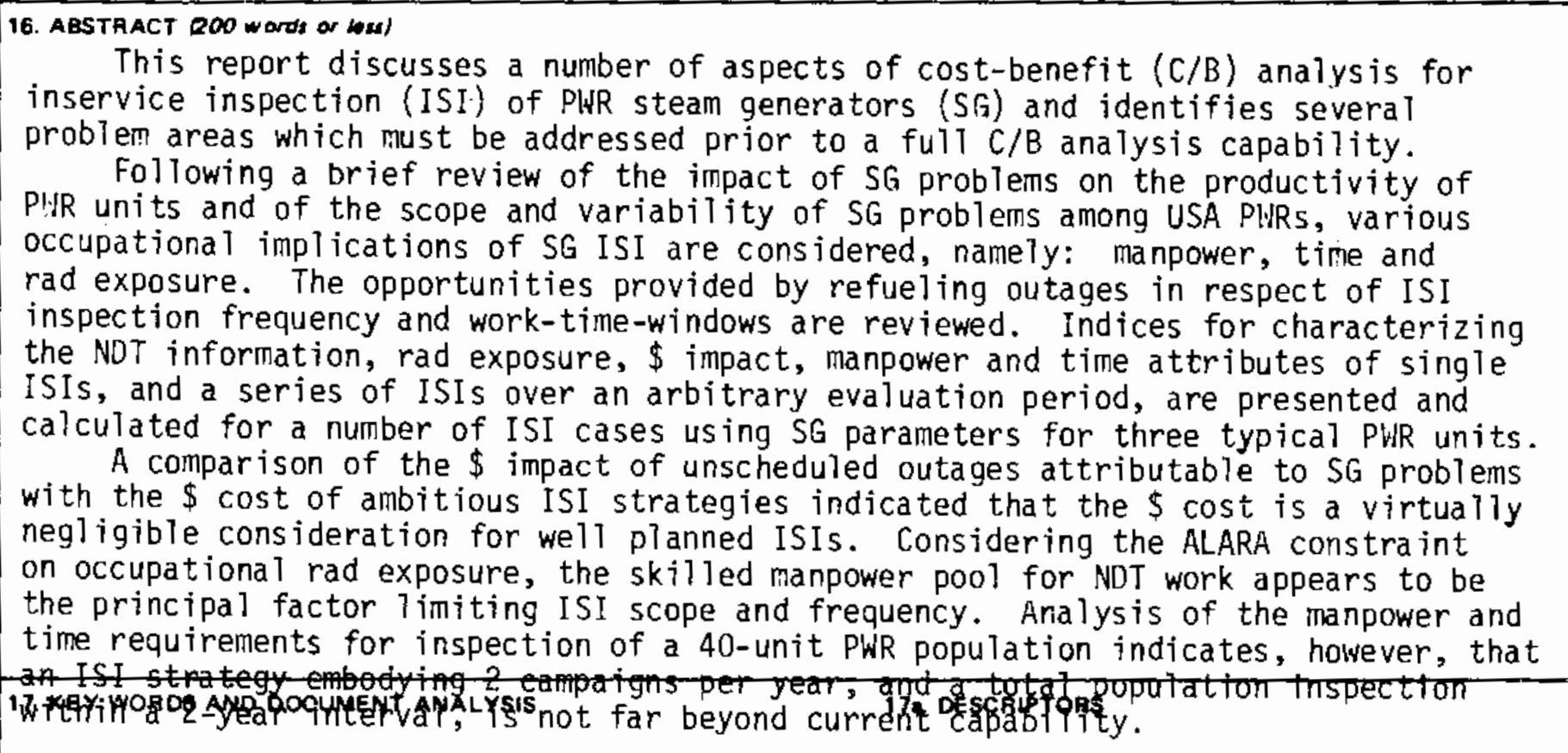 } \\
\hline \multicolumn{4}{|c|}{ 17b. IDENTIFIE RS LOPENENDED TERMS } \\
\hline \multirow{2}{*}{$\begin{array}{l}\text { 18. AVAILABILITY STATEMENT } \\
\text { Un } 1 \text { imited }\end{array}$} & \multirow{2}{*}{\multicolumn{2}{|c|}{ 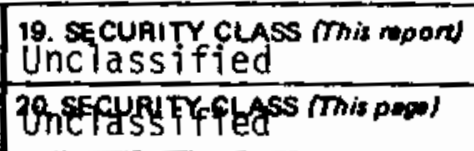 }} & 21. NO. OF PAGES \\
\hline & & & 22. PAICE \\
\hline
\end{tabular}


